
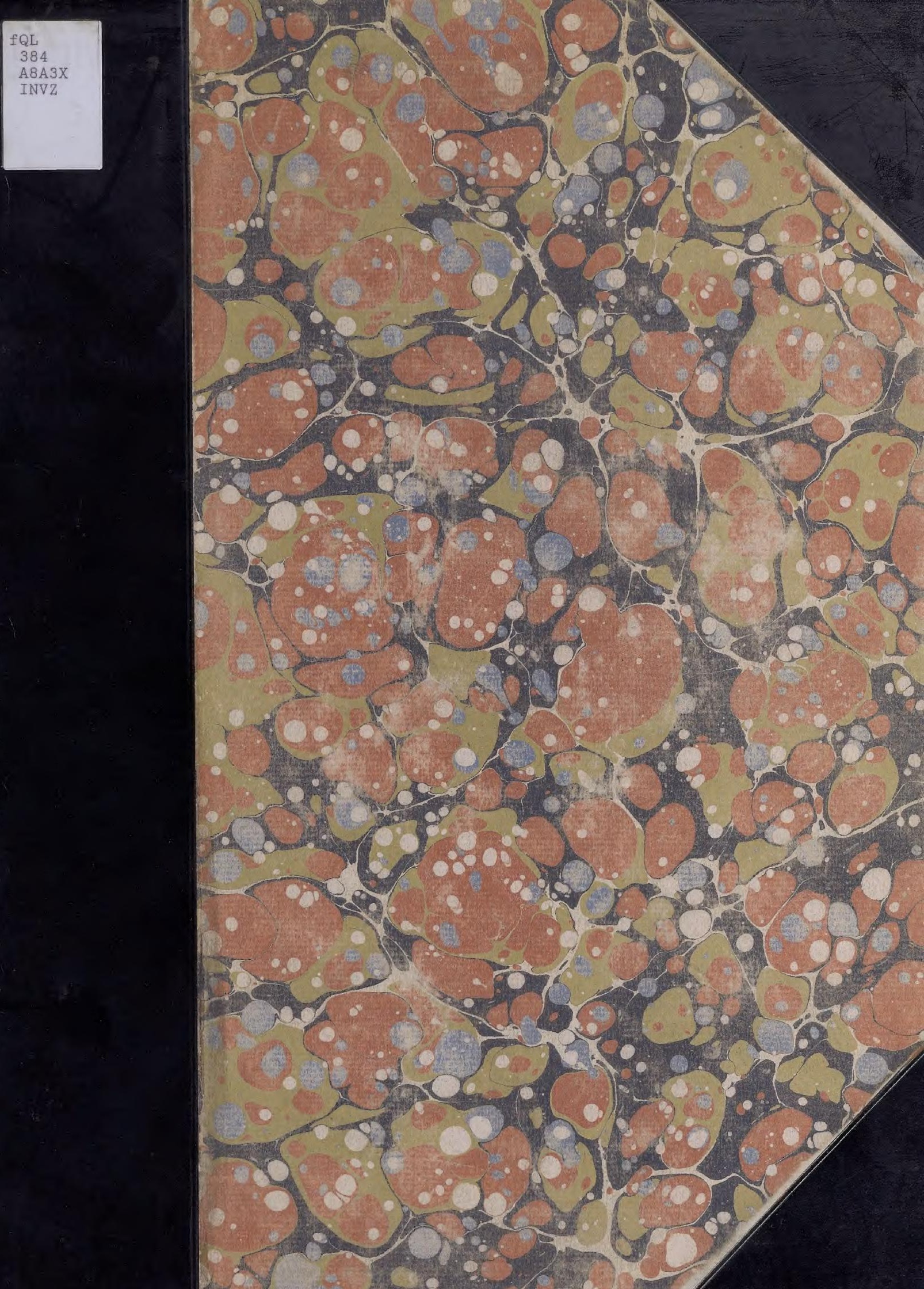







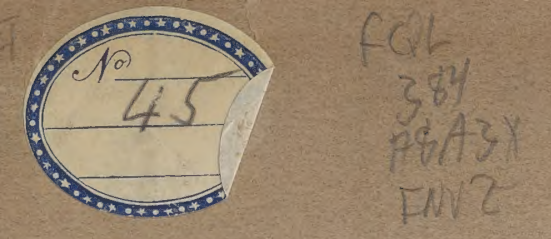

\title{
EMBRYOLOGY OF THE STARFISH.
}

BY

\author{
A L EXANDER A GASSIZ.
}

FROM VOL. V. OF L. AGASSIZ' CONTRIBUTIONS TO THE NATURAL HISTORY OF THE UNITED STATES. 



\section{P A R T I.}

\section{EMBRYOLOGY OF THE STARFISH.}

B Y

A L EXA D ER A G A S I Z. 


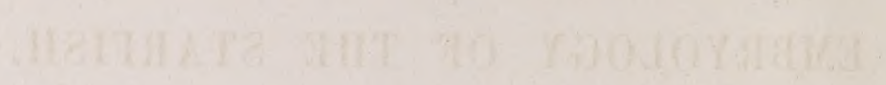




\title{
EMBRYOLOGY OF THE STARFISH.
}

\author{
CHAPTER FIRST.
}

\author{
ARTIFICIAL FECUNDATION, AND HISTORY OF THE DEVELOPMENT OF THE LARVA.
}

Differences of the Sexes. - Since the existence of different sexual organs in separate individuals was first pointed out among the lower animals, the tendency of every additional advance in our knowledge of their structure has been to bring out more fully the differences of sex between them. But recently, we did not even know that among the Medusæ there were male and female individuals; and yet, at the present day, it is a comparatively easy task to distinguish, among the larger Jelly-fishes, the males from the females. The difference of coloring is very striking. The spermaries of the males are often brilliantly tinged, while the ovaries of the females are of duller hues. We' thus find among Jelly-fishes the first indication of an 'almost universal law in the animal kingdom, and which is nowhere carried out to so great a degree as among Birds. A casual observer could not fail to distinguish a male from a female Aurelia, - though the great difference in the coloring of the males and females had not been perceived by naturalists till it was first pointed out by Professor Agassiz, in Aurelia flavidula Pér. et Les. In Melicertum, in Turris, in Staurophora, in Circe, a glance will suffice to determine the sex of the individual; while a single look through a magnifying-glass will reveal to us the sex of the smaller species, such as Eucope, Pennaria, Euphysa, and the like. The difference of the sexes of some Echinoderms is easily perceived by their difference of coloring at the time of spawning; among them are our common Starfishes and our Sea-urchins.

The males and females of our common species of Starfishes, Asteracanthion pallidus Ag. (A. vulgaris Stimp.?), and Asteracanthion berylinus Agass., can readily be distinguished by their difference in coloring: all those having a bluish tint being invariably females; a reddish or reddish-brown color indicating a male. Among the many 
specimens I have had occasion to open, I have thus far never found a single exception. When cut open, so as to expose the genital organs, the difference between the males and females is still more striking. The long grape-like clusters of reproductive organs extending from the angle of the arms, on both sides of the ambulacral system, to the extremity of the rays, present very marked differences in the two sexes. The ovaries are bright orange, while the spermaries are of a dull cream-color. At the time of spawning, which is very different in the two species mentioned above, the genital organs are distended to the utmost, filling completely the whole of the cavity of the ray; the abactinal system itself being greatly expanded by the extraordinary development of these organs.

Artificial Fecundation. - If we take a male and female Starfish in this state, and cut a portion of the genital organs into small pieces, we shall find that the eggs and spermaries escape in such quantities as to render turbid the water in which they are placed. Throwing these small pieces of the genital organs into shallow dishes containing fresh sea-water, and stirring the mixture thoroughly to insure the contact between the spermaries and the eggs, will be' sufficient to fecundate the latter. In order to make the operation perfectly successful, some precautions are necessary: all the pieces of the genital organs, which are left after repeated stirring, must be carefully removed; there must not be too many eggs in one dish, so that the water can have free access to them in every direction. The removal of the remnants of the ovaries and spermaries is very necessary, as the pieces which remain clodded together decompose very rapidly, and endanger the safety of the eggs, even when the water can be changed with the greatest facility. As soon as the fecundation is fulfilled, the water in the dishes must be repeatedly changed until it becomes perfectly clear, for the presence of too many spermaries; rendering the water milky, prevents a favorable result. It is best only to use one male and one female for the mixture in each vessel, as eggs taken from many individuals lessen the chances of success. The eggs sink to the bottom, so that the water can be poured off and changed without much danger of throwing them away. Immediately after the mixture is made, the water should be changed three or four times in succession; after that, every half hour, until the fourth hour, when an interval of two to four hours may elapse before renewing the water. As it is extremely difficult to change the water after the embryos have hatched and are swimming freely about in the jar, without losing many of them, it is advisable, before they hatch, which is about ten hours after the fecundation, to reduce the water to a minimum volume, and then simply to add a little fresh sea-water and remove the contents of the vessel to larger and larger jars. In this way the water can be maintained sufficiently pure, until the young embryos have taken the habit of swimming near the surface, when it may all be drawn off by means of a siphon. A great deal of time and trouble will be saved 
by this mode of procedure, and fewer specimens lost. The jars containing the eggs should be kept in a cool place; the most convenient method of securing a low and even temperature is to place the small jars in large tubs filled with cold water.

Changes in the Egg. - At the time of spawning, the eggs in the ovaries are so closely packed that they are pressed into all sorts of shapes, triangular, polygonal, elliptical; but when placed in water, and allowed to remain a short time, they soon become perfectly spherical (PI. I. Fig. 1). The following numbers are the ratios of the diameters of the yolk, the germinative vesicle, and the germinative dot, the outer envelope being 1 : the yolk is 0.75 , the germinative vesicle 0.22 , and the germinative dot 0.08. The formation of the egg in the ovary, and its changes up to the time of spawning, I have had neither time nor opportunity, thus far, to examine.

The spermatic particles, which swim about with great rapidity on escaping from the spermaries, soon find their way to the outer envelope of the egg to which they attach themselves, beating about very violently the whole time. The particles remain embedded in the thickness of the outer envelope, and are sometimes so crowded as to form a halo round the egg (Pl. I. Figs. 1-4). I have not, in a single case, seen any of the particles penetrate through the outer envelope and reach the yolk itself.

Probably a great deal of the difference of opinion which prevails among Physiologists, as to whether the spermatic particles penetrate through the successive envelopes of the egg to the yolk itself, is due to the want of precision there still exists in our knowledge concerning the envelopes of the yolk in the different branches of the animal kingdom. We do not know whether what we call the outer envelope of the egg of an Echinoderm is homologous to the outer envelope of the egg of an Acaleph, of a Polyp, or of Worms, Insects, or Crustacea, or how far these envelopes are found in the ovarian eggs of Mammals, Birds, Reptiles, and Fishes. And before we can come to a satisfactory result as to the place in the egg which the spermatic particles reach before changes can be observed to take place in the yolk, the eggs of the different classes of Animals must be carefully compared with reference to this point. The first phenomenon which precedes any change in the egg is a rotary motion given, to the whole egg by the constant beating of the spermatic particles; the germinative vesicle disappears (Pl. I. Fig. 2) soon after this, and next the germinative dot (Pl. I. Fig. 3).' The yolk has then alf the appearance of an egg which has undergone segmentation, and the yolk of which should consist of innumerable small spheres. The yolk has the same granular structure previous to segmentation which has usually been considered to belong to it only after the segmentation is complete. The resemblance between these two stages is still more marked in the eggs of Ctenophoræ, where the ratio between the diameter of the yolk and that of the outer envelope is large, and 
in which the segmentation is carried on until the whole yolk consists of such minute spheres that it is impossible at first sight to distinguish an egg of a Ctenophorous Medusa, which has undergone complete segmentation, from one in which the segmentation has not even begun, after the germinative vesicle and dot have disappeared. The disappearance of the germinative dot is accompanied by a separation of the yolk from the inner wall of the outer envelope of the egg (PI. I. Fig. 3); this is the first step towards segmentation, and the presence of such a marked interval would greatly facilitate the detection of spermatic particles upon the surface of the yolk, if any of them had penetrated through the outer membrane. The first trace of segmentation consists in a depression of the yolk, visible on one side of the sphere (Pl. I. Fig. 4), and is soon followed by a similar change on the opposite pole.

The segmentation takes place very rapidly, passing in about eight hours from the stage represented by PI. I. Fig. 3 to that of Pl. I. Fig. 21, immediately before the escape of the embryo from the egg. The spheres in the earlier stages of segmentation are well separated (Pl. I. Figs. 7, 9, 11, 13). They have a centrifugal tendency, and, as they increase in number, arrange themselves in a shell-like envelope, which eventually becomes the wall of the embryo. This tendency is already apparent when there are not more than eight spheres (PI. I. Figs. 13, 14); and as early as the stage represented on Pl. I. Fig. 16, where there are only thirty-two spheres, the envelope is quite prominent. The rotation of the spheres of segmentation commences before this (Pl. I. Fig. 6), and is entirely independent of the motion given to the whole egg by the spermatic particles; this stops soon after the rotation of the spheres of segmentation has commenced.

As the egg of the Starfish presents nothing peculiar in its process of segmentation beyond what has been just remarked, I refer the reader to the explanation of the plates for the details concerning every successive step of this process, as observed in Asteracanthion berylinus.

The Richtung's-Bläschen of Schultze, which he first noticed in the segmentation of Mollusks, and which were afterwards seen by Lacaze-Duthiers and by Robin, who traced their mode of development, were also observed in the segmentation of the yolk of our Starfish. They are noticed, before the yolk has been divided into halves (Pl. I. Fig. 5), as three or four small granules, situated at the extremity of the axis which is to divide the yolk into two portions (Pl. I. Fig. 6). They are developed from the yolk itself as a slight swelling, which afterwards becomes entirely distinct from the mass of the yolk (PI. I. Fig. 7), retaining always throughout the whole process of segmentation the same relative position to the axis of segmentation (Pl. I. Figs. 9-17). What part they play in the subsequent history of the embryo, I have not been able to ascertain. Without doubt they hold always the same relation to 
the first axis of segmentation, and are, as far as $I$ have observed them in the segmentation of Asteracanthion and of Toxopneustes, always at one pole of the first axis of segmentation.

The Embryo after hatching. - At about the end of the tenth hour after fecundation, the segmentation has been carried so far that the walls of the future embryo have become quite conspicuous, and it is now ready to hatch (Pl. I. Fig. 21). When the outer envelope is torn, the young rotate slowly about round a shifting axis, by means of very minute cilia placed over the whole surface; the walls are everywhere of the same thickness, and the embryo is perfectly spherical. A difference soon becomes evident; the walls thicken at one pole of the sphere (Pl. I. Fig. $22, a$ ), and the thickening is accompanied by a flattening of the same side (Pl. I. Fig. $23, a)$; the embryo has lost its regular spherical shape and its homogeneous walls (Pl. I. Fig. 23, a). The next change consists in a slight depression at this flattened pole (Pl. I. Fig. 24,a); the wall bends inward, forming a very shallow depression, growing deeper and deeper, until it forms a pouch extending half the length of the embryo (Pl. I. Figs. 25, 26, $d, 27, d$ ). While a cavity $(d)$ is thus formed by the simple folding in of the outer wall, the embryo is constantly lengthening and becomes more cylindrical; the walls of the extremity opposite the pouch becoming attenuated, while, immediately round the opening of the cavity, the walls have not lost their original thickness (PI. I. Figs. 26, 27, $\alpha$ ). Water flows freely into and out of this. cavity; currents are established, running in different directions along opposite walls of the pouch, showing this opening to be for the present a mouth; the pouch, or digestive cavity, sustains the same relation to the whole body as in the most regular and circular radiated animals, such as young Actiniæ, or young Porites. The motion of the embryo, which immediately after escaping from the egg is an extremely slow rotation, increases in rapidity as it lengthens, and by the time the cavity equals half the length of the embryo (Pl. I. Fig. 27, d), the motion is much accelerated. Instead of a simple slow rotation, with scarcely any motion of translation, the latter is now quite rapid, and is accompanied by a slow rotation round a vertical axis, through the centre of the longer diameter of the animal; the opening leading into the coecum is foremost during their motion.

At the end of about twenty hours after fecundation, the embryo has reached the condition just described; it is now somewhat pear-shaped, with rounded extremities (Pl. I. Fig. 27), having at one end an opening (a), leading into a pouch (d), which extends half the length of the cylinder. ${ }^{1}$ We have now the embryo in a condition

\footnotetext{
I So far, the changes which have been observed do not differ materially from what we know of the earlier stages of Echinoderm larvæ, from the obser-
}

vations of Derbès, Müller, and Krohn. As I have shown, in the Memoirs of the American Academy for 1864, the earlier stages of the Echinus larvæ, 
which can best be compared to the embryos of other Radiates; for there is as yet, nothing of the complication hereafter introduced in the subject by the development of bilateral parts, obscuring the plan upon which the embryo is built. It is an embryo closely resembling those of the other Radiates, in which, however, the class-characters, distinguishing it from the embryos of the other classes of the type, are already developed beyond question. In the young Polyps, the earliest appearance of the classcharacters is denoted by the presence of a few radiating partitions, dividing the cavity of the embryo into distinct chambers. In the Acalephs, in the most rudimentary stages, we already find the chymiferous tubes pushing their way through the spherosome; while, in our larvæ, the echinodermoid class-character, that of having distinct walls, forming the different organs, is already plainly visible from the mode of formation of this digestive cavity. What unites all these embryos in one great type is, that we have in them all, an axis around which are arranged the different elements of which they are composed. Our young Echinoderm, in this condition (Pl. I. Figs. 23-28), can be strictly homologized with the earlier stages of a Polyp at the time when the digestive cavity is first formed, before the appearance of the partitions; and to an acalephian embryo, where the digestive cavity alone is developed, previons to the pushing of the chymiferous tubes through the gelatinous mass. The stages subsequent to the condition of the embryo here described, represented in Pl. I. Fig. 24, not having been traced very carefully by previous observers, we have not had before us the means of forming a true conception of the mode of development of the Echinoderms; for to obtain a clear and precise idea of the functions of those problematic bodies which have puzzled Müller during the whole of his investigations, it is necessary to follow, step

as they have been figured by Derbès, agree in the main points with what has been observed of the earlier stages of our Amorican Echinus larvæ (Toxopneustes drobachiensis). With the exception, however, that Derbès, not having followed all the intermediate stages between his figures 15 and 16 in the Annales des Seiences Naturelles for 1847, did not see the transformations the digestive cavity undergoes, and committed, therefore, the very natural mistake of supposing that the first formed opening, which we have described as a mouth, retained the same function afterwards. $\mathrm{He}$, however, correctly noticed the separation of the three cavities, the cosophagus, the stomach, and the alimentary canal, into which this primary cavity is gradually differentiated, and has given a correct description of their relation to each other. Müller has taken up this same subject more where Krohn and Derbès have left it, and al- though he has traced the development from the egr of several Echinoderm larva, yet he has not given us as detailed descriptions and figuress of the earlier stages, as of those which were more advanced, and says simply, that in the main points his observations coincided with those of Krohn and Derbès. Krohn, who has artificially fecundated E. lividus, gives us it his figures some of the missing links in the chain of the observations of Derbès, and shows distinctly for Echinus lividus, that the first-formed opening becomes the anus eventually, and in what way this is brought about by the bending of the bottom of the digestive cavity towards one side of the larva, as is the case in our Starfish, and the formation at that point of a second opening, which becomes the true mouth, while the first-formed opening henceforth assumes the function of an anus. 
by step, the changes taking place in the pouch of the embryo, which is in this early stage its digestive cavity $(d)$; for it is a digestive cavity as much as the digestive cavity of a young Actinia or a Scyphistoma, where the same opening serves as mouth and anus. The mode of formation of the digestive cavity is entirely different in the two classes; in the Polyp it is hollowed out of the interior of the embryo, while in the Echinoderm the bending in of the wall forms the stomach. Hence the two cavities are not homologous, and the openings which lead into them, though performing similar functions - those of mouth and anus - are likewise in no way homologous, though they are in all built upon the plan of radiation. This opening always retains its double function in the Polyps and some of the Acalephs, while in the Echinoderms it becomes the anus after the true mouth has been formed, and the currents have ceased to circulate in the extremity of the pouch and to pass out through the same opening which admitted them.

If there is any doubt that Echinoderms, Acalephs, and Polyps belong to the same great type of the animal kingdom, a comparison of the young Echinodern, Acaleph, or Polyp in their earlier stages of growth, at a time when the spherosome has not yet been divided into its component spheromeres, will show how great their identity of development is, and how little there is in nature to base a separation into Echinoderms and Coelenterata, of this most natural great division of the animal kingdom, the Radiates. I shall return to this point when speaking of the homologies of the larvæ of Echinoderms.

Formation of the Mouth. - The perfect symmetry of the larva (PI. I. Fig. 27) is soon modified, and in the next stages of development (Pl. II. Figs. 2, 4), the digestive cavity (d) no longer runs in the centre of the larva, but is bent slightly to one side. If we examine one of the embryos about forty hours old (Pl. II. Figs. 5, 6), we find that great changes have taken place in the thickness of its walls. The outer wall has everywhere become much thinner, except near the opening thus far called mouth, where the decrease is not so marked. The walls of the digestive cavity, which were of an equal thickness for the whole length, have become exceedingly attenuated at the bottom of the sac, and have dilated to a considerable extent, forming a sort of reservoir with very thin walls at the extremity of the pouch (Pl. II. Figs. 4, 6, d, magnified and isolated, Fig. 1,d). These changes in the thickness of the walls, and in the form of the internal cavity, are also accompanied by corresponding changes of form in the embryo as a whole. The extremity opposite the so-called mouth has increased in bulk, and greatly exceeds in size the perforated extremity (Pl. II. Figs. $4,6)$ of the body.

When seen in profile (Pl. II. Figs. 2, 4, 5), still greater changes are visible; there is a decided difference between the two sides of the embryo, forming what is to become above and below; calling that part below, where the mouth is situated in voL. $\mathrm{v}$. 
the adult larvæ, and which is carried downward in its natural attitude while moving. The dorsal portion of the larva projects beyond the so-called mouth, so that the perforated extremity has become bevelled; the narrowing of the central portion of the larva has increased, and the digestive cavity which, in younger embryos, occupies the centre of the cylinder (Pl. I. Figs. 27, 28), is bent towards the lower side (Pl. II. Figs. 2, 4, 5, d). The outer wall has become thickened at a point opposite the bent extremity of the digestive cavity, and the thickening of the wall, together with the bending of the digestive cavity, goes on till the closed end touches the lower side at $n$.

The changes, which have taken place during the time elapsed since the twentieth hour, have been very gradual. The embryo now enters into a state where the changes are exceedingly rapid and important; so much so that, at the end of the third day, the embryo has, in a rudimentary state, all the parts which older, fullydeveloped larve have.

At the end of the second day, the reservoir at the extremity of the digestive cavity has changed its outline from a circular to a lobed one (Pl. II. Fig. 8, o); the lobes widen towards the sides, almost forming diverticula $\left(w, w^{\prime}\right)$, from the digestive cavity. During this time, the main digestive cavity has entirely lost its cylindrical form; it has become narrowed at the extremities and bulging in the centre (PI. II. Fig. 8, and isolated, Fig. 9). When seen in profile, and comparing it with earlier stages (PI. II. Figs. 2, 4, 5, 7, isolated, Fig. 10, a), it is at once noticed that the opening at one end, the present mouth of the larva, has little by little changed from a position at one extremity of the embryo (Pl. I. Figs. 27, 28, a), to a slightly eccentric one (Pl. II. Figs. 4, 5, 7). While the present mouth is changing its position from a terminal to an eccentric one, and while the digestive cavity has been expanding at the bottom into a large reservoir, its closed end is bending more and more towards one side (Pl. II. Figs. 2, 4), until it finally touches the outer wall of the embryo at $m$ (Pl. II. Fig. 5). At this point of junction an opening is formed, leading into the bottom of the digestive cavity (Pl. II. Fig. 7); this second opening $(m)$ is now the true mouth, and performs hereafter all the functions of a mouth, while the firstformed opening of the young embryo ( $\alpha$, Pl. II. Figs. 2, 4, 5, 7) is restricted in its functions, and performs hereafter only those of an anus; although in the early stages (Pl. I. Figs. 25, 26, 27, 28 ; Pl. II. Figs. 2, 4, 5, 6) it had performed the functions of a mouth. We have thus an apparent anomaly in the fact that the first opening becomes the anus, while the true mouth is only formed afterwards; but this difficulty is readily explained if we compare the functions of this firstformed opening, the so-called mouth, with what we find among Polyps, where one and the same opening performs the double functions of mouth and anus throughout life.

The diverticula $\left(w, w^{\prime}\right.$, Pl. II. Fig. 7, 10) do not extend, as would seem when seen 
from above (Pl. II. Fig. 8), at right angles from the main cavity, but trend obliquely upwards, as seen in profile (PI. II. Fig. 7), towards the other extremity of the embryo, as in Figs. 7, 10, Pl. II. The outer wall, which had formed a connection with the closed extremity of the digestive cavity, on the lower side, has been drawn out in the shape of a slender cone (o, PI. II. Figs. 7, 10, 11, 14, 17), and becomes the oesophagus, which leads to an opening ( $n$, the mouth), connecting the ventral side with the

- digestive cavity.

Nomenclature. - It will materially assist in the explanation of the subsequent changes of form, and obviate a great deal of circumlocution, if we at once call the different organs by their true names. The original opening $(a)$, which performed at first the functions of the mouth, is hereafter the anus $(a)$; the second opening, the true mouth $(m)$, is not formed until the embryo has arrived near the end of the second day; it is placed in the middle of the lower surface, and from this time forward, the former mouth assumes the function of an anus. That portion of the digestive cavity which leads from the mouth to its bulging portion, is the oesophagus (o), the bulging portion is the true digestive cavity, or stomach proper $(d)$, the short tube leading from the stomach to the anus, is the intestine $(c)$, while the diverticula $\left(w, w^{\prime}\right)$ are the two branches of the future water-system. The reasons for calling these parts, mouth, anus, esophagus, stomach, intestine, and water-system, will become apparent as we trace the development of the embryo in its more advanced stages, in the following . pages. ${ }^{1}$

The currents, which before had entered throngh the month $(\alpha)$, gone to the extremity of the cavity $(a)$, and been expelled again through the same opening (a), now change their course completely; there is a current which enters the mouth $(m)$, passes through the oesophagus $(0)$ into the diverticula $\left(w, w^{\prime}\right)$, then into the true stomach $(d)$, and is finally rejected through the anus $(a)$. From this time forward, it is quite an easy thing to observe the course of the food; it is taken into the mouth, by means of the currents produced around its opening, passes rapidly through the oesophagus, rotates for some time in the spherical stomach $(d)$, and then passes out slowly through the opening $(\alpha)$ of the alimentary canal $(c)$. As these currents are more and more distinet as the larvæ grow older, there can be no doubt that the function of the first-formed opening is eventually confined to that of an anus, after having performed the function of mouth dụring the first stage of growth of the larva.

Formution of the Water-Tubes. - By water-tubes, I mean the bodies which have received from Müller the name of problematic bodies, in their earlier stages of

1 Other terms are also frequently used, to denote
the different parts of radiated animals, which are not
usually adopted; they will be found fully explained in the third volume of the Contributions to the Natural History of the United States, by Prof. Agassiz, p. 73 , and seq. 
growth, and which he has called Schlauchsystem, when they appear, in the older larvæ, as broad tubes running on each side of the osophagus and stomach. These parts he considered as independent systems, but as they are only different stages of the same thing, as will appear below, they have received here the name which denotes most appropriately the function they assume of circulating water through the body of the larva.

The water-tubes $\left(w, w^{\prime}\right)$, at first (Pl. II. Figs. 7, 8, 9, 12, 13, 14) only diverticula * from the main digestive cavity $(d)$, become less and less connected with it; and, by the end of the second day, the constriction at the point of attachment, has almost entirely separated them from the digestive cavity (PI. II. Figs. 15, 16, w, w'). A marked difference is noticed in the rapidity of growth of these two bodies; the right hand one $\left(w^{\prime}\right)$, when the anus is placed in advance, and the mouth downwards, increases more rapidly, extending towards the dorsal side, which it eventually reaches, opening into the surrounding medium by a small aperture (Pl. II. Fig. 17, b), the water-pore, or, as Müller has called it, the dorsal pore. A comparison of Figs. 8 and 18 of $\mathrm{Pl}$. II., will perhaps render more evident the transformation of the diverticula $\left(w, w w^{\prime}\right)$ from the digestive cavity into two separate bodies. All we have to do is to swell out the lobed pouches $\left(w, w^{\prime}\right)$ of Fig. 8, Pl. II., then cut them off, removing them a short distance from the digestive cavity, and we shall have the two independent bodies $\left(w, w^{\prime}\right)$ of Pl. II. Fig. 18, which have little by little been changing their relation to the digestive cavity, as described above. This transformation I have actually observed in every stage of its progress, as it is represented here isolated (Pl. II. Figs. 9-16).

The walls of the oesophagus (o), of the digestive cavity $(d)$, and of the intestine $(c)$, which up to this time are of nearly the same thickness, quite rigid, capable of very limited expansion and contraction (Pl. II. Figs. 2, 4, 5, 7, isolated Figs. 10, 11), lose their uniform character with the gradual circumscription of these three regions. The walls now become quite different in their appearance, and the more marked the separation between these three organs, the greater the difference in the character of the walls which circumscribe them (Pl. II. Figs. 17, 19, 21, 23). In proportion as the stomach $(d)$ grows more spherical, the angle between it and the intestine $(c)$ is more acute, and the intestine $(c)$ becomes a longer and narrower tube, with walls much less thick than those of the stomach $(d)$. The walls of the oesophagus $(0)$ are even more flexible; the conical tube, leading from the mouth to the stomach, widening and taking a pistol-shaped form, the walls have become so movable, that the opening leading into the stomach can be closed and opened by the greater power of expansion and contraction of this part of the walls (Pl. II. Figs. 23, 25). The mouth $(m)$, as it increases in size, grows triangular, with rounded corners; the depression in which it is placed, divides the larva into two very distinct regions 
(P1. II. Figs. 19, 23, 25). Since the formation of the mouth, and the change of position of the first-formed opening to an eccentric one, we find the mouth and anus placed on one side of the larva. These openings present, at this stage (PI. II. Fig. 17), the same relations as the mouth and anus of Clypeaster and Scutella-like Echinoids, while at a much earlier period they are more like Pygorhynchus.

If we now return to the water-system, we find that the two diverticula $\left(v, w^{\prime}\right)$, mentioned above (PI. II. Figs. 15, 16), have entirely separated from the digestive cavity (PI. II. Fig. 18), and are now distinct cavities, having no connection whatever, either with the cavity from which they originated, or with one another; one of these cavities is entirely closed $(w)$, the other $\left(w^{\prime}\right)$ connects with the surrounding medium, by means of a very small opening, the dorsal pore (b, Pl. II. Fig. 23, and isolated Fig. 17). Such is the appearance of an embryo at the close of the second day after fecundation.

Müller never knew the origin of the water-tubes; in his last paper only, he becomes aware that they are independent at first, but subsequently unite. It must be remembered, in reading his earlier papers, that he sets at rest, in his last memoir, the doubts he expressed concerning the independence of the two branches of the water-tubes; in fact, to obtain a clear conception of Müller's views, it is advisable to read his last memoirs first, to be able to adopt at once the corrections he himself makes, during the laborious course of his investigations. The problematic bodies, however, still remained a puzzle to him, even at the time of his last memoirs, as he was never aware that they were simple diverticula of the digestive cavity, and were finally transformed into the two independent branches of the water-tubes, uniting, in subsequent stages of growth, to form the Y-shaped watersystem. Van Beneden saw, in the young Bipinnaria (Brachina Van Ben.), that the water-tubes are at first separate, but he did not trace their mode of formation, and no other observer has since returned to this subject.

Appcarance of the Chords of vibratile Cilia. - The cilia, spreading over the whole surface, which moved the embryo so rapidly at first, have almost entirely disappeared, and are no longer capable of propelling such a large mass; consequently, at this last-mentioned stage (Pl. II. Fig. 20), the larva is very sluggish, advancing but little, and rotating slowly about a longitudinal axis at the same time. During the third day, the movements become still more sluggish; it is then that we find the first appearance of the organs which are to propel the larva in future. The general outline does not change during the third day; the principal transformations are the greater bending and extending of the oesophagus and alimentary canal, the increase in size of the mouth, of the water-tubes, and the appearance of slight projections, small clusters of vibratile cilia, near the anterior and posterior sides of the mouth, which are the beginning of rows, extending in older larvæ in continuous 
lines all round the body, and their only means of locomotion (Pl. II. $v$, v', Figs. 20-28). These rows are at first two very short ares (v, $v^{\prime}$, Pl. II. Fig. 22), with their convexities placed opposite one another on each side of the depression in which the mouth is placed ( $v, v^{\prime}$, Pl. II. Fig. 21).

The general outline of the larva has, up to this stage (Pl. II. Fig. 20), undergone but slight modifications, the changes taking place principally in the digestive organs. The phases through which the larva passes in the next three days, are of a very different character; the alimentary canal, the stomach, and the cesophagus, become more circumscribed by the increasing difference there is noticed in the walls of these regions. The stomach $(d)$ is always marked by the greater thickness of its walls; while, with increasing age, the walls of the aesophagus $(o)$ become more attenuated, and capable of greater expansion and contraction (Pl. II. Figs. 25, o, 27). We notice, also, a rapid increase in the growth of the water-tubes $\left(w, w^{\prime}\right)$, which by the end of the sixth day (Pl. II. Figs. 27, 28) extend as far as the corners of the mouth and along the edge of the walls of the stomach, towards the anal extremity (Pl. II. Figs. 24, 26, w, w'). When viewed in profile (Pl. II. Figs. 25, 27), it will be seen that the plane in which these water-tubes run, is not parallel to the longitudinal axis, but inclined to it in such a manner, that the oesophagus passes between these two tubes. It is in these stages, represented in Pl. II. Figs. 20-28, that the passage from the initial, truly radiate form, to a bilateral one, is the most obvious, and it may be well to divell for a moment on the changes which are going on here, and compare them to what we find in other Radiates. Müller has always maintained, that the Echinoderm larvæ being bilateral, we had a passage from- a bilateral symmetry to a radiate type, while, in reality, this seeming bilaterality is subordinate to a truly radiate plan of structure. The first question to settle with regard to this is, whether we have a strictly bilateral form among the larvæ or not, and whether we do not find here a repetition of what is so constantly met with in the animal kingdom, - the undue preponderance of some parts, hiding effectually the plan upon which the whole animal is built; in fact, the engrafting of a subordinate type upon the type which remains predominant. With the gradual development of the plastrons alluded to, as formed from the chord of vibratile cilia, the embryo assumes more and more a shape which renders it quite difficult to perceive the original plan of radiation, concealed, as it gradually becomes, by the symmetrical arrangement of the edges of these plastrons, which leads one involuntarily to mistake their mode of execution for the plan upon which the animal is built. This apparent passage from a strictly radiating form to a seeming bilateral one, is nothing more than what we find constantly among the adults of this same class, and yet no one has attempted, for that reason, to make bilateral animals of the Echinoderms. The Spatangoids might as well be called bilateral, and not radiating 
animals, on account of the perfectly regular symmetrical arrangement of the fascioles, upon the whole of the spheromeres of which the body of one of these Spatangoids is composed, and in which even the ambulacral system presents marked features of bilateral symmetry. The case is exactly a parallel one; this chord of vibratile cilia, and the chord of fascioles, arranged so regularly, simply conceals in both cases the plan upon which the animal is built, but does not, in either case, change the plan of radiation into that of bilaterality. We should be as little justified in removing some of the Holothurians, such as Cuviera and the like, from the Radiates, simply because the greater preponderance of some of the ambulacra has brought out, in these animals conspicuously, a dorsal and a ventral side, and an anterior and posterior one. In the embryo of our Starfish, which told so. plainly, in its early stages, of the plan upon which it is built, that plan is now lost sight of in the extraordinary bilateral development of some of the parts. But, until Spatangoids and flat-soled Holothurians are proved to be truly bilateral animals, and not genuine Radiates, with subordinate bilateral features, these seeming bilateral Echinoderın larvæ must be considered as truly radiate, with bilateral features engrafted upon them.

Development of the Plastrons. - The cylindrical shape, characterizing the earlier stages of the larva, disappears soon after the appearance of the first trace of the appendages, which give to these larvæ such a peculiar appearance, and they now assume the features of the adult. The depression (Pl. II. Figs. 25, 27, $m$ ), in which the mouth is placed, becomes more marked; we have a greater separation of the oral $\left(v^{\prime}\right)$ and anal $(v)$ swellings of the vibratile chord, little by little changed into two independent breastplates, the edges bound with chords of powerful vibratile cilia, becoming the locomotive organs of the larvæ (Pl. II. Figs. 20, 22, 24, 26, 28). These plastrons, at first mere crescent-shaped shields (Pl. II. Figs. 20, 22, 24), extend gradually towards either extremity, become elliptical, and then somewhat triangular. The outline of the anal shield becomes sinuous, slight indentations point out the position of the future arms (Pl. II. Fig. 26, $e^{\prime} e^{\prime}$, Fig. 28, $\left.e^{\prime} e^{\prime}, e^{\prime \prime \prime} e^{\prime \prime \prime}\right)$; the rows of cilia creep gradually round the edge of this anal shield, turn towards the mouth again, and extend, on the dorsal side, along the whole length of the larva (Pl. II. Fig. 25); this chord of cilia makes a complete circuit, while the cilia, extending along the edge of the oral plastron, do not meet.

The formation of these plastrons is attended with great changes in the general outline of the larva; the anal extremity becomes pointed, triangular, with rounded edges; the body, on each side of the oral opening, bulges out beyond the general outline, and the oral plastron is more and more pointed, as it separates from the rest of the larva. This change of shape can perhaps be better appreciated when seen in profile, and comparing the drawings of larvæ three days 
and six days old; compare Pl. II. Fig. 19 with Pl. II. Figs. 25 and 27 seen from opposite sides. The great elongation of the oral extremity and the marked separation made by the opening of the mouth between the anal and oral plastrons, cannot fail to be noticed.

Comparison of Larve of Asteracanthion pallidus and A. berylinus. - Up to this time, all the larvæ described were raised by artificial fecundation from eggs taken out of the ovaries of Asteracanthion berylinus $A g$. At the time when I first discovered the larvæ of our Starfishes, I immediately examined the ovaries of our two most common species, the A. berylinus Ag. and A. pallidus Ag. I found that the eggs of the former were not sufficiently advanced to be fecundated, while those of the second species (A. pallidus) had all escaped. I am, therefore, positively certain that all the larvæ I am about to describe, belong to the second species, as they were all found swimming about, previous to the time of spawning of the A. berylinus. As the interval between the time of spawning of these two species is not less than three weeks, I had been able, during this period, to make a general sketch of the whole development, from the youngest larva found (PI. III. Fig. 1), to the time when the Starfish is formed, before beginning the artificial fecundation of the species just described, the A. berylinus Ag.

I thus obtained a general knowledge of the changes these larvæ undergo, and was enabled, when making the artificial fecundation, to pay special attention to the development of those parts, the origin of which was not easily traced in older larvæ. I was able in this way to carry on, at the same time, the comparative study of the development of two closely-allied species, belonging, undoubtedly, to one and the same genus, and to see how far differences could already be noticed in their early stages of growth; a glance at the figures of the young of one species (A. pallidus Ag.) on Plate III., compared with the figures of Plate II. of the second species (A. berylinus $A g$.), will show how far the development of allied species diverges. What is particularly characteristic, is the fact that specific differences make their appearance so early. Soon after it became evident that the embryos we were studying belonged to Echinoderms, it was apparent that they were different species. The order of appearance of the characters of the classes, the orders, the families, and genera, is one of the greatest importance in a zoölogical point of view; and we owe to Professor Agassiz to have pointed out, that the characters which make their appearance first, are by no means those which have been usually taken for granted; in the present case, we do not find it possible to discern the class, the ordinal the family, the generic, and the specific characters, in the order in which they are here mentioned. The specific characters are early stamped upon the embryo, and did we but know how to recognize individual differences among the lower animals, as well as we can already in some of the Fishes, we might find that 
with Echinoderms, as has been shown for Fishes by Professor Agassiz, the stamp of individuality is very early impressed upon the embryo. Long before we can tell that a young Perch belongs to the genus Ctenolabrus, we can already say with certainty whether it will be an individual colored red or gray, or brown or green.

The time of spawning of Starfishes is very short, as, three or four days after the A. berylinus began to spawn, it was quite difficult to find females with eggs; and a week after the beginning of the spawning, I never succeeded in finding a single one. Owing to this great difference in the time of spawning, and its short duration, there can be no doubt, from the date at which I first caught the Starfish larvæ floating about, to which of our two species they belong. A careful comparison of the youngest specimens also shows very striking differences, and will always.enable an observer to distinguish readily the larvæ of the two species, even in their earliest stages. Compare Pl. III. Figs. 1, 2, 3, 4, 5, with Figs. 22-28 of Plate II. These differences become more marked as they grow older, as will be seen when we describe adult larve. In fact, the larva of A. berylinus is pear-shaped, with the thick end at the oral extremity, while, in the larva of A. pallidus, the thick end of the equally pear-shaped, but relatively shorter body, is at the anal extremity. ${ }^{1}$

The principal points of difference in the young larva of this second species (the A. pallidus), from those previously described, are differences of proportions. The larvæ of the A. berylinus are elongated cylindrical; the oral extremity is somewhat broader and more prominent than the anal. The larva of A. pallidus can at once be recognized by its shortness; the small size of the oral extremity, when compared to the anal, the latter being by far the most prominent.

Water-system. - Before going on with the description of more advanced stages, I 'will take up the development of the water-tubes at the point to which we had traced them (Pl. II. Fig. 28) in the larvæ of A. berylinus. After the ends of the watertubes have extended beyond the oral opening (PI. III. Fig. 4), the tubes increase rapidly in diameter (P1. III. Figs. 6, 8, w, w'), bending at the same time towards the longitudinal axis (PI. III. Figs. 4, 5, 6, 8, 10, w, w'), the other extremity of the tubes creeping round the stomach until they touch, but without uniting ( $\mathrm{Pl}$. III. Figs. 6, 8, 10,w, w'). The tubes at the oral extremity bend towards each other (Pl. III. Fig. 4), come in contact (Pl. III. Fig. 6), and, soon after, a communication is made, the water-system assuming the shape of an elliptical ring ( $\mathrm{Pl}$.

\footnotetext{
1 Though we now consider the further progress of development of our larvæ in a different species from the first, we proceed without interruption, as the phenomena of growth are identical in both; and we link them here together only because our most complete observations for the younger stages relate to $\mathrm{A}$. voL. v.
}

berylinus, and to A. pallidus for the older stages. Had we presented these changes for a single species only, the one would have been defective in the beginning, the other in the end. As it is, our history is tolerably complete, the course and nature of the changes being identical in both species. 
III. Fig. 6, ww'); and the water which enters into the right tube through the dorsal pore (Pl. III. Figs. 2, 5, 7, b) can pass into the other branch on the opposite side of the stomach, through the fork at the oral extremity, and not round the stomach, where the water-tubes simply touch, but do not communicate. The small tube leading from the dorsal pore to the main branch of the water-system widens and becomes funnel-shaped as it approaches the main tube. The dorsal pore is cut obliquely across the end of this small tube, giving it an elliptical shape. By the time the two branches of the water-system have joined (PI. III. Fig. 6) at the oral extremity of the larva, it has assumed an entirely different outline from any we have met with in the former species. The anal extremity is very much flattened, the corners of the anal plastron project slightly beyond the general outline, the indentations have become very distinct, the oral plastron has grown rectangular with rounded angles and concave sides, the oral triangular opening leads into a deep pouch. The sides of the body are marked by three strong indentations (Pl. III. Fig. 8). The oral extremity of the water-system changes rapidly from a rounded to a pointed outline (Pl. III. Fig. 8, ww'); it advances more and more towards the oral extremity. In proportion as the dorsal region projects beyond the oral plastron, the water-system extends into this projection, sending off, at the same time, two branches leading into small appendages (Pl. III. Figs. 10, 11, $f, f$ ), (only developed in more advanced larvæ), which have, in the adult larvæ, a peculiar structure (Pl. IV. Figs. 4, 5, 6).

Changes of Form of the Larva. - The prominent changes now going on are only changes of degree. The larva has completely lost its cylindrical shape, and even the pear-shaped form it assumed afterwards; it has become rectangular, with deep indentations, gradually assuming the character of short arms. The transformation from the pear-shaped (PI. III. Fig. 1) to the rectangular flattened larva, with undulating outline (Pl. III. Fig. 6), can readily be traced by comparing the successive stages here represented. After the digestive cavity of the younger embryo (Pl. II. Fig. 7) is bent at the extremities, bringing the mouth and the anus on the same side of the larva, the anal and oral extremities increase rapidly in bulk, and the larva, when seen from above (Pl. II. Fig. 18)' or in profile (Pl. II. Fig. 19), becomes somewhat dumb-bell shaped. The depression thus formed grows deeper, especially on the lower side, at the time when the chords of vibratile cilia make their appearance (PI. "II. Fig. 21), and the mouth (PI. II. Fig. 21, $m$ ) is placed in the convexity of a deep curve. As the oral and anal vibratile chords extend towards the oral extremity, slight grooyes arise (PI. II. Fig. 23), starting from the depression in which the mouth is placed, and extending towards the oral extremity. These grooves are gouged out from the oral extremity; they extend but little way towards the stomach, forming a very well-marked chinnel separating the anal from 
the oral vibratile chord (P1. II. Figs. 25, 27). The oral is less broad than the anal plastron; the former retains its shield-like shape, while the sides of the latter become somewhat undulating from the bending of the ciliary chord (Pl. II. Figs. 26, 28). These slight undulations, as the larva grows older and more elongated, increase in size, giving it more and more a rectangular outline (Pl. II. Figs. 27, 28; Pl. III. Fig. 3, 4): With its quadrangular shape, the larva assumes also a more flattened character, and loses its cylindrical form, as will be readily seen in comparing Figs. 21 and 27, of Pl. II. These slight undulations of the ciliary chord are formed at points where accumulations of pigment cells have taken place. The ciliary chord, at first simply a wavy line (Pl. III. Fig. 4), soon becomes quite deeply indented by the formation of loops at these indentations (Pl. III. Fig. 6). The loops, at first, scarcely project beyond the general outline of the larva (Pl. III. Figs. 6, 7). Little by little they increase in length (Pl. III. Figs. 8, 9), extending slightly beyond the edge of the outline, like short arms; until, passing through somewhat older stages (Pl. III. Fig. 10), these loops are gradually transformed into larger and larger arms (Pl. III. Figs. 11, 12), and finally attain the shape of the long, slender arms of the adult Brachiolaria (Pl. IV. Figs. 1, 2, 4; Pl. VII. Fig. 8). During the process of the formation of the arms, the cut in which the mouth is placed becomes deeper (PI. II. Figs. 25, 27; Pl. III. Figs. 2, 5, 7, 9, 12; PI. IV. Fig. 4), as well as the groove extending along the sides of the larva, which runs from the median anal arms $\left(e^{\prime}\right)$ to the oral extremity, and separates the anal from the oral plastron. In all these larvæ, the ventral part of the anal and the oral plastron are much narrower than the dorsal portion of the anal plastron. This difference is at first slight (PI. II. Figs. 26, 28; PI. III. Figs. 3, 4); it becomes more marked with advancing age, passing through the different stages represented in Pl. III. Figs. 6, 8, 10, 11; Pl. IV. Figs. 1, 2; Pl. VII. Fig. 8; and in proportion as all the ridges and edges are more prominent, the surfaces circumscribed by them become flattened and more spreading.

Nomenclature of the Arms. - For the sake of brevity, I shall call the rudimentary appendages by the names proposed for them in the adult larvæ, and shall adopt the names given by Müller, with slight modifications, viz. ventral side, that on which the mouth is situated; dorsal, the side on which the water-pore is placed; anal plastron, what Müller has called "anales Bauchfeld," or "hinteres Bauchfeld"; oral plastron, what he calls "antorales Feld," or "vorderes Bauchfeld"; the oral region $(m)$ is situated between these two plastrons. The arms are designated according to their position by the following names: the median anal pair $\left(e^{\prime} e^{\prime}\right)$; the dorsal anal pair $\left(e^{\prime \prime} e^{\prime \prime}\right)$; the ventral anal pair $\left(e^{\prime \prime \prime} e^{\prime \prime \prime}\right)$; the dorsal oral pair $\left(e^{\prime \prime \prime \prime} e^{\prime \prime \prime \prime}\right)$; the ventral oral pair $\left(e^{5} e^{5}\right)$; the odd anterior arm $\left(e^{6}\right)$, from which projects, at the base, a single arm of a different character from the others; the odd brachiolar arm $\left(f^{\prime \prime}\right)$; 
and another pair of smaller brachiolar arms $(f f)$, connected with the oral ventral pair $\left(e^{5} e^{5}\right)$ of arms (PI. III. Fig. 11). The brachiolar arms are provided at their extremity with wart-like appendages (Pl. IV. Figs. 4, 5, 6; Pl. VII. Fig. 8); the other arms have nothing of the sort, but are surrounded by chords of vibratile cilia, making a complete circuit from the anal extremity round the dorsal side, while on the oral side it is not closed.

Development of the Arms. - In adult larvæ the arms have, at their extremity, clusters of orange pigment cells. These colored cells make their appearance early in the younger stages, and it is easy to trace the first appearance of the arms by the presence of these pigment cells. Before the appearance of the arms, the course of the chord of vibratile cilia is very sharply defined; it is like a narrow binding extending round the outline of the larva, seen either from above or from below (PI. III. Figs. 3, 4, 6, and Pl. II. Figs. 26, 28). When seen in profile (Pl. III. v, v', Figs. 2, 5, 7, and Pl. II. $v, v^{\prime}$, Figs. 25, 27), it follows the two edges of the deep groove which separates the dorsal from the ventral side. The median anal $\left(e^{\prime} e^{\prime}\right)$ arms are the first to make their appearance (PI. III. Figs. 2, 3, 4, 6, 7); these arms take the greatest development in the adult larva; the other arms appear also at the same time, but as simple bulgings of the ciliary chord. The anal ventral pair $\left(e^{\prime \prime \prime} e^{\prime \prime \prime}\right)$ and the odd dorsal arm $\left(e^{6}\right)$ are both developed about the same time (Pl. III. Figs. 8, 9, $\left.e^{6}\right)$; the odd anterior arm inçeasing in size, and changing its shape more rapidly at first than the median anal pair. The next set of arms formed is the dorsal pair $\left(e^{\prime \prime} e^{\prime \prime}\right)$; then follows the oral dorsal pair $\left(e^{\prime \prime \prime} e^{\prime \prime \prime}\right)$, and next the ventral oral pair $\left(e^{5} e^{5}\right)$. These develop very rapidly, and soon attain as large a size as the dorsal oral pair, which had preceded them (Pl. III. Fig. 10). In this same figure we see the first trace of a small thick arm $\left(f^{\prime \prime}\right)$, cut off square at the extremity, placed at the base of the odd anterior arm $\left(e^{6}\right)$, and also a similar $\operatorname{arm}(f f)$ at the base of each of the ventral oral pair $\left(e^{5} e^{5}\right)$; the water-system branches into this small pair of arms which are not surrounded with vibratile cilia (Pl. III. Figs. 9, 10, 11). Of the brachiolar arms, the one which is odd precedes the two that form a pair.

The chord of vibratile cilia keeps pace with the growth of the arms, and extends to their very extremity; the most important change which takes place, from the time when the median arms first appear, is the extraordinary increase of one of the diameters of the water-tubes. The portions $\left(w, w^{\prime}\right)$ extending along the stomach become much flattened; when viewed from above (PI. III. Figs. 8, 10, 11), their great increase in size is not seen; and it is only when examined in profile that the changes the water-system has undergone in the vertical diameter, compared to the transverse, can best be appreciated (Pl. III. Figs. 9, 12, w).

It is in this condition that Müller has seen the greatest number of his larvæ; struck by their symmetry, he has, throughout his memoirs, insisted upon the bilateral 
symmetry of the Echinoderm larva, as contrasting directly with the radiate structure of the adult animals. It appears to me that this interpretation of the form of the larvæ of Echinoderms is incorrect; they are radiate animals, and are no more bilateral than a large number of Radiates exhibiting bilateral characters, such as Arachnactis, the Ctenophoræ, the Spatangoids, and the Holothurians, as will be shown hereafter.

The larvæ figured on this plate (Pl. III.) correspond to the larvæ observed by Van Beneden, and called by him Brachina; the latter resemble more our larvæ than any figured by Müller. I am strongly inclined to believe that Van Beneden's Brachina will eventually prove to be the larvæ of the Asteracanthion rubens $M$. $T$., or of a closely-allied species. The more advanced specimens of his Brachina began to show signs of the brachiolar appendages, though Van Beneden did not notice them. See Fig. 8 of the Plate accompanying his notice in the Bulletin de l'Académie des Sciences de Belgique for 1850. These larvæ are easily distinguished from ours by the shortness and thickness of the arms, as well as the less elongated shape of the larva. The time of breeding is also different; the European species spawning during the end of March and beginning of April. The A berylinus spawns in the last part of July; by the 26th no eggs could be found in any of the females, and the other species (the A. pallidus) spawns during the third week in August. These facts are additional proofs of the specific difference between our species of Asteracanthion and the Asteracanthion rubens of Europe.

When seen in profile (Pl. III. Figs. 9, 12, w, ww'; Pl. IV. Fig. 4, w, ww'), the water-system runs in an arch, from the alimentary canal to the opening of the mouth,; here the diameter increases, forming a reservoir (ww'), from which are sent off small pouches $\left(f^{\prime} f^{\prime}\right)$, leading into the brachiolar arms $(f f)$; the whole of the oral opening is placed below the water-system. When seen from above or below (Pl. III. Figs. 6, 8, 10, 11; Pl. IV. Figs. 1, 2; Pl. VII. Fig. 8) the water-system is an elliptical ring tapering to a point in the odd brachiolar arm, enclosing the stomach and oesophagus, which form, as it were, a solid axis to this elliptical envelope. On one side of the stomach appears a large hole (Pl. V. Fig. 7 , $h$, anal part only; Pl. VII. Fig. 8), the opening of a cul de sac of one branch of the water-system passing between the stomach and the intestine. The portions of the water-system extending along the stomach appear made up of distinct chambers (PI. V. Figs. 6, 7, 8 ; w, w'); these chambers are merely the result of an optical delusion, arising from the greater or less flattening of certain parts of the tube, this gives it the appearance of having been divided off into segments.

The adult Larva. - The anal part of the larva, in its adult condition (Pl. IV. Figs. 1, 2), has become pointed; the general shape is still somewhat rectangular; the ventral and dorsal side are separated by a deep groove (PI. IV. Fig. 4), extending 
from the stomach, from the base of the median anal pair of arms, to the base of the ventral oral arms, thus separating the larva into very distinct dorsal and ventral regions (Pl. IV. Fig. 4), from the earliest stages of its growth. The body of the larva itself is capable of great motion; nothing is more common than to see the larvæ almost broken in two, by the strange habit they have of bending the oral extremity upon the opening of the mouth as a pivot, to such an extent, as to make quite an angle with the anal part (Pl. III. Fig. 5). The larvæ generally assume this position when disturbed, and usually remain stationary in the same attitude, simply striking violently. up and down with their extremities (compare Fig. 5 and Fig. 2, where the larva is at rest). The whole substance of the body is tinged with yellow, and is made up of large transparent cells with irregular nuclei, giving the mass about the consistency of a Salpa; very minute granular epithelial cells cover the whole surface. The powerful contraction of portions of the body is simply that of the cells themselves, and what has frequently been mistaken by Müller, when describing these larvæ, for muscular strix, are strings of such contracted cells. The extremities of the arms are tipped with orange, the stomach and the alimentary canal are of a slight yellowish-brown color, the chords of vibratile cilia are somewhat darker. The œesophagus is perfectly transparent, capable of violent movements; it expands and contracts by sudden jẹrks, forcing open violently the passage leading into the stomach, when the contents of the ocsophagus rush in, and are set slowly rotating in the stomach. The interior surface of the osophagus is covered with vibratile cilia, so closely crowded that the walls appear striated from the regularity of these rows (Pl. IV. Fig. 1; Pl. VII. Fig. 8); they are particularly powerful round the opening of the mouth.

The rejection of the digested food takes place quietly, and there are none of those violent jerks attending its admission into the digestive cavity. The anal opening simply expands, and the fecal matter is forced out slowly, in a constant stream, until the whole of the contents of the alimentary canal, which had become very much distended before the operation, has been cleaned out.

Motion and Habits of the Larva. - The adult larvæ move about rapidly by means of the cilia; their natural position is more constant than when young. The oral extremity is kept in advance while in motion, and the larva still rotates about a longitudinal axis, though not frequently; it generally moves with either the dorsal or ventral side uppermost, and quite frequently in such a way as to show the lateral groove. ${ }^{1}$ When at rest, the larvæ invariably assume one and the same position; the

1 The position in which the larvæ figured in this
memoir have been placed, requires a short explana-
tion. To be able to compare readily the different stages, it is necessary to have them all in the same position, and this should, if possible, be the natural attitude. But, in the younger stages of the larra, 
anal extremity is the lowest, and the oral extremity inclined to the vertical; in this attitude they often remain a long time, drifting about with the currents; their only movements being the expansion and contraction of the oesophagus, and the play of the arms. The movements of the arms are exceedingly graceful; comparatively longer and more slender than the tentacles of the Tubularians, they have none of the stiffness of their movements, the constant curving and thrusting in every direction reminding us rather of the motions of the tentacles of Phyllodoce and similar Annelids. They are never at rest, being always kept in motion to produce currents round the mouth of the larvæ; and, in addition to the action of the powerful vibratile cilia placed round the mouth, are continually bringing fresh water into the œesophagus.

The large triangular mouth (Pl. IV. Figs. 1, 2, 4, m; Pl. VII. Fig. 8) opens into a rectangular pouch (Pl. IV. Fig. $4, m^{\prime}, m^{\prime \prime}$ ), extending back from its posterior edge; from this pouch the osophagus tapers rapidly, and attains, near the apex of the mouth, the size $(0)$ which it retains till it joins the stomach. The surface of the oesophagus (o) presents a more or less corrugated appearance near its junction with the digestive cavity, owing to the somewhat greater thickness of the walls (Pl. IV. Fig. 1).

Brachiolar Arms. - The brachiolar arms $\left(f f, f^{\prime \prime}\right)$ are appendages belonging only to adult larvs. Our larva has three of them (Pl. IV. Figs. 1, 4, 5,6), one pair $(f f)$, and a somewhat larger odd arm $\left(f^{\prime \prime}\right)$, placed at the base of the odd anterior arm $\left(e^{6}\right)$; the branches of the water-system terminating in these arms, proceed from a large pouch $\left(w w^{\prime}\right)$ in the oral extremity (PI. IV. Fig. 4). The brachiolar arms are, like the others, tipped with orange, but have, in addition, wart-like terminal appendages, each having six to eight nipples, according to the age of the larva (Pl. IV. Figs. 4, 5, 6, 8; Pl. VII. Fig. 8). These knobs give to the short arms the appearance of the hind feet of Sphinx larvæ. In the hollow between the base of the brachiolar arms there is a small elliptical disk ( $f^{\prime \prime \prime}$, Pl. IV. Figs. 4, 5, 6; Pl. VII. Fig. 8), reminding us of the madreporic body of a Starfish, and a row of similar disks, two or three on each side of

the body of the embryo is not loaded down at one extremity by the young Starfish, thus compelling the larva to assume always one and the same general attitude when in motion. It is more common, in the younger stages, to see the embryo moving with the anal extremity uppermost; it would be as unnatural to turn these younger stages upside down, as it would be to represent an adult larva in anything but its natural attitude (Pl. VII. Fig. 8) with the anal extremity downward. I have therefore compromised, by representing all the stages in the same position in which they are generally represented by
Müller, to facilitate the comparison with his figures, and have given one figure of an adult Brachiolaria, in its natural attitude (PI. VII. Fig. 8), with which the others can be readily compared in their theoretical position. The figures here given are drawn from the larve as they appear swimming through the water; and I have endeavored, as much as possible, in representing them, to give an accurate idea of the mobility of the arms; avoiding, in this way, the unnatural stiffness which characterizes drawings made under compression, like the majority of those of Müller. 
the odd brachiolar arm, the pair of small brachiolar arms having no such appendages. It has been found convenient to retain for these peculiar arms the name of brachiolar, used by Müller to distinguish one of his genera (Brachiolaria) of Echinoderm larvæ. I have not succeeded in ascertaining the functions of the disks; the terminal buttons undoubtedly are used in the last stages of growth of the larva as supports, by means of which they can attach themselves, while the young Starfish is resorbing the larva; for during that process the larvæ never float about, but invariably sink to the bottom of the jar in which they are kept, and remain attached, apparently by means of the brachiolar arms, during the resorption of the larval appendages.

These larvæ are found floating in large numbers at night near the surface, among cast-off skins of barnacles, furnishing them with food during the time when they swim freely about, in company with multitudes of small Crustacea, Annelids, and Hydroids. They seem to be nocturnal, as I have only: found here and there single specimens, when fishing for them under exactly the same circumstances of tide and wind, during the day-time. 


\section{CHA T ER SECOND.}

\section{HISTORY OF THE DEVELOPMENT OF THE STAREISH PROPER.}

WE have thus far described the changes the embryo undergoes from the time it leaves the egg, and have traced its gradual transformation into the complicated being called Brachiolaria. All the phases through which the embryo passes thus far, have not the least resemblance to a Starfish, nor have we yet alluded to any of the changes which still take place to produce the Echinoderm proper. However wonderful the process by which an animal seems to pass from a radiate form, to an apparently bilateral one may be, the changes we shall see now taking place, by which this seeming bilateral animal is again reduced to a strictly radiate structure, are perhaps still more remarkable.

For the development of the Starfish itself, we must turn back and examine the larva in some of its younger stages, in order to trace the first changes in its anal extremity. There alone, transformations take place affecting the development of the Echinoderm proper, until the whole of the complicated framework, upon which the Starfish is fastened has disappeared, and has been resorbed by the very Echinoderm it has helped to raise. The Brachiolaria is completely drawn into the body of the young Starfish, before it leads an independent existence. This is contrary to the observations of Müller and of Koren and Danielssen respecting Bipinnaria asterigera; where it is said that the Starfish and the Bipinnaria separate, both becoming free. The process by which the young Starfish eventually resorbs the Brachiolaria (PI. IV. Figs. 7, 8, 9) is similar to that observed by Sars in the development of Echinaster, where the whole larva and all its appendages are gradually drawn into the body, and appropriated during the growth of the young Starfish.

It has already been shown that the anal portions of the water-system, as they increase in size, spread little by little over the surface of the stomach; the edges creeping towards each other and surrounding the stomach on both sides, like a cap, yet without uniting. The funnel leading from the dorsal pore shortens, as the water-system extends towards the dorsal region, and the anal extremities of the water-tubes come so near together (Pl. V. Figs. 1, 2, 3, 5, w, w') that we might voL. . 
almost be tempted to believe they join, like the oral portions, and thus form a complete circuit (Pl. III. Fig. 10); this, however, is not the case, as an examination in profile of the above figures readily shows.

First Appearance of the Starfish. - In the drawings here given to illustrate the development of the Starfish, only a small portion of the Brachiolaria is figured, that which has direct reference to the Starfish itself; as this part is limited to the anal extremity of the larva immediately surrounding the stomach, the anal extremity alone of the Brachiolaria is drawn, with the arms cut off, somewhat beyond the opening of the anus. To make the references to the figures of Plate V. more satisfactory, a reference has also been made to a drawing of a whole Brachiolaria, in a stage of growth nearly identical, in order to show more readily the relation of the Starfish to the whole framework of the Brachiolaria. These stages are so similar that, with this explanation, it will always be possible to refer the anal extremities, upon which we are tracing the development of the Starfish, in its different phases of growth, to some figure of Brachiolaria, very nearly representing its actual condition. The stages of development figured in Plate $\mathrm{V}$. have been selected without reference to the Brachiolaria, and simply for the sake of the young Starfish, and would, if drawn on the same scale as the other figures of the Brachiolaria here given, show no differences, which would make the mode of growth of the young Echinoderm more intelligible. For instance, the earlier stages of the development, such as Figs. 1-7, correspond to the stage of Pl. III. Fig. 10; while the more advanced Fig. 8, corresponds to that of Pl. III. Fig. 11, and the others to the adult stages of the Brachiolaria on Plate IV., when the Starfish undergoes extensive changes, while none take place in the general appearance of the Brachiolaria.

Up to the stage of the larva represented on Pl. III. Fig. 6, 7, the outline of the left water-tube (left when seen from above in its natural attitude), in a profile view, is that of a flattened cylinder (Pl. V. Fig. 1, $v^{\prime}$ ), with the end slightly bent towards the anal opening. There is formed, near the point where the upper line of the water-tube bends downwards, a marked indentation, having in the centre a slight projection. There appear, soon after starting from the anal edge of this depression, five very faintly-defined folds, the first trace of the future ambulacral system, extending obliquely across the water-tube $\left(w^{\prime}\right)$ (Pl. V. Fig. 2, $t$; Pl. III. Fig. 8). If we examine the other side of the anal extremity, we find deposited, opposite the angles of these folds (PI. V. Fig. 2, $r^{\prime}$ ), five rods of limestone; the anal part of the larva having at the same time lost its former transparency, and assumed a dull-yellow color. These two parts are the first traces of the future Starfish. The limestone rods, and the whole of the granular surface covering the right water-tube, with the dorsal pore, forms eventually the abactinal area of the adult Starfish. While the folds, running obliquely across the left water-tube, are the first rudiments of what is to become the 
rows of suckers extending along the lower side of the future rays; the rods are placed exactly opposite what will hereafter be the extremity of the rays.

It is apparent, from the above description, that the abactinal area (the rods), and the suckers (the folds across the water-tube), are not situated in one plane, or even in parallel planes. The arc containing the rods, and the are passing through the folds, make an acute, nearly a right angle, as is better understood by referring to older stages. It will also be seen, by a glance at the drawings (Pl. V. Figs. 1, 2, 3, 5 ; Pl. III. Figs. $7-10, t)$, that the folds denoting the place where the suckers will make their appearance, and the rods $\left(r^{\prime}, r^{\prime \prime}\right)$ marking the position of the future rays, are neither of them closed curves, but are always open, forming a sort of twisted crescentshaped arc. I shall show how these curves become closed, when describing the young Starfish immediately after it has resorbed the larva, and is ready to crawl about by means of its suckers; and point out the changes these parts undergo to form diverging rays, also the manner in which the warped surfaces developing the actinal and abactinal regions are brought into parallel planes.

Relative Position of the actinal and abactinal Areas. - The folds of the water-tube $\left(w^{\prime}\right)$, which forms the actinal area, are not contained in one plane, but are placed upon a spiral; the same is the case with the five limestone rods situated on the surface of the other water-tube $(w)$, which forms the abactinal region. When we look at the Brachiolaria from the side, that is, when facing the groove which separates the ventral from the dorsal side, as in Pl. IV. Fig. 4, or in the corresponding profiles, from the side of the right and left water-tubes of Pl. V. Figs. 1, 2, 3, 5, 10, 11, 12, we see either the actinal or abactinal side of the Starfish. We look in one case at the water-tube $(w)$ upon which is developed the abactinal system; while in the other profile, drawn from the opposite side, we see the water-tube $\left(w^{\prime}\right)$ which develops the actinal system; the two water-tubes are placed on different sides of the stomach, and have no connection whatever at this extremity, but are separated by the whole diameter of the stomach, over parts of which these tubes have spread like a cap. It will at once be noticed that, in any of these figures, each side of the future Starfish makes an independent open curve; these curves form what appears to us, when seen from the profile view, part of a circular arc. On looking, however, at the same sides from the ventral or dorsal view of the larvæ, as in Pl. IV. Figs. 1, 2, or the corresponding views of PI. V. Figs. 4, 6, 7, 8, 9, 13, 14, we do not see the arc formed by these sides projected as a simple straight line, as it would be were it all contained in one plane. The extremities of the arc, both of the actinal and abactinal area, - that is, the two ends of it which are nearest, one to the water-pore, and the other to the anus, - are seen, as in Pl. V. Figs. 1, 2, 3, 5, 10, 11, 12, one on one side of an axis passing through the centre of symmetry of the Brachiolaria, and the other on the other side. The only curve which fulfils the conditions of 
such a projection is that of a warped spiral, so that, in reality, when passing (in Pl. V. Fig. 10) from $r_{1}^{\prime \prime \prime}$, along the edge of the disk, to $r_{2}^{\prime \prime \prime}, r_{3}^{\prime \prime \prime}, r_{4}^{\prime \prime \prime}, r_{5}^{\prime \prime \prime}$, we do not move in a plane, but are constantly winding, somewhat as when ascending a spiral staircase; this is seen in Pl. V. Fig. 9, when passing from $r_{5}^{\prime \prime \prime}$, the arm placed nearest the anus, along the edge of the abactinal area, to $r_{1}^{\prime \prime \prime}$, the arm next to the water-pore $(b)$. It is the same for the actinal arc, which forms a spiral identical to that of the abactinal area, only bent in the opposite direction.

The actinal and abactinal regions are, in reality, two warped spiral surfaces, making an angle with one another, separated by the whole width of the stomach. This is best seen in a view from the dorsal or oral side (Pl. VII. Fig. 8), when the folds are distinctly visible one above the other, but so arranged as to be all seen at the same time (Pl. V. Figs. 4, 6, 7, 8; Pl. III. Figs. 8, 10, 11). Three of the folds are near the edge, while the other two are placed close to the digestive cavity on the ventral side. This spiral, seen from the dorsal or from the ventral side, has all the appearance of the foot of a bivalve ( $t$, Pl. V. Figs. 4, 6, 8). The spiral position of the five rods indicating the position of the future rays of the Starfish $\left(r_{1}^{\prime \prime \prime}-r_{5}^{\prime \prime \prime}\right)$ is also apparent from the same point of view. Two of the rods are placed on the dorsal side of the larvæ, running somewhat obliquely $\left(r_{1}^{\prime \prime \prime}, r_{2}^{\prime \prime \prime}\right)$, the three others $\left(r_{3}^{\prime \prime \prime}, r_{4}^{\prime \prime \prime}, r_{5}^{\prime \prime \prime}\right)$ turning away still more from the median line; the last $\left(r_{b}^{\prime \prime \prime}\right)$ placed very near the edge, on the ventral side, close to the base of the median arms (PI. V. Figs. 3, 5, 6, 8, 9, $\left.r_{1}^{\prime \prime \prime}-r_{5}^{\prime \prime \prime}\right)$; the nearest distance between these two spiral surfaces being fully as great as the width of the water-tube: in fact, it seems as if the rudimentary tentacles and the dorsal system had as yet no connection whatever with one another (Pl. V. Figs. 6, 8).

It is very important that this oblique position of the actinal and abactinal areas, as well as their great distance apart, should be distinctly kept in mind; as it will explain many of the errors committed by previous writers on this subject, and greatly assist us in correctly understanding many points in the anatomy of Echinoderms hitherto unexplained.

From what has been shown thus far, it is self-evident that the water-tubes, the problematic bodies, as Müller has called them in their early condition, are the surfaces from which the future Starfishes are developed, and not the surface of the stomach. The spiral of tentacles is developed by folds placed on one side of the stomach (Pl. III. Figs. 6, 8, 10, 11), on one of the water-tubes $\left(w^{\prime}\right)$, that with the water-pore $(b)$; while round the other water-tube $(w)$, placed on the other side of the stomach, is formed the spiral surface of the abactinal system. The stomach has remained as it was before, and has in no way contributed to the formation of the young Starfish. A glance at any figure of the larvæ, either in profile or from above or from below, will show that no change has taken place in the shape of the 
stomach, or any part of the alimentary canal, as Müller believed (Pl. V. Figs. 1, 8; PI. III. Figs. 1-11), but that a kind of cap has been formed round it by the watertubes. Owing, however, to the accumulation of very fine granules of limestone, the anal extremity has by this time lost its transparency; this would be easily mistaken for an encroachment on the stomach itself. In proportion as the abactinal region becomes solidified (Pl. III. Fig. 11; Pl. IV. Figs. I, 2; Pl. VII. Fig. 8), the stomach loses its globular shape, and becomes from this time forward flattened and pearshaped. Previously to the formation of the Starfish on the surface of the two water-tubes, placed on opposite sides of the stomach, we could trace no change of form in the stomach itself. From the time, however, when the Starfish encroaches little by little upon the anal extremity of the larvæ, it pushes slightly to one side the stomach and the intestine, owing to the great increase in bulk of its actinal and abactinal areas. The anal portion of the water-tubes now swells and contracts in such a way as apparently to divide that portion of the water-tubes into chambers; but, on watching the circulation of the fluid in the water-tubes, for any length of time, the currents can be followed flowing from one of these elliptic chambers to the other, plainly showing the different planes in which the ventral and dorsal part of the tubes are placed to be the only cause of this delusion.

Müller has distinctly stated, over and over again, during the course of his investigations, that the young Echinoderm was formed by encroaching upon the stomach itself; I am satisfied, from repeated observations of this point, in Starfish, Sea-urchin, and Ophiuran larvæ, that this is not the case. The mistake arises from the fact that the water-tubes, by their extension and increase, cover and conceal part of the stomach, forming a sort of hood over it; the two sides of the young Echinoderm, separated by the whole width of the stomach and the thickness of the two watertubes, forming upon the outer surface of the latter, and not in any way encroaching upon the stomach, which is simply enclosed by the actinal and abactinal areas of the Echinoderm. Had I not traced this with the greatest care, I should scarcely venture to doubt the statements of Müller, but I am satisfied that he was mistaken in this explanation of the mode of the formation of the Echinoderm. ${ }^{1}$

Formation of the ambulacral System. - We have already seen that the very first changes which take place in the water-system $\left(w, w^{\prime}\right)$ consist of the five folds $(t, \mathrm{Pl}$. V. Fig. 2) extending obliquely across the exterior surface of one of the water-tubes $\left(w^{\prime}\right)$. From the fact that these folds develope across the surface of an elliptical tube, the five folds naturally form a twisted spiral, with pentagonal outline each side of this spiral, forming the first nucleus of the five ambulacral tubes. I speak

1 It may not be out of place to say, that Professor Agassiz, during this investigation, satisfied himself of the accuracy of every point. which seemed in the least contradictory to the statements of Müller. 
constantly of pentagonal spirals, pentagonal ambulacral system, and pentagonal abactinal system. In using these terms, I do not mean a pentagon with five equal sides, the adjacent sides making equal angles with one another and surrounding a closed surface, but simply that we have five sides limiting an open space, the two extremities of this five-sided figure being separated by the whole vertical diameter of the water-tubes. One extremity of the ambulacral five-sided open figure is placed at the water-pore (b, Pl. V. Fig. 2), the other at the opposite side of the water-tube on the surface of which the ambulacral system is developed. The two extremities of the abactinal open five-sided figure are placed, one above the water-pore (b, Pl. V. Figs. 8, 9, 13, $\left.r_{1}^{\prime \prime \prime}\right)$, the other on the opposite side of the water-tube, which develops the abactinal surface on one side of the anus ( $\alpha$, PI. V: Fig. 14, $\left.r_{5}^{\prime \prime \prime}\right)$. A glance at the figures of the Brachiolaria from the dorsal or ventral side (Pl. IV. Figs. 1, 2; Pl. VII. Fig. 8; Pl. V. Figs. 8, 9, 13, 14) shows that the two surfaces, upon which the actinal and abactinal areas are developed, do not correspond to one another, or fit into each other as in the full-grown Starfish. That is, if the ambulacral system were projected upon the abactinal system, in order to bring these two surfaces into the same relation which they hold in the adult Astertcanthion, we should find the ambulacral system projecting beyond the outline of the abactinal system, and placed nearer the mouth of the Brachiolaria, while a portion of the abactinal system - that which is placed at the anal extremity of the larva - would, in the same way, project beyond the outline of the ambulacral system.

The sides of this twisted pentagonal spiral are somewhat concave, and the apex of the angles of adjacent sides are rounded. It is in consequence of the changes taking place at the apex of the sides of this irregular ambulacral pentagon that we have the simple apex gradually transformed, by its gradual extension beyond the general outline of the open pentagon, into the five-folded loops (PI. V. Figs. 10, 12), each of which corresponds to an ambulacral tube and its accompanying suckers in an adult Starfish.

The ambulacral pentagon with concave sides and rounded angles, seen in profile (Pl. V. Figs. 2, 5; Pl. III. Figs. 7, 9, t), changes its shape rapidly; the convex cavity becomes greater, the apex of each angle of the pentagon more prominent and less pointed, a double line is formed by the ruffling of their folds (PI. III. Fig. 11), and each apex of the pentagon has the appearance of a small loop projecting beyond the curved sides; the loops grow larger and larger, until they have reached a size somewhat less than one-third of the diameter of the water-tube, when they stand out freely from the pentagon, and seem to form no part of the water-tube (Pl. V. Figs. $10,11,12, t$; P1. IV. Fig. 4). When seen either from above or from below, the folds appear as small flaps on the broad side of the foot-like appendage projecting from the surface of the stomach, formed by the folding of the water-tube (PI. V. Figs. 4, 
6, 8, 9, 13, 14, $t$; Pl. III. Figs. 10, 11; Pl. IV. Figs. 1, 2; PI. VII. Fig. 8). These small folds are, in reality, nothing but open bags communicating with the main water-tube $\left(w^{\prime}\right)$; small pouches leading from it. The outer and inner fold of each loop do not remain concentric, and we can soon trace, in the inner fold, changes similar to the first folding of the water-tube. The rounded end of the inner fold becomes triangular; this is the first indication of the formation of the separate suckers (Pl. V. Figs. 10, 11, 12, tt tt t). The ambulacral pentagon remains in this state until the Starfish has resorbed the many appendages of the larva.

Formation of the abactinal System. - Let us now follow the corresponding changes of the abactinal system, accompanying the modifications, just described, of the ambulacral pentagon. On examining the anal extremity, at the time when the larva has reached the state represented on Pl. III. Fig. 10, we are at once struck with the fact that the outline of the abactinal system has undergone analogous changes to those of the actinal pentagon. Instead of remaining a uniform spiral, the two ends of which are separated by the whole height of the water-tube, while the two areas are divided by the combined width of the stomach and the two water-tubes, it has a slightly-lobed pentagonal outline, the convexities corresponding to the apex of the pentagon of suckers (PI. V. Fig. 5, $r_{1}^{\prime \prime \prime}-r_{5}^{\prime \prime \prime}$; Pl. III. Fig. 10). The rods, simple at first ( $r^{\prime}, \mathrm{Pl} . \mathrm{V}$. Fig. 2), have increased in size; small $\mathrm{Y}$-shaped appendages have developed at their extremities. We also see that in the intermediate spaces, corresponding to the concavities of the lobes of the actinal system, a second set of small rods ( $r^{\prime \prime}$, Pl. V. Fig. 5), of a similar character to the large ones, have developed. The whole of the abactinal system has become coated with a very fine granular deposit of limestone; and the edge of the surface, connecting the two extremities of the abactinal pentagon, can readily be seen in profile (PI. V. Fig. 5). The five large rods placed in the middle of the sides of the spiral abactinal pentagon, and the five small ones placed in the angles of this same pentagon, are the first trace of the plates composing the abactinal surface of the young Starfish.

The water-pore (b, Pl. III. Fig. $10 ; b$, Pl. V. Figs. 7, 8) remains open, the only change being an accumulation of limestone matter round the opening, forming a sort of solid tube to protect it. This water-pore, as we shall see hereafter, eventually becomes the madreporic body; and the canal formed by the deposition of limestone is the stone canal of the full-grown Starfishes.

Abactinal System. - The double line on the edge of the abactinal pentagon (Pl. V. Fig. 2) is formed by the thickness of the surface of the abactinal system. This double line, at first only slightly undulating, becomes gradually more indented (PI. V. Figs. 3, 5); at the same time, additional rods arise round the primary ones with such rapidity that we soon find a complicated net-work of limestone rods, forming ten clusters (Pl. V. Figs. 8, 9, 13, $\left.r^{\prime}, r^{\prime \prime}\right)$, five large $\left(r^{\prime}\right)$ and five smaller ones $\left(r^{\prime \prime}\right)$ 
round the original rods. This net-work is produced by the addition of a Y-shaped rod, at each extremity of a simple primary rod; presently, eight Y-rods arise upon the shanks of the first set of Y-rods, followed by a third set upon the shanks of the second set, and so on; in this manner are formed the closed polygons composing the clusters of the patches of limestone deposit (Pl. V. Fig. 9, $r^{\prime}, r^{\prime \prime}$ ). The small granular cells, filling the larger meshes of the net-work, increase in number, rendering the whole abactinal system somewhat opaque; when the larva is seen in profile from the abactinal side, the outline of the stomach (Pl. V. Fig. 5) can be traced exactly as it was before the Starfish had begun to form; and outside of it, the edge of the future back is distinctly visible (Pl. V. Fig. 5).

As the two water-tubes are placed on opposite sides of the larva, it follows that when seen in profile (Pl. V. Figs. 11, 12), from the left or from the right, it presents, in the one case, a full view of the tentacular pentagon $(t)$, and only the lower oral edge of the abactinal system; the net-work of limestone meshes being quite indistinct, as seen through the thickness of the abactinal surface (Pl. III. Fig. 7 ; Pl. IV. Fig. 4; Pl. V. Figs. 10, 12), while, in the other case, a full view of the abactinal pentagon (Pl. III. Fig. 10; Pl. IV. Fig. 4; Pl. V. Figs. 5, 11) is obtained, and the arrangement of the different rods forming the plates of the limestone net-work is distinctly seen. A view of the larva from the dorsal side (Pl. III. Fig. 11; Pl. VII. Fig. 8; Pl. V. Figs. 8, 9, 13) shows the abactinal system extending in such a way as to surround the stomach entirely on one side, while the tentacular pentagon covers it on the opposite side. This attitude gives us the position of the lobes $\left(r_{1}^{\prime \prime \prime}-r_{5}^{\prime \prime \prime}\right)$, the future rays of the Starfish, next to the water-pore $\left(r_{1}^{\prime \prime \prime}, r_{2}^{\prime \prime \prime}\right)$, while $a$ view from the oral side (PI. V. Figs. 4, 14) indicates the trend of the lobes on the opposite extremity of the spiral of the abactinal system $\left(r_{4}^{\prime \prime \prime}, r_{5}^{\prime \prime \prime}\right)$.

Formation of the Rays of the future Starfish. - The plates of the abactinal system early reach a condition when the changes they undergo are merely quantitative, and the only modifications affecting the appearance of the Starfish take place on the edge of the disk. A depression is formed in the middle of the convexity of the lobes of the abactinal area; this is soon followed by two other depressions in the middle of the small arcs thus formed, dividing each lobe of the pentagon into four smaller lobes; at the same time the indentations between the original sides of the pentagon have grown much deeper, separating these five lobes in a very marked manner. We can now no longer mistake the true character of the lobes; they are the five rays of the Starfish, but as the actinal and abactinal regions are not yet fitted together, as we find them in the adult (Pl. V. Figs. 10, 11, $r_{1}^{\prime \prime \prime}-r_{5}^{\prime \prime \prime}$; Pl. IV. Fig. 4), they represent only the dorsal sides of the rays. A glance at Fig. 9 of the same Plate (Pl. V.), seen from the dorsal side, will show how far the suckers $(t)$ are removed from the abactinal portion of the arm which is to protect them. The 
position of the water-pore $(b)$ is immediately on the edge of the disk, at the extremity of the dorsal end of the pentagon (P1. V. Figs. 10, 13, b).

Formation of the Spines. - Such is the state of the abactinal system when the pentagon of tentacles is composed of simple loops; let us now examine this system in more advanced larvæ, at the time when the inner fold of the loops has become triangular at the extremity. When seen from the ventral side (Pl. VII. Fig. 8), we find that the small lobes have become wart-like projections, surrounding the whole edge of the abactinal system (Pl. V. Fig. 9). These projections are composed of accumulations of $\mathrm{Y}$-shaped rods, connected with the system of net-work in the larger plates. The surface of the abactinal system has also become covered with these wart-like projections, rendering the outline irregular. In an abactinal profile, smaller tubercles are seen on each arm, identical in everything except size, with those of the edge; the tubercles are young spines, arranged in regular lines (Pl. VI. Figs. 2, 4, 6); one row of four alternating on the edge of the abactinal system with one row of three, this again with one of two, followed by single tubercles, forming a pentagon, placed in the apex of adjoining rows, in the angle between two arms; the older tubercles are those nearest the edge.

When the young Starfish has reached this state, it has the rudiments of nearly all the external parts of the adult. I shall, therefore, apply to these rudimentary organs the names usually given to them. The spines are warts, not rising much above the general level of the abactinal region, and they are arranged in regular rows. The position of the net-work of limestone meshes has become well circumscribed, the plates formed by them occupying the position of the original rods. The five smaller plates in the angles of the arms are arranged round a central plate, the larger plates alternate with them and occupy nearly the whole of the surface of the arm; this arrangement is identical to that of the plates of the abactinal surface, as shown in Pl. VI. Fig. 10, $l_{,} l_{1}, l_{2}$. The indentations of the rays are now so well marked (Pl. V. 'Figs. 12, 13) that there is quite a large open space between the outer spines on the edge of any two adjoining arms. On examining the plates formed by the net-work of limestone meshes, we see that the cells are polygonal; they are usually hexagonal, and are more or less quadrangular near the exterior of the plate. The original rod can be recognized by the larger cell it has developed (Pl. V. Figs. 9, 13, $r^{\prime}$ ); and it is from this central cell that the others diverge, growing smaller and smaller as they approach the edge.

In the present stage of the young Starfish, the anal extremity of the Brachiolaria (Pl. VII. Fig. 8) has almost entirely disappeared, and the embryo Starfish has taken its place (Pl. V. Figs. 9-14). This embryo is so heavy that, when floating, about, it loads down the anal part, which is always the lowest, and the larva is compelled to move always more or less obliquely, having to drag this great weight vor. v. 
after it. The water-pore remains in the position in which it was at first, in the angle of the arm $\left(r_{1}^{\prime \prime \prime}\right)$, which opens the pentagon, and is encased in a stronger deposit of limestone.

Resorption of the Brachiolaria. - While the Starfish is growing upon the outer surfaces of the two opposite water-tubes, and is gradually becoming a part of the Brachiolaria, no changes take place in the external appearance of the larvæ ( $\mathrm{Pl}$. IV. Figs. 1, 2; Pl. VII. Fig. 8). But when the Starfish has become so far advanced as to occupy a very prominent position at the anal extremity of the larva (Pl. IV. Fig. 4; PI. VII. Fig. 8); the complicated appendages designated as arms, which have served for the development and for the locomotion of the Starfish, are resorbed by the little Echinoderm.

We now come to a most interesting period in the history of our Starfish. The larvæ, very active up to this time, grow sluggish; the body, which, with the exception of the anal portion, is, in the early stages, perfectly transparent and clear, becomes cloudy and opaque. Changes are first visible in the side arms (Pl. IV. Figs. 7, 8, 9); they contract, and apparently divide into many large cells. Next in turn the anal ventral arms, and, lastly, the dorsal arms, contract in the same manner. This contraction of the arms is accompanied by a corresponding shrinking of the anal part of the larva, beyond the mouth (Pl. IV. Fig. 9), so rapid that in a few hours the anal arms have shrunk to quite a small compass (Pl. IV. Fig. 9); the oral dorsal arms, and the oral ventral arms contract in their turn, until there remains nothing but the brachiolar arms, brought close to the Starfish by the shrinking of the mass of the body (Pl. IV. Fiy. 8). They soon follow the rest, and we can actually see the gradual disappearance of this complicated fabric. It has served its purpose of developing and feeding the young Starfish, which has now reached a state when, in a few hours, it will move about independently, having resorbed, for what purpose is not known, the whole of the framework. Not a single part is dropped off, the whole of the larva passes into the Starfish, and, before twelve hours have elapsed from the commencement of the first sign of contraction of the anal tentacles, nothing is to be seen of the larval appendages, except a few indistinct swellings on the actinal side of the little Starfish (Pl. VI. Fig. 1).

The Starfish after the Resorption of the Bipinnaria. - The process of resorption, which I have frequently had the opportunity to examine and trace in all its stages, leaves no doubt, at least in this case, that the young Starfish does not separate from the Brachiolaria. We cannot, therefore, consider the Starfish and the framework (the Brachiolaria) as two individuals, leading a separate existence at different stages of growth, but must regard them both as one and the same thing. This is in direct contradiction to the statements of Müller, and of Koren and Danielssen, with regard to the Echinoderm, the development of which they have had occasion 
to watch. I must add, that my own observations concerning the development of Echinoids and of Ophiurans have led me to an entirely different opinion from the one they have expressed; see my remarks on the embryology of Echinoderms, in the Memoirs of the American Academy for 1864.

Closing of the actinal and abactinal Areas. - Although the young Starfish has now resorbed all the appendages of the Brachiolaria (Pl VI. Figs. 1, 2, 3, 4, 6, 7), it is very different from the adult; the rays do not yet make a complete circuit, nor are they similar to each other; the pentagon of tentacles is still open, and the first step, preceding any other great change, is the closing of the actinal and abactinal areas, by which the two regions are brought into their proper relations. While the arms of the larva are shrinking away, the tentacular and abactinal pentagons are drawn closer together by the contraction of the water-tube. The extremities of the two open pentagons approach each other simultaneously by the flattening, in opposite directions, of the two pentagonal spirals, until the surfaces are brought into parallel planes, and the space, still separating the two ends of the pentagon (PI. VI. Fig. 4) gradually diminishes, when they finally join; the Starfish is then in its normal condition, and the circuit is completed, though the embryo is by no means symmetrical.

Development of the ambulacral Tentacles of the Starfish. - While the closing of the spiral goes on, the pentagon of the tentacular side is undergoing great changes. We will follow these until the tentacles have acquired their normal shape, and then return to the changes of the abactinal surface. The points of the inner folds of the tentacular pentagon, as seen in Pl. V. Figs. 11, 12, $t$ t t , become rounded, forming a rosette, dividing each loop into five lobes. The terminal lobe in its turn goes through the same process; two smaller lobes are developed on each side of it (Pl. VI. Figs. 3, 5), thus dividing the original simple loop into seven lobes, a terminal one $\left(t^{\prime}\right)$, and three pairs $(t t t)$ arranged symmetrically on the sides. The first-formed lobes retain their greater size until the tentacles are well developed, which at first is always in proportion to their proximity to the base of the loop. The odd lobe, from which the last pair of tentacles was formed, does not participate in the rapid growth of the others, and is soon outstripped by all the lobes formed along the side of the original loop (PI. VI. Figs. 3, 5). The point at which additional tentacles are formed is plainly seen in this early stage of growth; a pair is always added at the outer extremity of the arm, immediately at the base and on the side of the odd tentacle (the eye-bearing tentacle), which remains at the termination of the ray during the whole life of the Starfish. It is quite the reverse with the additional spines of the abactinal surface of the disk; they are always formed upon the disk, and are pushed out upon the arms by younger spines growing up nearer the centre of the disk. This will be plainly seen when describing more advanced 
conditions of the young Starfish. As the loops increase, they expand, lose their character of simple folds, and soon become quite extensive sacs ( $t t t, \mathrm{Pl}$. VI. Fig. 8), opening into the main tube $\left(t^{\prime \prime}\right)$, from which they were formed, until, finally, they attain the shape represented upon Pl. VI. Fig. 9. They soon grow long enough to be quite movable; they contract at the base, the walls thicken towards their extremity, and they become club-shaped. The result of this contraction is a change of the tentacular cavity into a rudimentary radiating tube $\left(t^{\prime \prime}\right)$, with the tentacles attached to it; it also draws together the first pair of tentacles, which are usually seen in such a way as to appear like knobs (Pl. VI. Fig. 5). This basal pair does not lengthen so rapidly as the second pair, which in a couple of days becomes the longest (Pl. VI. Fig. 9). Before the base of the radiating tube ( $\left.t^{\prime \prime}\right)$ has contracted, the adjacent basal tentacles of adjoining loops are placed nearer together than those of the same basal pair, the basal tentacles thus forming five pairs of tentacles (PI. VI. Fig. $8, t t)$, separated by the radiating tube $\left(t^{\prime \prime}\right)$. In proportion as the tentacles elongate, the separation between them and the radiating tube is more distinct, and very soon the tentacles appear like club-shaped branches projecting from it (PI. VI. Fig. 9); the first pair of tentacles are somewhat shorter and stouter than the second, which is the longest, while the three terminal tentacles have nearly the same size, the odd tentacle $\left(t^{\prime}\right)$ not showing, as yet, the slightest tendency to become club-shaped, though developed so much earlier than the larger basal pairs at its base.

Formation of the Sucker of the Tentacles of the Starfish. - When the tentacles have reached the state of PI. VI. Fig. 9, they develope rapidly; the walls at the extremity of each tentacle thicken so much, that the cavity becomes a pointed tube set into a somewhat conical head, which grows more club-shaped, and projects beyond the walls of the tentacles as they increase in length, so that, when the basal pair of tentacles equals again in length the second pair (Pl. VI. Fig. 12), the clubs at the extremities are supported upon comparatively narrow bases. This club-shaped termination is the future disk of the tentacle, the sucker, by means of which the Starfish adheres so firmly to rocks. From an early period, even when there is only one large pair of tentacles at the base of the ray, and when the others exist only in the most rudimentary condition (PI. VI. Fig. 5), these tentacles are used by the embryo in adhering to the surfaces upon which it is placed; and, though they are not provided with a regular sucking disk, they fasten themselves so firmly, by means of these loops, that it requires considerable force to make them loose their hold.

1. Formation of the Eye. - We have seen that, unlike the others, the odd terminal tentacle does not become club-shaped, but increases slowly in length alone, the walls retaining a uniform thickness. It is not till all the pairs of tentacles are well developed that we begin to perceive slight changes (Pl. VIII. Fig. 5). The open- 
ing leading into the radiating canal contracts, the basal portion of the tentacle swells, and it assumes a somewhat pear-shaped form, the swelling at the base increases, principally on the oral side, and we soon trace in it an accumulation of pigment cells (Pl. VII. Fig. 6, e), which, by the time the other tentacles have developed knobs, and equal in length the diameter of the arms, has become a brilliant carmine spot (Pl. VI. Fig. 12, e; Pl. VII. Fig. 6, e, and Pl. VIII. Fig. 5, e): This odd tentacle, placed at the extremity of the radiating tube, is the ocular tentacle. Ehrenberg discovered the presence of eyes in Starfishes, but their true relations to this odd terminal tentacle was first pointed out by Professor Agassiz, in his Homologies of Radiata.

Formation of the Mouth of the Starfish. - From the manner in which the tentacles are formed by folds of the water-tube, it is plain that, in the younger stages of the Echinoderm, the two ends of the circular tube must remain disconnected; the rapid accumulation of limestone particles on the lower surface prevents us, however, from ascertaining this point. Soon after the larva has disappeared, the whole actinal surface between the pentagon of tentacles is covered by a membrane; this membrane, in the centre of which is placed the mouth, is the remnant of that part of the larva situated in the groove between the anal and oral plastrons ( $m$, Pl. VI. Fig. 12; Pl. VII. Fig. 1). The mouth of the Starfish, however, is not in reality the mouth of the larva. During the shrinking of the larva, the long oesophagus has becomed shortened and contracted, bringing the opening of the mouth of the larva to the level of the opening of the oesophagus, which becomes eventually the true mouth of the Starfish.

Before the limestone particles have accumulated sufficiently to cover the base of the radiating tubes, the mouth is movable, shifting its position from one side to another indifferently (Pl. VI. Figs. 3, 7, 8, 12, m; Pl. VII. Fig. 1), though by the time the deposit of limestone has formed a small pentagon inside of the base of the radiating tubes, it has lost its mobility. The water-pore (Pl. VI. Fig. 12, b), or the madreporic body, connects with the circular tube through a long, narrow tube, and is placed on the actinal side in the angle between two rays; it is, as yet, only a simple opening, protected by a thick funnel-shaped limestone projection (Pl. VI. Fig. 12, b). The young Starfish has no other anus than that of the larva, which is placed on the very edge of the disk; but, with the rapidly increasing deposit of limestone cells, it is soon hidden from view, and I have not been fortunate enough to find it again in more advanced young. I am therefore unable to say how the anus opens outside, though it undoubtedly leads, at this time, through one of the many limestone cells. Owing to the difficulty of tracing its opening in the dædalus of round cells, I am not able to state this positively, never having seen, from any point, discharges of fecal matters. Like the madreporic body, it is not yet upon the abactinal area, but on the actinal 
side, near the edge of the disk. The madreporic body itself would have been lost in a similar manner, had it not been possible to track it by means of its connection with the circular tube (Pl. VI. Fig. 12); and, even then, it was only by the closest attention, and at moments when the position of the young Starfish was especially favorable for the inspection, that the opening of the madreporic body could be distinguished from that of the surrounding limestone cells.

Formation of the actinal Limestone Surface. - The actinal side of the disk is at first a narrow flat band (Pl. VI. Fig. 3), following the general outline of the rays. This band increases in breadth, loses its convex outline, and soon reaches the terminal tentacle, when the actinal band has assumed a pentagonal shape. Inside of this small pentagon is situated the ambulacral system, entirely independent, as yet, from the limestone deposit on the actinal surface, the whole rosette of tentacles expanding and contracting, with perfect liberty, in every direction. This freedom soon ceases; the points of the limestone pentagon develope rapidly towards the, centre of the disk, and soon reach the base of the radiating canal (Pl. VI. Fig. 7). There they unite by bridging the intervening spaces, and form five triangular openings, enclosing the tentacles, which are still at liberty, with the exception of this band across the base of the radiating tubes (Pl. VI. Fig. 9). The additions made to this deposit of limestone take place more rapidly near the bridge, where additional limestone cells are sent out, enclosing at first the basal pair of tentacles, but leaving the remaining five still unconfined. The next pair is then imprisoned by a similar process, without, however, interfering with the terminal tentacles. Finally, the last pair of tentacles is surrounded in a like manner, and all the tentacles are now confined somewhat as we find them in the adult (PI. VI. Fig. 12 ; Pl. VII. Fig. 1). A row of limestone cells, extending along the median line, separates the base of the suckers, while transverse bands join the larger cells of adjoining spaces. It is plain that the transverse bands correspond to the ambulacral plates of the adult, and that, in the earlier stages, the embryo Starfish has no trace whatever of any interambulacral system. This mode of formation of the ambulacral system may explain the absence of interambulacral plates in the Crinoids and Ophiurans. The deposit of limestone is not sufficiently transparent to allow a good view of the radiating canal, or of the formation of the vesicles of the tentacles.

Formation of the Spines of the young Starfish. - We have seen that, at the time of the closing of the young Starfish, the abactinal region is already covered with regular rows of spines (Pl. VI. Fig. 4). These spines are, however, simple warts, slight protuberances, in which limestone cells are formed, connecting with the general network. The cells of these spines are arranged in regular tiers one above the other: the younger cells, formed at the base, being always more numerous, and pushing up the older ones. All the cells send off $\mathrm{Y}$-shaped appendages, which unite, forming 
stories (P1. VII. Figs. 3, 4, 5) of circular cells; the cells of the spine near the edge do not close, but project beyond the margin, giving the spines the appearance of small gothic spires.

The first row of spines formed - viz: those immediately on the edge of the rays - increase rapidly, curving sideways, expanding at the tip, and assuming as fantastic shapes as those of Rhabdocidaris. Orbygniana (Pl. VI. Figs. 10, 11, 12, $p p$ ). The other rows of spines, diminishing in size as they approach the centre, are exactly similar to the former $\left(p_{12}, p_{2}\right)$, but not so broad at the extremity, and somewhat more slender. New spines are always added between those originally at the extremity of the rays and the centre of the disk; the latter always remain the most advanced and most prominent of the spines, even when the young Starfish has assumed many more of the features of the adult than it has at present, and has reached a stage when it would not be mistaken for anything but a Starfish, closely allied to our common species.

Net-work of Limestone Cells. - As we have seen in the earliest stages of the Starfish, there are, on the abactinal area, rods from which, by the addition of Y-shaped processes, clusters of polygonal cells are gradually formed (Pl. VII. Fig. 7); one cluster in the middle of each ray (PI. VI. Fig. 10, $l_{2}$ ), one around the smaller rod placed in the angle of the rays $\left(l_{1}\right)$, and a still smaller one round the rod. placed in the very centre of the abactinal area $(l)$. The large clusters extend and unite along the edge of the rays, forming a continuous net-work; it is from the cells of the edge that the limestone deposit is formed, which extends over the abactinal surface. The clusters of cells placed in the angle of the rays do not unite laterally, though they become indirectly connected in the more advanced stages of our Starfish, joining with the plates of the rays by a few cells (Pl. VI. Fig. 10). The central plate remains unconnected with the others in the most advanced of the young which I have raised from the Brachiolaria. The whole of the net-work is quite movable, and the plates, before they become united, are capable of independent motion by the contraction of different portions of the abactinal area.

Change of Outline of the young Starfish. - With advancing age, the outline of the young Starfish is greatly modified; at first, when the actinal and abactinal areas are not yet closed, while the larval appendages are still visible on the lower side of the young Starfish (Pl. VI. Figs. 1, 2), and immediately after the larval appendages have disappeared, and the surfaces of the actinal and abactinal areas are brought, nearer together (Pl. VI. Figs. 3, 4), it is hardly more than an irregular pentagon, with slightly convex sides, and small rounded notches cut in at the angles (Pl. VI. Figs. $3,4)$. These notches become deeper, the arms of the Starfish assume more the appearance of a greek cross (Pl. VI. Figs. 6, 7); the sides of the rays are strongly concave and the concavity is increased with the development of the spines to such 
a degree, that the extremity of the ray is almost twice as broad as its base (Pl. V.I. Figs. 10, 11, 12). The outline of the inner wall of the disk can be easily seen through the limestone net-work. The pentagonal form, so different from that of the adult, is still less like it when seen in profile (Pl. VII. Fig. 2). The abactinal area rises like a high, rounded cone, supported upon the spines $(\dot{p})$ of the edge of the disk; the tentacles project far beyond the edge on every side (PI. VII. Fig. 2). In fact, the regular rows of spines, their great size, the convexity of the disk, are features so unlike our usual conception of a Starfish that, without closer examination," one would readily mistake this Echinoderm, at first sight, for a young Sea-urchin, like the flat, conical Echinocidaris.

The tentacles are longer than the rays, extending far beyond the edge in front and on the sides. The pairs of tentacles move in every direction; but the odd tentacle is always curved upward, and carried between the two middle spines of the extremity of the rays. When we see the Starfish in profile (Pl. VII. Fig. 2), the red eye-speck appears prominent near the edge of the disk, surmounted by the up-turned tentacle $\left(t^{\prime} t^{\prime}\right)$, of a slight rosy hue. This manner of carrying the terminal tentacle reminds us strongly of the way in which Aginopsis, as well as the young of so many of our Hydroid Medusæ, carry their marginal tentacles: Nemopsis, Staurophora, Turritopsis, Willia.

This is the most advanced stage of the young Starfishes (Pl. VI. Fig. 11), which I have succeeded in raising in confinement. When we compare this with an adult, having long, slender-pointed rays, four rows of suckers, its surface covered with pedicellariæ and water-tubes, surrounding individual spines, like so many wreaths, we cannot fail to be struck with the astonishing changes of form which must still take place to bring this pentagonal star to any shape resembling a slender fiverayed Starfish. In fact, when we remember how rarely embryologists continue the study of the egg beyond the moment of hatching of the embryo, it is not to be wondered at, that this same young Starfish should be introduced to us again and again, in its different stages of growth, under half a dozen new names, both generic and specific. It is only by a thorough knowledge of all the changes of form through which these young embryos pass, from the first moment of their existence till they are full-grown, that we can hope to remedy this evil.

The next state in which our young Starfish is found is, when magnified (Pl. VIII. Fig. 1), even more different from the adult than the pentagonal state of Pl. VI. Fig. 11. The young Starfishes figured on this Plate (Pl. VIII.) were all found attached to roots of Laminaria, thrown up on the beaches, in the neighborhood, after a storm; and from their different stages of growth, as compared with the oldest Starfish raised from a Brachiolaria (Pl. VI. Fig. 11), specimens of which were also found upon these roots, it is probable that the sizes here figured are one (Fig. 1), 
two (Fig. 8), and three (Fig. 10) years old. A considerable number of specimens were picked up in this way, and they could all be arranged into very distinct groups, representing the Starfishes of the present and of two previous seasons. There seemed to be no gradation from one group to another, such as we have among the young Sea-urchins, which, in consequence of their manner of breeding during the whole year, form series, the relations of which it is impossible to determine. In this connection I would say, that by arranging the Starfishes found upon our rocks into series according to their size, we are able to obtain a rough estimate of the number of years required by them to attain their full development; this I presume to be somewhere about fourteen years. ${ }^{1}$ They begin to spawn before that time, as specimens have been successfully fecundated which evidently were not more than six or seven years old. It is during the fourth year that the rate of growth seems to be most rapid. A young Starfish, measuring one and a half inches across the arms, was kept, during five months, alive in Mr. Glen's tank at the Museum, and during that space of time it grew to three inches.

In the youngest specimens (PI. VIII. Fig. 1), it is easy to see how the young Starfish has changed its outline from a pentagonal cross (Pl. VI. Fig. 11) to the one here represented. The original plates are sufficiently distinct to enable us to trace the process. The arm-plates at the extremity, have been pushed away from the body by the addition of new spines formed at the base of the ray, and on 'each side of the interradial plates $\left(l_{1}\right)$ (the ovarian plates?). The terminal plate $\left(l_{2}\right)$ is perfectly well defined at the extremity of each ray, and, by cutting off the remainder of the arm, and bringing the extremity of the ray close upon the disk, we should have our former pentagonal Starfish almost identically the same; the only change being the greater stiffness of the suckers, the more rounded character of the spines, as well as their greater number upon the original radial plates. The spines have almost entirely lost their fan-shaped embryonic type, and are gradually assuming the aspect of the full-grown rounded spines of the adult Starfish. Here and there, however, a spine still occurs which has retained its fan-shaped outline.

Owing to the elongation of the ray, the single median line of spines stands out very prominently, and this, together with the rows of large spines extending from the interradial plates on each side of the rays, gives to the young Starfish the appearance of a small Oreaster. The median line of spines is supported by a long, narrow limestone plate, extending distinctly from the basal plate almost to the terminal radial, plates totally independent, also, of the prolongation of the ovarian plates $\left(p_{\mathrm{c}}\right)$ which make a broad binding on each side of the ray, uniting with the terminal plate

1 For an account of the method adopted by Professor Agassiz for ascertaining the age of many voL. V. of our marine animals, see Proceed. Essex Inst., 1863, p. 252. 
so as to form a continuous limestone chord round the edge of the Starfish. The interradial plate projects from the angle of the rays towards the basal plate, spreading somewhat, to fill up the space between the median arm-plates. We find, in this stage (Pl. VIII. Fig. 1), the first dorsal water-tubes $\left(d^{\prime}\right)$; there are five pairs, one tube on each side of the ovarian plate $\left(p_{c}\right)$. But, as yet, no pedicellariæ have appeared.

From the lower side, no trace of the plates of the interambulacral system can be seen, beyond the spines which have formed at the extremity of the ambulacra. The ambulacral pores are arranged in a single row on each side of the median line, and the slender last-formed tentacles are placed at the extremity of the ray, nearest to the odd ocular tentacle; while the tentacles nearest the mouth are quite short and stout, having a large sucking disk, and resembling, in all respects, those of the adults. The separation of the different ambulacral plates is very faint, and does not become well marked till a later stage. The odd ocular tentacle has retained its function; the eye-speck has increased greatly in size, as well as the bulb to which it is attached, while the walls of the tentacle are nearly as thin as in the younger stages (Pl. VIII. Fig. 5), exhibiting no trace of the formation of any sucking disk. Nearest to this, are found the last-formed tentacles, easily recognized by their length, and the somewhat less developed sucker. These and subsequent stages of the young Starfish show undoubtedly that new tentacles are formed at the extremity of the rays, while new portions of the upper part of the arm are formed at the base; that is, the actinal system is developed at its periphery, while the abactinal system is developed at the centre.

In young Starfishes of two years (Pl. VIII. Fig. 8), the median plate is longer, more closely crowded with spines; the terminal plate being less prominent, though still distinct, while the processes from the median and lateral plates are quite large. No additional dorsal water-tubes have been formed since the last stage ( $\mathrm{Pl}$. VIII. Fig. 1). When examined from the oral side, the median line is becoming more strongly marked, and the lateral and ambulacral spines more prominent. These features give to the young Starfish a more pointed appearance, and the resemblance to the adult now becomes more apparent.

In somewhat older specimens (three years old), (P1. VIII. Fig. 10), we finally trace the first appearance of pedicellariæ (Pl. VIII. Figs. 2, 3, 4, $p^{\prime}, p^{\prime \prime}$ ), the dorsal tubes (Pl. VIII. Fig. 10, $d^{\prime \prime} d^{\prime \prime}$ ) are found arranged in greater number along certain portions of the rays; while the median and lateral plates have increased so much in size that the terminal plate has lost entirely the preponderance which it had in younger stages, and the extremity of the arm actually assumes a rounded outline. The dorsal tubes $\left(d^{\prime \prime \prime}\right)$ are found numerous on both sides of the median arm-plate, and along the edge of the oral lateral plates $\left(d^{\prime \prime}\right)$, diminishing somewhat in size as 
they approach the extremity of the ray; they are not open at the tip. The central basal abactinal plate is still distinct from the others.

The development of the pedicellarix around the base of the spines gives us no clue as to the function. which they perform in Starfishes (PI. VIII. Figs. 2, 3, 4). At first a simple projection, they early assume the character of the head of pedicellaria without stems, the rounded swelling becoming conical, after which the fork of the head begins to be distinguished. In Plate VIII. Figs. 2, 3, 4, we have the different stages of the spines $(p)$, and the pedicellariæ $\left(p^{\prime}, p^{\prime \prime}\right)$, found at their base. It was impossible in these young Starfishes to discover the place of the madreporic body.

From the oral side, these Starfishes (PI. VIII. Fig. 9) exhibit scarcely any difference from those of the stage last described, with the exception of the somewhat more crowded ambulacra. There is a row of median ambulacral spines $\left(u^{i}\right)$, quite. small, defining the plates distinctly, as well as the presence, of a very distinct row of spines $(u)$, the ambulacral spines, along the edge of the ambulacral plates. In the most advanced of these Starfishes, we must specially call attention to the absence of a well-defined interambulacral system. The young Starfish is still eminently ophiuroid in its most important embryonic features.

Professor Sars, in his Norge's Echinodermer, has described a new genus, which he has named Pedicellaster. I think there can be but little doubt, on comparing the figure he has given of his Starfish and the different stages of our Asteracanthion, that his Pedicellaster will turn out to be the young of one of the species of Asteracanthion of the northern coast of Europe. The single row of ambulacral pores, the ocular tentacle, the arrangement of the pedicellariæ, the size, all confirm the idea of its being only a young.

Successive Phases of Development of the Larvoe of Starfishes. - Before applying the information thus far obtained to the solution of more general problems, it may be well to consider what are the normal stages of growth, at different periods, in the history of our Starfish larvæ. During the earlier stages of its existence, the young developed from the egg (Pl. I. Figs. 22-28) laid by one of our Asteracanthion has no resemblance whatever to the future Starfish. This first condition we might call the pyriform, or Scyphistoma stage; when it is simply a symmetrical radiate animal, reminding us of earlier stages of Polyps and Acalephs. It then assumes the shape of a dumb-bell, becomes slightly one-sided (Pl. II. Figs. 2-19), and has, in its most advanced state, no other appendages but the simple crescent-shaped, slightly undulating, vibratile chord (Pl. II. Figs, 20-24). The simple straight digestive cavity is now differentiated into three distinct regions. This second stage we might call the Tornaria stage, from its resemblance to the Echinoderm larvæ, called Tornaria by Müller, in which all the parts of the adult larva are simply hinted at in the most rudimentary form, and during which it is eminently cylindrical. Another well- 
marked epoch is that during which the larva passes from the cylindrical, or, as we have called it, the Tornaria stage, into a quadrangular, somewhat compressed form; and the complicated system of locomotive appendages, so greatly developed in the Brachiolaria, is gradually laid out, thus preparing the larva for the last stages of its existence, characterized by the development of the young Echinoderm. This third stage, corresponding to that observed by Van Beneden, may appropriately be called the Brachina stage. During this period, the former independent water-tubes $\left(w, w^{\prime}\right)$ of the Tornaria stage (the problematic bodies of Müller) become united, and are gradually transformed into the Y-shaped, elliptical water-system (the Schlauch-System of Muiller); this present stage (the Brachina stage) is therefore marked by the great modifications of the water-system (Pl. II. Figs. 25-28; Pl. III. Figs. 2-10). In the last stage, which we shall call, with Müller, the Brachiolaria stage (Pl. III. Fig. 11; Pl. VI. Figs. 1, 2, 4; Pl. VII. Fig. 8), the rudimentary locomotive organs, laid out during the Brachina stage, attain their greatest development, as long, slender arms. The great changes which take place on the anal extremity of the water-tubes, on both sides of the stomach, characterize the present stage (the Brachiolaria stage). These changes upon the surface of the two branches of the water-tube lead to the formation of the future Starfish. But the incipient Starfish is; as it were, a part of the Brachiolaria, or rather the Brachiolaria is undergoing local transformations which lead to the formation of a Starfish. They present thus, for a time, the appearance of a double existence, as if a new being were forming in one which had completed its growth. This third period, during which the two-fold nature is preserved, is the one which constitutes the Brachiolaria stage. In the Brachiolaria stage there are several marked periods: the parts which appear at first on the surfaces of the water-tubes have no connection, and stand in such indefinite relation to each other, that they do not seem to tend towards a common result. But in proportion as the young Echinoderm progresses in its development, the relations of the two areas, formed on the surfaces of the two water-tubes, are more apparent; and we finally reach the last of the strictly larval stages, when the Brachiolaria, with its complicated system of locomotive appendages, becomes secondary to the young Echinoderm and is completely resorbed by it, when the embryo enters into its truly echinodermoidal condition (Pl. VI. Fig. 1), the different stages of which we have already described.

Examination of the Character of the Development. - The mode of development of Starfishes, which we have thus divided into phases, as observed in our Asteracanthion, cannot be called a case of alternate generation, nor is it a metamorphosis in the ordinary sense of the word. It is a mode of development peculiar to Echinoderms, entirely different from that of any other class of Radiates. It is not an alternate generation, for the Brachiolaria can in no way be called a nurse, as each Brachiolaria 
produces but one Starfish, and the whole of the larva is resorbed by the Starfish, not an appendage being left out. Nor is it strictly a metamorphosis, as the changes which take place are so gradual that at no time can the line of demarcation be drawn between two stages with any degree of precision, as in Crustacea or Insects, where the casting of an envelope marks distinctly different epochs. There is, however, something in these successive phases of development which reminds us of the metamorphoses of Insects. There is a sort of general similarity between this process of resorption, and the growth and changes in the chrysalis of Lepidoptera, ending in a butterfly. In the latter case, the chrysalis, though retaining its character throughout the whole growth and development of the Insect, has an earlier stage when it seems to be purely chrysalis, and a later one immediately before the hatching of the perfect Insect, when the butterfly seems to be gaining the ascendency, and the whole outline of its form may be seen through the chrysalis, which now seems to be only its envelope. And yet the character of the development, during its Brachiolaria stage, recalls vividly the phenomena of alternate generations. It is, nevertheless, strictly echinodermoid, and whether we observe it in the Ophiurans, the Sea-urchins, or the Holothurians and Crinoids, there seems no doubt, from the observations of Miuller, Busch, Thompson, Krohn, and Agassiz, that it is carried on according to one and the same plan in all the orders of the class, where we have corresponding differences in their various modes of development; and with reference to the separate existence of the larva and of the Echinoderm, urged by other observers, I can only say that nothing of the kind has occurred in those Echinoderms the changes of which I have traced, whether it be an Ophiuran, an Echinus, a true Starfish, or a Holothurian.

\section{RECAPITULATION.}

I shall, in a few words, recapitulate the development of these Starfishes, in order to be able more fully to compare my observations with those of previous writers, and the reasons of the differences, when they exist.

Changes of the Yolk. - The yolk separates, after fecundation, slightly from the outer envelope. The segmentation takes place rapidly; as soon as the yolk has divided into eight portions, they arrange themselves in such a manner as to enclose the remaining space, which is more and more separated as the spheres increase in number, until, finally, there is a complete envelope formed of spheres of segmentation.

Scyphistoma, or pyriform Stage.-At the time the young escapes from the egg, it is spherical, and the walls of the envelope are of the same thickness. One side becomes thicker, the embryo flattening at this extremity, which is bent in so as to form a slight cavity, in which fluids circulate. This cavity extends half-way the length of 
the larva, then swells at the extremity, the walls become thinner, the pouch formed at the end of this cavity develops laterally, forming two smaller pouches, which afterwards become hollow bodies, entirely separated from the main cavity, whence they originated (the problematic bodies of Muiller).

Tomaria Stage. - The main cavity bends slightly towards one side, and eventually unites with a depression formed there. This depression becomes the mouth; the other opening, which was the first to be developed, and served the purpose of a mouth, is changed to an anus. This agrees with the observations of Krohn, who shows that in an Echinus larva the mouth is formed after the anus. The bent tube, or cavity, divides into three distinct regions, forming the oesophagus, the stomach, and the alimentary canal.

Brachina Stage. - The small disconnected hollow bodies (the water-tubes, the problematic bodies of Miiller) are not alike; the left one (left, when seen from above) connects with the surrounding medium by means of an opening, the water-pore. This opening in the Starfish is the madreporic body. The water-tubes elongate so as to reach beyond the mouth, when they approach each other and unite, forming a $\mathrm{Y}$-shaped tube.

Brachiolaria Stage. - Arms are developed from the sides of the larva, edged with rows of vibratile cilia. Some of these arms are of a different character, having peculiar appendages, the so-called brachiolar arms. It is on the outer surface of the water-tubes that the Starfish is developed (not from the stomach, as stated by Müller); one of the tubes, the left, when seen from above, developing the actinal or ambulacral side; the other developing the abactinal area. These two areas are open, pentagonal, warped, spiral surfaces, making almost a right angle with each other. The open pentagons do not close till after the Starfish has resorbed the whole of the larva.

Echinodermoidal Stage. - The complicated system of arms and the whole of the Brachiolaria are resorbed by the Starfish, which does not separate from the larval stock, as seems to be the case of Bipinnaria, from the statements of Müller and of Koren and Danielssen. The arms of the Starfish are broad and short in the young, and not symmetrical; the suckers are pointed, have no terminal disk, and are arranged in two rows, the sucking disk being developed later. The embryo, if compared to Acalephs, might then appropriately be said to be in its. Ephyra stage. The odd terminal tentacle has an eye at its base, and no disk is ever formed at the extremity of this tentacle. The abactinal surface is very arched, the spines are arranged in regular rows, and the arrangement of the plates reminds us of the plates of Crinoids; the plates first formed retaining their embryonic or crinoidal character. The anus opens near the edge of the disk, on the lower side; the madreporic body is situated on the edge, but moves to the abactinal area, in more advanced 
stages. About a fortnight is required for the egg to pass through its different stages, for the embryo to be hatched, and the larva to have reached the condition when the young Starfish is ready to resorb the Brachiolaria; and another week must elapse before it reaches the stage represented in Pl. VI. Fig. 11. Those which I raised from eggs artificially fecundated retained this shape four months. 


\section{H A P T E R T II I R D.}

\section{EMBRYOLOGICAL CLASSIFICATION OF STARFISHES.}

THE study of the young forms, or morphological embryology, if I may so call it, is destined to play an important part in Systematic Zoölogy; though investigations of this kind can only be carried on under peculiar advantages not easily obtained. The fact that many marine animals live, in their early stages, under stones, or firmly attached to roots of Laminarians, in deep water, and are only occasionally thrown upon the beaches after storms, when their small size prevents us from obtaining them in any great number, increases the difficulty of this kind of observations. We must, therefore, limit ourselves to those animals which pass the greater part of their lives near the surface of the water, or within the limits of tide-marks. A commencement has already been made in this direction, in the study of Fishes, the young of which live among the eel-grass, and of the young of the several species of Ctenophoræ, which are so abundant during the summer months along our coasts. For an account of these investigations, I would refer the reader to the Illustrated Catalogue of the Museum of Comparative Zoölogy.

Comparison of young and adult Starfishes. - The difference in appearance between the young and the adult of our Starfishes is so great, that they would not be placed in the same family by one unacquainted with their transformations. The young has characters which, if taken singly, recall a variety of families; in fact, the combination of characters belonging to different families is almost always a sign that these features will disappear, or become modified with age.

Here I must again insist on the importance of the constant comparison of the younger stages of growth with the adult. We are so little accustomed to consider these younger stages in our description of animals, that we necessarily lose many elements of the greatest importance, whenever we attempt to associate the adults of any class in natural groups, without taking into account the characters of their young; and naturalists, who have not yet entered upon this method of study, cannot conceive what extraordinary facilities this kind of investigation affords for 
tracing the more complete affinities among animals. One of the principal reasons why embryologists have overlooked these investigations, may be found in the fact that they rarely examine more than one species of each type at a time. Who would place the young Echinus, with its Cidaris-like spines and straight simple ambulacra, among the true Echinidæ, or take a young Spatangoid for anything but an Echinus? What has the pear-shaped outline and long tentacles of a young Bolina - which is, indeed, a diminutive picture of a Pleurobrachia - in common with the adult, with its long, twisting rows of ambulacra, and wing-like projections of the spheromeres beyond the actinostome? Yet these embryonic characters remind us of familiar forms, and cannot fail to give us an insight into the relative standing of the forms through which they pass.

Let us commence with our embryo Starfish at the time when it is just forming, and when the first outlines of the abactinal region can be traced. Suppose its development were to stop there (Pl. V. Fig. 5), that the slight lobes should close, soon after the formation of the coating of limestone granules over the abactinal area, we should have a condition strongly reminding us of a Culcita, with its arched back, its almost circular outline, and the total absence of any very prominent spines. In the next stage (PI. V. Fig. 12), the cuts between the rays have become somewhat more marked, the plates of limestone cells are well developed, and there are tubercles in place of future spines. The resemblance of this stage to such forms as Anthenea, Pentagonaster, and the pentagonal Starfishes, in which we find a great development in the abactinal plates, is at once apparent. In a somewhat more advanced stage, the rays are slightly more marked, the spines quite well developed; this type is represented among living Starfishes by such forms as Pteraster, Paulia, Pentaceros, Artocreas, Oreaster: unless it were known beforehand that Pl. VIII. Fig. 1 represents a highly-magnified young Starfish, the figure would readily pass for a new species of Oreaster. The corresponding changes of the actinal surface are not the less important. In the early stages, the tentacles are pointed, they have no disk (PI. VI. Figs. 3, 9); it is only afterwards that they are developed (Pl. VII. Fig. 1; and Pl. VI. Figs. 10, 11, 12). In fact, the tentacles of our young Starfish, in its earlier stáges, resemble those of Astropecten, Luidia, and Ctenodiscus. We are, therefore, at once provided with a set of characters taken from the young; enabling us to decide the comparative value of the various features, and the order in which they are to be taken. From the tentacles alone we are fully justified, upon embryological data, in placing Starfishes with pointed tentacles lower than those which have disks, like Asteracanthion. Another embryological feature is the fact that the embryo has only two rows of tentacles, while in the adult Asteracanthion we find the tentacles arranged in four rows. Combining these characters, as we find them in the adults, we have at once good and conclusive reasons for voL. $\mathrm{v}$. 
placing lowest, in the scale, all those Starfishes which have, like Ctenodiscus, a pentagonal outline, and at the same time pointed tentacles; next in order would come the Starfishes with pointed rays and pointed tentacles, without suckers, like Luidia and Astropecten; above them pentagonal Starfishes, with plates like Authenea and Hippasteria, and two rows of tentacles, provided with suckers; then those with more prominent rays, and tentacles also ending in suckers, like Pentaceros and Artocreas; higher still, the Starfishes, with long slender arms, and only two rows of tentacles with suckers, such as Cribrella, Ophidiaster, and the like; while highest in the order we should place the genuine Asteracanthion, with four rows of tentacles, with suckers, and highly-developed spines on the abactinal area.

The same principles applied to the different families would place Starfishes, having plates without spines, lower than those in which the net-work of limestone is covered with spines on the abactinal surface. This classification is not very different, as far as regards the order of the three families proposed by Müller and Troschel. It differs materially, however, in the standing given to pentagonal Starfishes in a short paper by Professor Agassiz, in the Proceedings of the Natural History. Society of Boston. From this it is plain, that the mere study of the adult is not a sound foundation for a natural classification. The echinoid characters of the young Starfishes were not known at that time, which would naturally give the pentagonal Starfishes an entirely different position. Nor is it always sufficient to have traced the development of any one species; unless it happen to stand highest in its group, its different phases would not tell us anything of the relative standing of the other members of the group with which the adult is associated. Embryologists should, therefore, whenever it is possible, select those species for investigation which, upon anatomical evidence, stand highest in their group.

There are other embryonic features, recalling not simply families of the same suborder, but characters of other lower orders. The situation of the anus on the actinal side, the presence of the madreporic body on the same area, are features of the Crinoid̆s and Ophiurans. These peculiarities are. soon lost, and the madreporic body gradually finds its way upon the abactinal area. The opening of the anus next to the mouth is eminently crinoidal, and it is accompanied by other structural details reminding us still more of that order. "If we were to imagine a stem on the central plate of the abactinal area, the young Starfish, when seen from the abactinal side, would have all the appearance of a Crinoid. 'The central plate corresponds to the basal plate (Pl. VI. Fig. 10), the set of five plates in the angles of the arms to the interradial plates, and the arm-plates themselves to the radial plates of a Crinoid; and, to make the resemblance still stronger, the anus opens near the mouth, on the same side with it, as in Comatula. This analogy had already been pointed out by Professor Agassiz, in his Lectures on Embryology; and 
it shows conclusively that Starfishes are built upon the same plan with other Echinoderms, contrary to the views long entertained by Johannes Miiller. This comparison to the plates of a Comatula can be carried out to its fullest extent, and is exceedingly instructive if made with the young Comatula, of which an admirable figure has been given by Professor Allman, in his valuable memoir on the prebrachial stage of Comatula, in the Memoirs of the Royal Society of Edinburgh for 1863. The arrangement strikes one, at once, as identical, though the plates are by no means homologous. The central plate occurs in both, but the most prominent plates, occupying indeed the greater part of the abactinal region of the young Starfish, are the same plates which eventually develope with others at the base of the arms; those at the angle of the arms being but little developed. It is quite the reverse with Comatula, in which the arm-plates are but small, at this stage; though, according to Professor Allman, who quotes Carpenter, these small radial plates eventually encroach upon the others, at the time of the appearance of the arms, the rest of the calyx being formed by the five lairge interradial plates. I cannot agree with Professor Allman in considering the central plate otherwise than as a solidified homologue of the basalia of the other Crinoids figured by him; the only difference being that in some cases the plates composing this piece are soldered together, as in Comatula, while in others they are kept distinct, as in Coccocrinus, and the like. From the peculiar way in which young tentacles are formed in Starfishes, may not the strange toothed plates noticed by Professor Allman, at the base of the tentacula (or cirri, as he calls them), be young tentacles? Their position seems to me to make this very probable.

Position of the Madreporic Body. - There has lately been a great deal of discussion among writers on Echinoderms, as to whether the madreporic body was, or was not, a proper point to start from in determining the axes of the body; Agassiz, on one side, maintaining that the madreporic body was constantly in the same relation to the different parts of the Echinoderms, while Müller, Cotteau, and Desor have warmly opposed this view. The mode of formation of the madreporic body seems to me to decide this question in favor of the former view. The madreporic body is invariably formed on the left water-tube of the Brachiolaria, and is placed, during the development of the Starfish, at the angle of the upper arm. The future position of the madreporic body opposite the third arm of the open pentagon, after it has closed, is therefore the natural consequence of its position. The opening of the anus, on the contrary, has no such clear and precise relation to the middle arm. At any ràte, however this may be, one thing is perfectly apparent, - viz.: that the madreporic body is always placed in - the suture of the terminal arms of the pentagon, which brings it opposite the third arm. Thus, the madreporic body gives us the means of dividing the Starfish into symmetrical halves, and of determining the position of the 
odd arm. The case of the Echinometradæ and Salenidæ is constantly quoted to show that the madreporic body is not connected with any definite axis. But might it not be that a stage, which is embryonic in the young Starfish - viz.: that preceding the closing of the actinal and abactinal areas - is probably retained in those Echinoid families in which the process of closing is not completed? And may not the unsymmetrical position of the madreporic body in such cases be owing to the continuance of this embryonic character? - the natural result of which would be, to throw the madreporic body slightly on one side of the middle line, so that, though still retaining its position opposite the third arm, an axis, passing through them both, would not divide the spherosome into symmetrical portions. If there were in nature such forms as asymmetrical Starfishes, analogous to the Echinometradæ, they would be represented by the embryonic Starfishes of Pl. VI. Figs. 1-6, in which a line, drawn through the madreporic body and the middle of the odd arm, would not divide the Starfish into symmetrical halves. Suppose the flattening of the young to be completed without the loss of this want of symmetry, and we have a form representing EchinometraStarfishes, if any such exist in nature. The fact that, in some of these Echinometradx, the axis, passing through the madreporic body and this long arm, crosses the median line from opposite sides, could be easily explained on the supposition that the former is placed on the ventral instead of the dorsal side of the larva, an assumption which is not unfounded, as this occurs in Ophiurans, and in young Starfishes. In this way, the change of position in the direction of the axis which is found in Acrocladia and Podophora on one side, and in Echinometra on the other, could be easily explained. In Echinoids, the actinal and abactinal areas are formed upon the exterior surfaces of the water-tubes, as in Starfish larvæ. This I have shown in the paper referred to above, published in the Memoirs of the American Academy for 1864. The earlier appearance of the tentacular pentagon in Echinoids and in Ophiurans is that of a spiral on the surface of the water-tubes, similar in plan to that observed in our Starfish larva; it is evident that the additional plates formed in a young. Sea-urchin arise spirally, and from what is known of the mode of formation of the young Echinus and young Ophiuran, it follows, necessarily, that the ambulacral system in both must have been open pentagons, becoming connected only by the closing of the surfaces upon which the young Sea-urchin or Ophiuran were developed.

An examination of the figures of our young Starfish, just after the resorption of the larva (Pl. VI. Figs. 2, 3, 4), in which a line, drawn from the madreporic body through the middle of the odd arm, would by no means divide the Starfish symmetrically, confirms the above explanation of the eccentricity in Echinometra. Supposing the spiral to have been formed from the other side, the obliquity would be in the opposite direction. Of course this is simply a supposition on my part, 
which future examination must verify; but it seems to me such a natural explanation of the whole difficulty, that I give it here for what it is worth. The multiplication of madreporic bodies in many Starfishes need not invalidate the view I have taken of its value, as we need only ascertain which is the original one, the others being only supplementary. I have found larva with two water-pores (madreporic bodies), but I have never succeeded in raising them. 


\title{
CHA P TER FOURTH.
}

\author{
EXAMINATION OF THE INVESTIGATIONS OF FORMER OBSERVERS.
}

Review of Miiller's Observations. - It is with the greatest diffidence that I enter upon this part of my subject. It seems the height of presumption, for one who has scarcely any claim to recognition, to begin by criticizing so many statements of one of the great masters of our science. Yet I hope to show, from Müller's own figures, that the observations I have made upon the development of our Starfish, though they do not agree with his earlier memoirs, yet coincide entirely with a few figures which he has given on the last plate of his great memoirs on the embryology of Starfishes; and that it is only because Miuller neglected the earlier stages of development, that he failed to arrive at the conclusions to which I have been led by the above investigations. I trust that I have succeeded in describing the successive stages in this development, with clearness enough to enable me now to draw a comparison, which the reader may easily follow, with the last drawings made by Müller, and to show that, had he had the good fortune to see so complete a series as that which I have traced, he would undoubtedly have entirely remodelled his former views, with the same frankness which has characterized all his memoirs. No preconceived theories, no observations, however careful, have ever been allowed by him to interfere in the least with his subsequent observations. Hence the great diffculty of following Müller in his intricate discoveries; each memoir modifying, correcting, and sometimes entirely contradicting, the previous ones, so that we must, as it were, begin his book at the end, in order rightly to understand his meaning. Any one who has tried to follow the development of a single animal, so that nothing should be wanting in the evidence of the successive stages, will easily understand how later observations continually modify and explain what had previously been considered as well understood.

Although Sars was the first who followed the development of an Echinoderm which, at first sight, did not seem to differ very materially from what was known of the development of other Radiates, yet Müller was the first to trace the wonderful changes of the young Echinoderms; his memoirs have been the basis of all 
subsequent investigations, which are insignificant when compared to the immense amount of labor involved in his researches. It is not simply the history of a single animal of a class; it is the history of a whole class, which is gradually unfolded in his successive memoirs. The very fact that so little has been done in the embryology of Echinoderms since the days of Müller - for, in fact, with the exception of Krohn and Thompson, no one has followed these transformations - is a sufficient proof of the great difficulty attending investigations of this kind. It must also be remembered that these animals are so small that it requires the most practised eye to detect their presence; their habits also are such that we may spend days in watching for them, without obtaining a single specimen, and again be overwhelmed with such an amount of material as to be at a loss where to begin. This can but heighten our admiration of the untiring zeal and perseverance of Müller in following out the development of such a large number of species, in a field where everything was unknown, and where his powers as an observer must have been taxed to the utmost.

Bipinnaria and Brachiolaria. - A glance at the figures of Bipinnaria and of Brachiolaria of Pl. IX. of Müller's seventh Memoir will show how different they are, with few exceptions, from the figures of the same larvæ in his former memoirs; compare Pl. VII. of his third Memoir and Pl. II. of his second Memoir. From the figures and explanations given by the author, it is evident that he had observed, in the last larva of Starfishes which he found, the very characters which have enabled me to correct his observations. He has seen the two Y-shaped water-tubes extending the whole length of the Bipinnaria. He has seen, also, that the pentagon of the future back of the Starfish was open in its 'younger stages, though he did not succeed in tracing the position of the tentacular pentagon, nor does he perceive the connection of these two pentagons with the water-tubes. And, finally, if he had kept his Bipinnaria alive but a short time longer, he would have seen brachiolar appendages develope, and have satisfied himself that Brachiolaria is only an adult state of what he calls Bipinnaria. It must be remembered, however, that the original Bipinnaria of Sars, the Bipinnaria asterigera, has entirely different characters from the Bipinnaria of Müller. Judging from the development of our Starfish, it seems to me that Müller's Bipinnaria von Helsingör, second Memoir (Pl. I. Figs. 1-7), is probably nothing but a younger stage of his Brachiolaria von Helsingör (PI. II. Figs. 4, 5; and Pl. III.). Van Beneden's Brachina, in its turn, is a still younger stage of the same thing, or of an allied species. A comparison of the above figures of Müller, and of the figures of Pl. III. of this Memoir, will leave no doubt on this subject. For the same reasons the Brachiolaria of Marseilles is probably only the adult of a Bipinnaria, closely resembling that of Marseilles (second Memoir, Pl. I. Figs. 8, 9), if it is not the same species. In the Brachiolaria figured on Plates II. and III. of the second Memoir of 
Müller, the young Starfishes are evidently on the point of resorbing the arms. The larvæ present all the appearance of contraction and distortion usually accompanying this process, and Müller's figures agree entirely with the various attitudes which they assume during this resorption.

If we now turn to his fourth Memoir, which contains the fullest descriptions, we shall see that although in many of the figures of Müller the Starfish, at least one side of it, has been drawn correctly, yet his statements and some of the figures which he gives, cannot be reconciled with one another. On Plate II. Figs. 5, 6, of his fourth Memoir, we have the evidence, from his own drawings, that his Bipinnaria had two water-tubes; yet, in the subsequent stages, Müller says positively that it has only one water-tube, the one with the water-pore, - a statement which is entirely contrary to the earlier stages of his Bipinnaria. From what I have shown of the mode of development of these water-tubes, of their increase in size in proportion to the age of the larva, it is quite improbable, notwithstanding the statement of Müller, that one of them should disappear; he also says, that they are not to be confounded with what he calls "wimpernder Schlauch," while our observations of Asteracanthion go to show that these two systems are but one.

The discovery of the water-pore in Müller's Bipinnaria was a great step towards solving the question of the origin of the madreporic body, which he rightly conjectures to be nothing but the water-pore. He also notices the rosette of tentacles, or, more properly speaking, the five radiating tubes from which the tentacles eventually branch. He fails, however, to notice that this rosette, like the cap of the Starfish, as he calls the back, is open; and although he has occasionally represented it as such, he has not perceived the true relation between the positions of these two areas. He says distinctly that the cloak-like envelope, or the abactinal area, originates upon the surface of the stomach, whereas it lies, in reality, upon the surface of the second water-tube, which he says does not exist in his Bipinnaria; while the water-system, or the ambulacral system, originates on the water-tube in such a way that the two open warped pentagonal surfaces make a very large angle with one another; Müller, however, did not notice that they were open and warped surfaces.

Van Beneden's observations, in which he says that the two branches of the Yshaped water-tubes are separate in the young, and become united in the adult, are fully confirmed by my observations. Müller has called these small bodies, while they are still separate, problematic bodies; he says they disappear in older larvæ, and have nothing to do with the "Schlauch-System." It is evident, from my observations, that the Schlauch-System is only the advanced condition of the problematic bodies, which are isolated on each side of the body in the young larvæ (see Pls. II., III. of this Memoir, and Van Beneden's Brachina), and become united in a Yshaped water-system (Schlauch-System), when they reach the condition of Bipinnaria of 
Mi:iler. It would seem, from his figures, as if the abactinal pentagon closed, while the Bipinnaria is still visible. I am rather inclined to think that more advanced larvæ will be found to, be Brachiolaria-like, as is the case with our Starfish and the Brachiolaria from Messina; and that this apparent closing up is due to the fact that the larva is not in its normal state, or that the drawings are made somewhat foreshortened. In the second Memoir of Miiller, on Plate I., we see that the Y-shaped water-system (Schlauch-System) has been noticed in two of the larvæ (Figs. 4, 7), while in the intermediate stages, and in younger larvæ, it has escaped his notice. It is undoubtedly to Müller's want of acquaintance with the earlier and later stages of his Bipinnaria, that we must ascribe the discrepancies which occur in his observations. Many of the more important points in the structure of the young larvæ; naturally escaped Derbès and Krohn, who were not familiar with the adult larvæ; neither of these observers tell us anything of the presence of the water-tubes, or of the first appearance of the young Echinoderm.

Bipinnaria asterigera. - Müller's views concerning the different organs of Bipinnaria asterigera of Koren and Danielssen are undoubtedly correct. What they took for a respiratory opening, leading into the cavity, is the mouth; they had correctly seen the anus, as well as its connection with the intestine of the Starfish. Judging from the figures of Müller, and of Koren and Danielssen, there are evidently striking differences, in the termination of the intestinal canal, from that of our Starfish. In Bipinnaria asterigera the anal opening is on the abactinal side of the Starfish, while in our young Starfish it is still on the actinal side. The position of the young Starfish, with reference to the stomach of the larva, seems still to require further investigation, as it is not possible to say, from the figures of Müller, or from those of Koren and Danielssen, what is its true relation, and whether it has the same oblique position which it occupies in our young Starfish. The investigations of younger specimens than those examined by Müller, or Koren and Danielssen, will at once settle this point, as well as the mode of formation of the mouth of the young Starfish, and its separation from the Bipinnaria. From the figure given by Müller, in his third Memoir (Pl. VII. Figs. 5, 6, 7), I am led to think that the position is also an oblique one; and that, though the Starfish may separate from the Bipinnaria, yet it is undoubtedly the opening of the oesophagus into the stomach, which becomes the future mouth of the Starfish, as in our Asteracanthion. In his third Memoir, Müller shows conclusively, that the madreporic body is not the scar left by the junction of the young Starfish with the Bipinnaria, but corresponds to an opening leading into a short tube between two of the arms; and also points out the probability of its correspondence with the opening leading into one of the water-tubes which he had noticed in Auricularia. This supposition is fully confirmed by the observations we have made of the coincidence of the water-pore vOL. v. 
and of the madreporic body. The slit in the Starfish, noticed by Müller and Koren and Danielssen, was probably owing to the fact that in their young specimens the spiral was not yet closed and flattened, as is the case in older Starfishes.

From the drawings of Sars, and of Koren and Danielssen, it would seem as if a large tube extended into the long appendage opposite the arms. If this is truly so, it leaves no doubt that the long, tail-like appendage of the Bipinnaria is homologous to the brachiolar appendages of our larvæ, only developed to a much greater extent, and with all the arms placed nearer together, immediately round the mouth. A comparison, after careful examination of the position of the Starfish in the Bipinnaria asterigera, with the mode of development as noticed in Echinaster (Cribrella) A. flaccida, and A. Mülleri, will be the means of settling the true affinities of the singular ventral appendage of these larvæ, and of deciding whether they are, as $\mathrm{I}$ have suggested, the homologues of the brachiolar appendages, - a result which seems probable from the observations made, by Professor Agassiz, of a circulation in this peduncle, in a species of Asterias (A. flaccida, Ag.) closely allied to Asteracanthion Mülleri, the mode of development of which is identical with that observed by Sars.

Professor Thompson, who has had occasion to study the sedentary mode of development of several Echinoderms, has given us the most accurate description of the structure of this peduncle, in a species which he calls Asterias violaceus. A glance at his figures and descriptions, will suffice to show us the complete identity between the brachiolar appendages and this peduncle, in which there is a circulation arising from a branch of the water-tube, and at the base of which, at the point of junction of the three arms, we find a peculiar disk, having the same structure as the elliptical disk, noticed at the base of the brachiolar arms in our Starfish larvæ. But we cannot agree with Professor Thompson, that this peduncle is the first sign of an ambulacral tentacle, the ambulacral tentacles being developed at a totally different part of the water-tube.

Different Types of Larve. - Müller did not suspect that his Bipinnaria and Brachiolaria were the larvæ of different species of Asteracanthion. The observations of Sars, who had traced the embryology of Asteracanthion Mïlleri, in which the eggs attain their full development without leaving the mouth of the parent, seemed to preclude the possibility of these nomadic larva belonging to the same grenus. He even went so far as to say that his Bipinnariæe belonged to the same genus as the Starfish of the Bipinnaria asterigera. This is undoubtedly an error, for the Starfish of the Bipinnaria asterigera, as figured by-Müller, and by Koren and Danielssen, has already the characters of a Pteraster; and it is evident that the Bipinnaria of Muiller, being a young Brachiolaria, which I have shown to be the larva of an Asteracanthion, cannot belong to that genus.

The larvæ which I raised by artificial fecundation from Asteracanthion berylinus 
and Asteracanthion pallidus - species which have their representatives in Europe, and which have, up to the present time, been included in the same genus with Asteracanthion Mülleri - are free-swimming larvæ, resembling the Bipinnaria of Müller. These facts can, therefore, leave but little doubt that Müller and Van Beneden have observed the larvæ of Asteracanthion rubens $M: T$., and of allied species; the larvæ of which have been called by them Bipinnaria, Brachiolaria, and Brachina, and are only different stages of one and the same generic type. The difference of the two modes of development of A. Miilleri and A. pallidus is so great, that these two groups of species have been separated into two genera by Professor Agassiz. The Brachiolaria from Triest and Messina present very striking differences, from the northern Brachiolaria. These lairvæ are probably the young of Asterias tenuispinus, which is so common in the Mediterranean. In his revision of the Starfishes, Professor Agassiz has also separated this species from the true Asteracanthion, under another generic name. We have next the Bipinnaria asterigera, still another type of larva, belonging in all probability to another family, differing from both the other larval forms. As Bipinnaria asterigera can only be the larva of a Pteraster, Ctenodiscus, an Astropecten, or of an Hippasteria, either of which belong to families distinct from the Brachiolaria type of larvæ, we find differences in form, modified by structural features, characterizing the larval conditions, as well as the adult stages of families of the same order; while structural peculiarities in the larvæ, characterize the different generic divisions more plainly than in the more advanced conditions. It is evident, from the observations of Professor Agassiz and of Sars, that the Asterias violaceus of Thompson, of which he has traced the embryology in the Microscopical Journal, must be placed in the same genus with A. Mülleri, and may, perhaps, be identical with it; unless the true A. violaceus $L$. has also a similar mode of development. There is still another type of Echinoderm larvæ, which in all probability are the larvæ of Starfishes, - viz. : the Tornaria type. - In this type there is not the excessive development of the ciliary chord into long, slender arms, characteristic of the Brachiolaria; there are only slight, wavy indentations, corresponding to the position of the arms of the Brachiolaria, as we find them in the younger stages of the larvæ (Pl. III. Fig. 4; Pl. II. Fig. 26). In fact, this type of larva, in its adult condition, seems to be a permanent embryonic type of the younger stages of the Brachiolaria. I would infer from this that the Tornaria will probably prove to be the larva of Ctenodiscus, A'stropecten, or Saya, or of some Starfish with pointed ambulacral suckers: Having had the opportunity to examine several of the Tornaria type of larvæ at Naushon, in different stages of development, I hope to return to this subject at a future time. 


\section{H A P T E R F IFTH.}

\section{ON THE PLAN OF DEVELOPMENT OF ECHINODERMS.}

WE have constantly insisted, during the whole of this Memoir, upon the radiate plan of our Starfish larve, in their diferent stages of growth. We have, however, seen that this radiate plan of structure, at certain periods of their existence, is so far hidden, by the apparent bilateral arrangement of the locomotive appendages, as readily to escape notice. We have also had occasion, in discussing the development of these apparently bilateral appendages, to show that Müller's views of the bilateral nature of these larvæ, were founded upon mistaken analogies. It now remains for us to examine, somewhat in detail, the theory put forth by Huxley, in his Review of Müller's observations, concerning the articulate nature of the Echinoderm larvæ. The facts already stated respecting the development, of these larvæ show that they have only a very remote analogy to some of the larval forms quoted by Huxley, to strengthen his interpretation of the investigations of Müller. Misled, perhaps, by the names which Müller has given to some of these larvæ ("Wurmförmige Larven"), he has allowed this analogy to influence him so far, that he revives the old opinion of Oken, and refers the Echinoderms to the type of Articulates. Huxley has given us no observations of his own bearing upon the subject, but endeavors to justify his assertion by reducing all these forms to one hypothetical type, having an elongated form, a straight intestine, with the mouth at one extremity, the anus at the other, and girded by a circular ciliated fringe, just like the larvæ of some Annelids. The region in front of the ciliated fringe he calls protrochal, and the region behind the fringe postrochal; and then, by an ingenious process, he shows how all these different forms might be produced by the greater or less development of one or other of these regions. He then attempts to prove, further, that there is an intimate connection between the point where the young Echinoderm is developed, and the position of the rows of vibratile fringes; according to him, Starfishes being developed in the postrochal and the Echini in the prætrochal region. Any one who has observed these larvæ alive, cannot fail to see that whatever may be the position of these vibratile fringes, the young Echinoderm, whether it be an Echinus, a Starfish, 
or an Ophiuran, is developed in exactly the same spot on the sides of the stomach, upon the outer surface of opposite water-tubes, one of them forming the actinal, the other the abactinal, surface of the future Echinoderm. The hypothetical form of Huxley, is indeed one which has never been observed, as in all larvæ of Echinoderms the mouth and anus are always on the same side, - viz: on the lower surface of the larva. It is only during the first few days, after hatching from the egg, that the so-called mouth is placed at one end; but this, however, is not observed beyond the time when this opening performs the double function of mouth and anus, and leads into a very short digestive cavity. By the time the true mouth begins to be formed, the future anus, which has served the purpose of mouth thus far, has already changed its position to the lower side. The mouth is, in fact, never formed at one extremity, but always in the centre of the lower surface, some time after the anus, or temporary mouth. This has been demonstrated by Krohn and myself, with reference to the Echinus larvæ, and I trust that the preceding pages have shown it to be also the case with our common Starfish. The division into rings, of what Müller calls the Wurmförmige Asteridenlarve, is only an optical delusion, dne to the lines formed upon the abactinal surface during the closing of the pentagon.

The radical difference in the mode of formation of the oesophagus, stomach, and intestine, in the Echinoderm larvæ, as compared with the larvæ of Annelids, a number of which I have examined myself, and among them those most resembling Echinoderm larvæ, will, perhaps, be the strongest proof that they do not belong to one and the same type. The digestive cavity of Annelid larvæ is formed by the liquefaction of the interior of the larva, while in the Echinoderm larvæ the digestive cavity is formed by the bending in of the outer wall of the larva itself. The appendages of Annelids, which give them their superficial resemblance to the larvæ of Echinoderms, are those surrounding the mouth, while the principal appendages of the Echini and Starfish larvæ are developed from the vibratile chord which is developed round the anus. There is nothing more characteristic of the Echinoderms among Radiates than the isolation of the digestive cavity by means of distinct walls. This feature is so strongly marked that a larva can be recognized as an Echinoderm larva before its radiate characters are developed. It is only later that the circular tube, the water-system, is formed, and, still later, that the ciliary appendages, which have nothing to do with the formation of the Echinoderm, make their appearance long after the first rudiments of the Echinoderm (the water-tubes) are present.

It seems to me that the different modes of development in Holothurians, Echini, true Starfishes, Ophiurans, and Crinoids, different as they are apparently, may easily be reduced to a single type. We have in Ophiurans two different modes of development, one by means of the Pluteus, the other by means of the mode of development observed by Krohn and Schultze. We have two similar modes 
of development in the Starfishes, the one as observed by Sars and Agassiz, in Echinaster, the other in which the embryo assumes the shape of a Bipinnaria or Brachiolaria; and, finally, in the Holothurians we have these two modes represented by the Auricularia type, and the type of the "Wurmförmige Holothurienlarve." The difference between these two modes seems to be one of time; in one case, the eggs are retained by the parent until they have passed through many of their changes, and are freed in a stage corresponding to that of our young Echinoderm after it has resorbed its Pluteus, its Brnchiolaria, or its Auricularia. In the other case, the egg goes through all these changes after it has left the parent, developing this complicated system of arms, which seems to be simply a means of locomotion for the young Starfish till it shall have acquired a sufficient size to be able to' take care of itself, and use its suckers as organs of locomotion.

Have we not here, in Echinoderms, something analogous to what we have in Discophorous Medusæ? In Cyanea and Pelagia, for instance, where, in one case, the young Acaleph passes through a Scyphistoma stage before it reaches the Ephyra condition, while in Pelagia, on the contrary, the "Ephyra is at once produced from the egg, without passing through the Scyphistoma stage.

I think it can be easily shown that there is, in reality, no difference in these two modes of development; it is merely a question of quantity. In Cribrella, in Pluteus, in Brachiolaria, or in Auricularia, the young Echinoderm is developed on the outer surface of the water-system. The water-tubes obtain a great prominence in Auricularia, in Brachiolaria, and in the Pluteus-like form of the Ophiurans and Echini, while, in types of development like those of Echinaster, they remain more rudimentary; the only appendages developed in this last type being those which correspond to later periods of growth in the Starfish larvæ, - viz.: the brachiolar appendages. The peduncle, and its appendages, by means of which the young Echinaster fastens to the rocks, are strictly homologous to the brachiolar appendages of our Starfish larvæ. In fact, when the young Starfish has resorbed all the arms, and there is nothing left of them, except a few swellings on the actinal side, to mark their former position, the brachiolar appendages are in exactly the same position as that occupied by the peduncle of the Echinaster larva. Had we known nothing of the previous modes of development, and found those young Starfishes at once in this stage, nothing would have been more natural than to have assumed that they had arrived at this stage by the same mode of development. The cavity, noticed in the peduncle of the Echinaster larvæ, is part of the water-system, corresponding to the branch of the water-system leading into the brachiolar arms of our Asteracanthion larva.

The same is the case with the two modes of development of Ophiurans and of Holothurians; they are shorter ways of arriving at the same point, whether they pass through what we shall call hereafter the Pluteus type of development, or the 
Echinaster type; in either of the orders, it is one and the same thing differently carried out. The larvæ of our Cribrella, which I have had frequently-occasion to examine, have satisfied me that the process of development is the same, with the exception that it is shorter. The larvæ of Ophiurans, which Professor Agassiz has examined at Charleston, would lead to the same conclusion with reference to the Ophiurans; while, from the drawings of Muiller, it is easy to satisfy one's self, with the above data, that the two types of development of Holothurians, examined by him, are only modifications of each other. As the only larvæ of Holothurians, which I have seen, belong to the "Wurmförmiger" type, I am unable to state this from actual observation. It is evident that we have also in Comatula these two types of development. Professor Agassiz has frequently observed in a species of Comatula found in Charleston, S. C., that the young embryos remain attached to the parents; while Thompson and Busch have found the larvæ swimming freely about.

The mode of development of these two types having been shown to be one and the same pattern, modified in such a way that the same result is reached either by fewer stages, or by a greater or less rapidity in the process, it remains for me to show that the larvæ we have had before us, in the complicated form of a Brachiolaria or a Pluteus, is really built upon the radiate plan. We find a good startingpoint in the water-tubes, which, as I have shown, become the circular tube of the young Starfish, from which the ambulacral system is afterwards developed. This water-tube, it is true, is not circular; it is not continuous, and yet it is the homologue of the circular tube of Acalephs, the radiating tubes being developed only afterwards, when the pentagon of tentacles is formed. The mouth is placed within this circular tube; and the fact, that the mouth of the larva is brought; by the contraction of the œesophagus, close upon the stomach, does not change its position with reference to this circular tube. The water-system contracts with it, changes its position, and surrounds eventually the new opening, by the flattening and closing of the Starfish.

The brachiolarian and plutean stages, are the acalephian stages of the Echinoderms, corresponding to the Hydrarium forms of the Acalephs, in their Polyp stage; the arms of the Pluteus stage, with their chords of locomotive cilia, recalling strongly the strange filiform appendages of portions of the spheromere, covered with locomotive flappers, as in Euramphæa, and other Ctenophoræ. The resemblance of the larvæ of Echinoderms to Ctenophoræ had already been pointed out by Baer, and more recently by Professor Agassiz, who was not then acquainted with the observations of Baer. This comparison seems to have found but little favor with more recent investigations. Leuckart, in his Bericht for 1862, simply says that no further proof has been adduced by Professor Agassiz to show that the homology holds good. A writer in the Natural History Review for 1861 seems to consider 
the whole comparison so puerile as not to be worth even a moment's consideration; and the off-hand way, in which he dismisses the whole subject, shows his total want of appreciation of the arguments by which this view is supported. If the writer of the said article had ever seen the young of Brachiolaria, of Pluteus, or, still better, the young of Tornaria, swimming about amongst crowds of young Ctenophoræ, such as Idyia, Pleurobrachia, Mertensia, or Bolina, he would not have passed such a sweeping judgment on this comparison. The motions of a Tornaria are so similar to those of young Ctenophoræ, that I venture to say that many a skilful naturalist would be deceived, as to their true nature, on first seeing them moving about together in the water. The Tornaria has. no appendages developed into long arms, as in the adult Brachiolaria or Pluteus. The appendages remain always abortive, the larvæ in their adult condition resembling young Ctenophoræ. From an examination of drawings given by Müller, Professor Agassiz was induced, to make the same comparison already hinted at by Baer, and we have seen that it is sustained in every particular. Gegenbaur has also noticed the resemblance between young Trachynemæ and Echinoderm larvæ.

From what has been said, it is evident that the plan of radiation underlies this apparent bilaterality of the Brachiolaria, and of the Pluteus. 'The throwing of the whole of the stomach and the alimentary canal on one side, the complicated system of arms arranged with perfect symmetry on each side of the axis, passing through the mouth and the anus, does not change, though it partially conceals, the radiate plan. We have Holothurians which always creep upon three of their ambulacra, where a dorsal and a ventral side, an anterior and a posterior region, are subordinate to the plan of radiation; and the same takes place to a less extent in Spatangoids. Among Polyps even, which are, as it were, the simplest type of radiate animals, an anterior and a posterior region are strikingly shown in the case of Arachnactis. The additional spheromeres are all added at one extremity of the mouth-slit, and yet the Actinia is made up of radiating spheromeres. The earliest stages of the larvæ of Echinoderms, before the appearance of the water-tubes, reminds us forcibly of the young Actinia soon after it has escaped from the egg, or of the first stages of growth of a Scyphistoma, after it has attached itself to the ground, previous to the formation of tentacles. What constitutes the difference in the structural plan of these animals belonging to different classes, in their primary stages of growth? They are all built according to one and the same idea, so carried out as to be eminently echinodermoid in one instance, acalephian in another, and polypoidal in a third. In young Echinoderms, as in young Ctenophoræ, we find nothing of the remarkable preponderance of certain parts which gives these young their bilateral appearance in more advanced conditions. Their radiate character is extremely prominent at first, but becomes gradually obscured and hidden under the guise of this bilaterality, which 
is, after all, due only to the excessive development of certain spheromeres as compared with the others.

The case of these larvæ is only an additional example of what we find so often in nature, that one plan of structure apparently prevails, while, in reality, it is only an external analogy, obtaining a great predominance in certain parts, but subservient to the primary plan, even though the latter be perceived only on closer examination. This view solves a question which has hitherto perplexed all investigators of this subject, - viz: how it was possible that a larva, which has always been considered as bilateral, should produce a radiate animal by a process of internal gemmation. It is, indeed, a bilateral larva, but built upon a radiate plan; a larva recalling a lower class of this branch of the animal kingdom, an acalephian larva giving rise to an Echinoderm, which, from its very beginning, is a radiate animal, having all its spheromeres developed at the same time, and equally. ${ }^{3}$

These transformations are, however, peculiar to the class of Echinoderns; they constitute neither a metamorphosis, nor a case of alternate generation. The egg becomes the embryo larva, nothing essential is lost during the process, no intermediate individual comes into the cycle. It is the yolk which becomes the larva, the latter being, in its turn, transformed into the young Echinoderm. This larva is, in short, an acalephian larva, reminding us somewhat of the twin individuals of free Hydroids, though adapted to the mode of development of the Echinoderms. But, in the latter, we have no intermediate condition corresponding to the Polyp-like Hydroid in Acalephs, from which the Medusæ or reproductive individuals arise, and, in their turn, bring forth the Hydroid again, which completes the cycle by developing another set of Medusæ.

If the views here taken of the plan of development of Echinoderms be correct, they introduce a new set of facts respecting their affinities with the Polyps and Acalephs, which cannot fail to have an important bearing on the question of the separation of the Echinoderms as a distinct type from the two latter groups. The Echinoderm plutean form, with its mouth, stomach, intestine, with the water-system, originally forming a part of the digestive cavity, bears, as it seems to me, the same relation to the Ctenophoræ which the Hydroid Polyps hold to the true Polyps. The Ctenophoræ may be considered, as it were, the prophetic type of the Echinoderms, as the Polyps are the prophetic type of Acalephs. We have in the Ctenophoræ a digestive cavity, from which branches the water-system, and that peculiar funnel, opening outwards, through which the fecal matters of the Ctenophoræ are discharged,

\footnotetext{
1 For a closer comparison of young Ctenophoræ and Echinoderm Larvæ, see the Illustrated CatavOL. v.
}

logue of the Museum of Comparative Zoölogy, No. II., now in press. 
reminding us at once of the almost identical arrangement of an Echinoderm Pluteus, in the relations of the intestine to the stomach. The plutean forms certainly show that the plan, upon which the Echinoderms are built, does not differ from that upon which the Acalephs are built, and that we have between the Echinoderms and Acalephs the same connection, based upon the identity of plan which exists between the Acalephs and Polyps. We cannot, therefore, admit that the views so frequently urged, and so universally admitted, in support of the separation of the Acalephs and Polyps, as a distinct type (Coelenterata), from the Echinoderms, have any real foundation in nature; and still less can we concur in them, when we remember that the main argument in their favor rests upon the assumed total want of connection between the ambulacral system and the digestive system. Now this connection has been shown, by Professor Agassiz, to exist in the adult of many Echinoderms, while the facts above stated prove that it also exists in the early stages of the embryonic development, when, in fact, the water-system is formed from the digestive system. With this evidence falls the strongest argument for the validity of a classification by which the type of Radiates would be broken up, and the Polyps and Acalephs separated from the Echinoderms, as a distinct type, under the name of Coelenterata. We are, therefore, justified in affirming that the type of Radiates constitutes an independent type of the animal kingdom, containing three equivalent classes, — Echinoderms, Acalephs, and Polyps. 


\section{EXPLANATION OF THE PLATES.}

To avoid useless repetitions in the description of the Figures, the same letters are used, throughout these Plates, to denote identical parts. It will greatly facilitate the reading of this memoir to become familiar with the notation here adopted.

\section{EXPLANATION OF THE LETTERING ON PLATES I. - VIII}

\section{$a$, anus.}

b, dorsal or water pore, madreporic opening.

$c$, alimentary canal.

$d$, digestive eavity, stomach.

$d I$, abactinal water-tubes in angle of rays of young Starfish.

$d^{\prime \prime \prime}$, water-tubes of lateral line of rays of young Starfish

$d^{\prime \prime \prime}$, water-tubes of median line of rays of young Starfish.

$e$, eye of Starfish at base of odd tentacle $\left(t^{\prime}\right)$.

$e^{\prime}$, median anal arms of Brachiolaria.

$e^{\prime \prime}$, dorsal anal arms of Brachiolaria.

$e^{\prime \prime \prime}$, ventral anal arms of Brachiolaria.

$e^{\prime \prime \prime \prime \prime}$, dorsal oral arms of Brachiolaria.

$e^{5}$, ventral oral arms of Brachiolaria.

$e^{e}$, odd terminal oral arm of Brachiolaria.

$f$, brachiolar arms.

$f^{\prime}$, branch of water-tube $\left(w w^{\prime}\right)$ leading into $f$.

$f^{\prime \prime}$, odd brachiolar arms.

$f^{\prime \prime \prime}$, surface-warts at base of odd brachiolar arm $\left(f^{\prime \prime}\right)$.

$h$, hole of cul de sac of water-tube $w$.

$l$, central abactinal plate of young Starfish.

$l_{1}, l_{1}, l_{1}, \ldots$ interbrachial abactinal plates of young Starfish.

$l_{2}, l_{2}, l_{2}, \ldots$ brachial plates of young Starfish.

$m$, mouth.

$m^{\prime}$, pistol-shaped oral pouch of cesophagus.

$m^{\prime \prime}$, anal pouch of œsophagus.

$n$, opening for passage of ambulacral sucker. $o$, cesophagus.

$p$, spines on edge of ray of Starfish.

$p_{1}$, spines of exterior rows along abactinal surface of rays.

$p_{2}$, spines of middle row on abactinal surface of rays.

$p_{3}$, central spine of abactinal surface of Starfish, on central plate $\left(l_{1}\right)$.

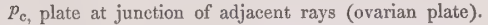

$p^{\prime}, p^{\prime \prime}$, different forms of pedicellariæ.

$r$, abactinal surface.

$r^{\prime}$, first set of five limestone rods which appear on abactinal surface, and which eventually become the brachial plates (ll ).

$r^{\prime \prime}$, second set of five interbrachial limestone rods, which eventually become the interbrachial plates (li ).

$r_{1}^{\prime \prime \prime}-r_{5}^{\prime \prime \prime}$, rays of young Starfish; $r_{1}^{\prime \prime \prime}$ being ray next to madreporic body, when Brachiolaria is seen from the dorsal side.

$s t$ and $s$, actinal region.

$t, t, t, \ldots$ tentacles of the young Starfish.

$t^{\prime}$, odd tentacle.

$t^{\prime \prime}$, ambulacral tube.

$u$, lateral ambulacral plates, surmounted by spine.

$u^{\prime}$, median ambulacral plates with very small spines.

$v$, vibratile chord, anal part.

$v^{\prime}$, vibratile chord, oral part.

$w$, water-tube, developing abactinal area.

$w^{\prime}$, water-tube of Brachiolaria leading to madreporic opening $(b)$, developing actinal area.

$w w^{\prime}$, portion of water-tube of Brachiolaria formed by junction of $w$ and $w^{\prime}$. 
In all the figures of the Brachiolaria, Plates I.-IV., the attitude which has been given to them is not a natural attitude. This has been done purposely, for the sake of making the comparison with the memoirs of Miller easier. The only figure of a Brachiolaria which is in its natural attitude, is that of Pl. VIII. Fig. 8. The young Brachiolaria does not, however, move with the anal part below, till the latter is loaded down by the development of the Starfish, and we see them swimming about, before that time, almost in every possible attitude.

Plates I., II. Embryology of Asteracanthion BERYLINUS $A g$.

Pl I. Figg. 22-28, Pl. II. Figs. 2-19, Scyphistoma stage ; P1. II. Figs. 20-24, Tornaria stage; P1. II. Figs. 25-28, Brachina stage.

\section{PLATE I.}

Fig. 1. A mature egg, surrounded by spermatic particles, soon after the artificial fecundation. The egg has assumed a spherical shape, and contains the germinative vesicle and dot. There is no trace of any interval between the yolk and the outer envelope.

Fig. 2. The germinative vesicle has disappeared, but the germinative dot remains.

Fig. 3. The germinative dot is no longer visible; the yolk has contracted, and is separated by a slight space from the cuter envelope. The egg has all the appearance of having already gone through the segmentation; the whole yolk being made up of small spherical cells, resembling very minute spheres of segmentation, although the segmentation has not yet commenced. Two hours after fecundation.

Fig. 4 shows the first trace of segmentation, consisting in a depression on one side of the yolk.

Fig. 5. The yolk has become flattened on opposite poles; the Richtungsbläsehen are visible on one side of the yolk.

Fig. 6 shows the yolk divided into two united ellipsoids, the whole yolk rotating slowly, always in one direction, from right to left. The Richtungsbläschen are at one pole of the axis of segmentation.

Fig. 7. The two segments of the yolk have entirely separated. The Richtungsbläschen are likewise isolated at one pole of the axis of 'segmentation.
Fig. 8. First trace of a further segmentation; one half of the yolk is partially divided.

Fig. 9. The two yolk segments are about to separate into four.

Fig. 10. The four yolk segments are all distinct, and almost transformed into regular spheres.

Fig. 11. Different view of Fig. 10, showing the position of the segments.

Fig. 12. The yolk about to separate into eight spheres. Fig. 13 shows eight spheres of segmentation, all of which are more or less spherical; the spheres are arranged in two clusters of four, on opposite sides of the envelope.

Fig. 14. This view of the egg shows the tendency of the spheres of segmentation to arrange themselves on the circumference.

Fig. 15. The yolk is divided into sixteen spheres.

Fig. 16. The shell of segmentation is composed of thirty-two spheres; owing to the position from which the egg is viewed, only half the shell of segmentation is visible.

Fig. 17. The thirty-two spheres are again subdivided.

Fig. 18. The spheres of segmentation are still smaller than in the preceding figure.

Fig. 19. These spheres have become so small, that the walls of the spherical shell formed by them can be readily distinguished.

Fig. 20. The walls have become still more distinct in consequence of the close packing of the small spheres, which are now somewhat polygonal, owing to their pressure upon each other.

Fig. 21 represents an egg ten hours after segmentation; the spheres are still more polygonal; the rotation of the yolk is quite rapid, and the embryo is ready to break through the outer membrane; the shell envelope is very distinct from the inner contents, and has a uniform thickness.

Fig. 22. An embryo after its escape from the egg; the wall is no longer of the same thickness throughout, but has become very much thickened at one pole (a), while the spheres of segmentation are somewhat indistinct.

Fig. 23. The embryo has been slightly flattened at the pole $(a)$, where the wall is thickest; the planula, if we may so call it in its present condition, reached this stage at the end of about eleven hours.

Fig. 24. The wall of the flattened pole has been pressed in so as to curve slightly inward (a).

Fig. 25. The depression (a) has become much deeper, and the spheres of segmentation have entirely disap- 
peared, twelve hours after fecundation. The depression at $a$, assumes here somewhat the aspect of a digestive eavity.

Fig. 26. Seventeen hours after fecundation; the embryo has lost its spherical shape and has become somewhat pear-shaped; a transverse section is still circular. The depression made by the thickened walls has increased in depth; the opening (a) performs the functions of a mouth and anus; $d$ indicates the bottom of the digestive cavity.

Fig. 27. Twenty hours after fecundation; the depression has the appearance of a small pouch $(d)$ hanging in a pear-shaped body with circular section, showing no deviation from the absolute radiate type; the opening (a) still performing the double functions of mouth and anus. Currents of water circulate in this cavity, as they would in the digestive cavity of any Polyp or Acaleph in about the same stage of development.

Fig. 28. Twenty-two hours after fecundation; the embryo has become somewhat more cylindrical, losing its pearshaped form, but is still circular when seen in a transverse section. The cavity $(d)$ has slightly expanded at the closed extremity, and is comparatively deeper and wider; the walls of the body are much reduced in thickness, except at the perforated region. The body is somewhat translucent, and slightly tinged with ochre color. The opening $(a)$ still serves as a mouth, although, in more advanced stages, a second opening is formed, which is the true mouth, at which time the present mouth then becomes the anus.

\section{PLATE II.}

In Figs. 1, 3, 9, 10, 11, 12, 13, 14, 15, 16, 17, the digestive cavity alone is represented.

Fig. 1. The digestive cavity of Fig. 2, seen by itself from above, has expanded into a large reservoir at the extremity, the walls of which are quite thin.

Fig. 2. The embryo of Fig. 1 seen in profile; the cayity is no longer in the axis, but is bent to one side. The larva has also lost its symmetrical outline, and the dorsal part of the perforated extremity projects somewhat beyond the opening of the present mouth (the future anus).

Fig. 3. The digestive sac of a larva somewhat more advanced than Fig. 2, in which the present mouth (a) (the future anus) has been brought to the lower side.

Fig. 4. The larva of Fig. 3 seen in profile; the pouch at the closed extremity of the bent digestive cavity is now nearer the lower side than in Fig. 2, having approached the slight depression $(m)$ placed in the middle of the larva.

Fig. 5. A larra somewhat more advanced, seen in profile, in which the pouch has actually come in contact with the wall of the lower side at $m$. The dorsal region of the perforated extremity projects still more beyond the opening of the present mouth (a) (the future anus) than in the preceding stage, Fig. 4. The digestive cavity is not yet divided into distinct regions.

Fig. 6. The same larva as Fig. 5, seen from above, forty-two hours after fecundation; large epithelial cells have appeared on the surface.

Fig. 7. A somewhat more advanced larva, seen in profile; the digestive cavity is no longer a simple bent tube, as in Fig. 5 ; it is strongly contracted near the extremities, one of them projecting upwards $(w)$. At the point of contact of the digestive cavity with the outer wall at $m$, a second opening has been formed, connecting by a short tube with the pouch of the digestive cavity. This second-formed opening $(m)$ is the true mouth, while the first-formed opening (a) now becomes the anus, after having, up to this stage, performed the functions of mouth and anus; end of the second day.

Fig. 8. The same larva as Fig. 7, seen from above, to show the position of the lobes $\left(w, w^{\prime}\right)$ formed on each side of the pouch of the digestive eavity $(d)$, which, in Fig. 7, appear like projecting angles $(w)$.

Fig. 9. Isolated digestive cavity of a more advanced larva, showing still more plainly the transverse contractions of the digestive carity by which the asophagus $(0)$, the stomach $(d)$, and intestine $(c)$ are gradually formed, and also the greater projection of the earlets of the pouch which have become quite elongated laterally; the opening $(o)$ in the centre is the tube leading to the mouth.

Fig. 10. The same as Fig. 9, seen in profile; the tube (o) now connects very freely with the mouth $(m)$, formed in the depression, mentioned in Figs. 4, 5, and with the digestive cavity; the currents now change their course, and circulate in the opposite direction. While the larva was in the state represented by Fig. 6 , the currents of water enter at the mouth, the future anus (a), circulate in the pouch $(d)$, as well as in the earlets formed from the thickening of the wall, and then issued again from the same opening $(a)$. Now the water enters through the mouth $(m)$ (the 
last-formed opening), passes through the narrow conical tube $(o)$ into the digestive cavity $(d)$, communicating with the earlets $\left(w, w^{\prime}\right)$, and out through the anal opening (a), which was the first formed, and formerly performed the functions of mouth.

Fig. 11. Isolated digestive cavity, seen in profile, showing the tube leading from the mouth $(m)$ to the digestive cavity $(d)$, and earlets $\left(w, w^{\prime}\right)$, more developed than in Fig. 10.

Fig. 12. The same seen from above.

Fig. 13. Oral end of an isolated digestive cavity, in which the earlets, formed by the pouch, are more distinct from the digestive eavity than in any of the former stages. There is a slight constriction at their base of attachment, the first indication of their final separation from the alimentary canal.

Fig. 14. Isolated digestive cavity seen endwise, to show the tube leading from the mouth to the digestive cavity, at right angles to the pouch of the earlets.

Fig. 15. Isolated digestive cavity seen, from above, in which the earlets $\left(w, w^{\prime}\right)$ (the future water-tubes) are so far differentiated as to be quite distinct from the digestive cavity. The walls of the earlets are exceedingly attenuated, and are scarcely connected with the main digestive cavity.

Fig. 16. The same as Fig. 15, seen from below, to show the position of the mouth and anus on the same side of the larva.

Fig. 17. Part of the same larva seen in profile; on account of the obliquity of the earlets, one of them $\left(w^{\prime}\right)$, as it increases in size more rapidly than the other, soon reaches the outer surface of the larva and opens into the surrounding medium by meaus of a small aperture $(b)$. The walls of the tube (csophagus) leading from the mouth to the first swelling of the digestive cavity ( $d$ ) (the stomach), and of that part of the tube leading from the stomach to the anus, have a very different thickness. They are sufficiently distinct in their character to enable us to distinguish readily three regions; forty-eight hours after fecundation.

Fig. 18. The two small bodies $\left(w, w^{\prime}\right)$, the former earlets of younger stages formed from the pouch at the closed end of the digestive eavity (the problematic bodies of Müller), have entirely separated from the digestive cavity from which they were formed; seen from above, the three divisions of stomach, intestine, and esophagus are plainly marked out.

Fig. 19. The same larva in profile.

Fig. 20. The same figure from below, shows the presence of short crescents of vibratile cilia $\left(v, v^{\prime}\right)$ placed in opposite directions near the mouth and anus ; sixtyfive hours after fecundation.

Fig. 21. $\Lambda$ somewhat more advanced larva, seen in profile; the anal crescent $(v)$ of vibratile eilia is seen as a small wart between the mouth of the anus, the oral crescent $\left(v^{\prime}\right)$ projects beyond the general outline. The division into csophagus (o), stomach (d), and intestine $(c)$ is quite prominent. The stomach has a tendency to approach the anal dorsal extremity.

Fig. 22. The ame as Fig. 21, seen from below, to show the triangular shape of the mouth $(m)$. The greater size of the problematic bodies $\left(w, w^{\prime}\right)$ (the watertubes), which increase independently at an unequal rate, and also the position of the oral and anal vibratile crescents.

Fig. 23. The same larva seen in a profile, to show the position of the mouth in a strongly-marked depression; the great increase in size of the oral part of the œsophagus; the swelling out of the stomach, and the bending of the intestine back towards the mouth, so as to make a small angle with the trend of the stomach; at the end of the third day after fecundation.

Fig. 24. Larva seen from above. The only difference in this stage from the preceding is in the greater increase of the vibratile crescents, forming two small plastrons, and of the water-tube. The intestine also bends so as to make almost a right angle with the stomach, which is pushed out further towards the anal extremity.

Fig. 25. More adranced larva, seen from the left profile, in which the oral pouch has assumed its characteristic pistol-shape. The stomach and intestine make a sharp angle with each other, the latter being much longer than the stomach proper. In its present aspect it elosely resembles a retort, the stomach being the receiver, the intestine the tube. The anal and oral vibratile crescents have greatly extended, the one on the oral and the other on the dorsal side, to the extremity of the body.

Fig. 26. The same as the preceding seen from below; the oral plastron is quite large, projects beyond the sides of the body; slight indentations can already be traced in the anal plastron, indicating the position of the future arms $\left(e^{\prime}\right)$. The water-tubes have increased in length, and extend half way from the base of the stomach to the oral plastron.

Fig. 27. A larva six days after fecundation, seen from the right profile, the water-tubes extend beyond the 


\section{EXPLANATION OF THE PLATES.}

opening of the mouth. The tube leading from the water-pore $(\mho)$ (dorsal pore) to the water-tube $\left(w^{\prime}\right)$, is quite distinctly seen.

Fig. 28. The same larva as Fig. 27, seen from below; the intestine as in Fig. 26, is thrown to one side of the axis of the larva. The water-tubes extend also along the sides of the stomach towards the anal extremity; the sinuosity of the anal ciliary chord indicates the position of the future anus.

\section{Plates III. - VIII. . Embryology of Astera- CANTHION PALLIDUS Ag.}

\section{PLATE III.}

Owing to the transparency of these larvæ, it is not easy to ascertain whether they are seen with the mouth downwards or upwards, unless we ascertain the position of the madreporic body. In all these figures, whenever the water-tube $w^{\prime}$ is on the left of the figure, the mouth is turned upwards.

Fig. 1. The youngest larva of this species, seen from the mouth side, corresponding to PI. II. Fig. 20 ; a comparison of these two figures will show the great difference between the larvæ of these two species of Starfishes. In the former, the chords of vibratile cilia appear much earlier, and the oral plastron is well defined; while, in the other species, it is not before it has reached the condition of Pl. II. Fig. 26, that the oral plastron is as well developed.

Figs. 2-10. - Brachina stage.

Fig. 2. A larva seen from the left profile, corresponds to the stage of Pl. II. Fig. 27 of A. berylinus; with the exception of the size of the water-tubes, the larva of this species is much stouter, shorter, and the anal portion is the most prominent, while the larva of the A. berylinus is quite slender and elongated.

Fig. 3. The same larva as Fig. 2, seen from the dorsal side.

Fig. 4. A more advanced larva, seen from the dorsal side; the undulations of the ciliary chord indicate the future arms, the water-tubes extend beyond the mouth, and have already begun to bend towards each other.

Fig. 5. The same larva seen from the left profile, to show the bent attitude frequently assumed by the larva when disturbed.

Fig. 6. This larva, seen from the mouth side, is more developed than any raised by artificial fecundation from the eggs of $\mathrm{A}$. berylinus. The water-tubes have greatly inereased in diameter; they have united beyond the mouth, and extend on each side of the stomach so as almost to meet, but without uniting. The mere indentations of the previously figured larva correspond to accumulations ' p pigment cells, and to the thickening of the vibratile ehord, accompanied by the formation of rudimentary lobes, which indicate plainly the position of the median arms $\left(e^{\prime}\right)$, the dorsal anal $\left(e^{\prime \prime}\right)$, the ventral anal $\left(e^{\prime \prime \prime}\right)$, and dorsal oral arms $\left(e^{\prime \prime \prime}\right)$. The greatest accumulation of pigment cells, and the thickening of the vibratile chord, is found at the rudimentary median arms $\left(c^{\prime}\right)$. The anal ventral pair of arms ( $\left.e^{\prime \prime \prime}\right)$ is especially well marked.

Fig. 7. The preceding figure seen in profile, the mouth to the right, shows the great development which the oral position of the water-tube has taken; also the mode of formation of the oral ventral pair of arms $\left(e^{5}\right)$, as well as the first sign of the odd brachiolar appendage $\left(f^{\prime \prime}\right)$.

Fig. 8. Larva seen from the dorsal side. The arms have increased greatly in size since the stage represented in Fig. 6. The oral portion of the water-tube has become very pointed; it extends into the odd oral $\operatorname{arm}\left(e^{5}\right)$, which has also elougated, and stands out prominently beyond the oral plastron.

Fig. 9. The same figure scen in profile, with the mouth downward. The vibratile chord is a deeply undulating line, following the edge of the arms, which extend beyond the general outline. The water-tube, it will be seen, forks also at the oral extremity; one branch extending into the odd arm $\left(e^{6}\right)$, the other toward the angle made by the base of this arm and the pair of oral ventral arms $\left(e^{5}\right)$. The great increase in size of this odd arm will be seen when compared to Fig. 7 of this plate.

Fig. 10. Larva seen from the mouth side. Thus far the arms had altered but little the character of the outline of the larva. In this figure, however, some of them are sufficiently developed to be capable of extensive motion. The median arms $\left(e^{\prime}\right)$ especially are far in advance of the others. All the anal arms develope so as to become more slender at first, and assume their true character sooner than the oral arms, which, during the early stages, are always more heavy, and take their final shape later than the anal arms. At the angle, where the oral ventral arms and the odd - arm come together, at the base of the oral arms, slight swellings are formed $(f)$, which are the first trace of the pair of brachiolar arms $(f f)$, the odd brachiolar arm being only seen in the profile 
view, Fig. 12, $f^{\prime}$, though it can be traced as a double outline of the odd arm $\left(f^{\prime \prime}\right)$. We can already see a constriction in the water-tube as it passes into the odd arm, and from this (nearer the mouth) are sent off two small pouches $\left(f^{\prime} f^{\prime}\right)$, which enter into the brachiolar pair of arms $(f)$. The first trace of the actinal area of the future Starfish is also plainly visible $(t)$ on the water-tube $\left(w^{\prime}\right)$, on the left of this figure.

Fig. 11. A more advanced larva than Fig. 10, seen from the mouth side, in which the oral arms have assumed all the characters of the anal appendages. The brachiolar arms are quite well developed; the intestine and the stomach are slightly crowded to one side by the greater increase of the actinal area $(t)$ of the Starfish; the ambulacral pentagon of the future Starfish is still more marked $(t)$ than in previous stages. Brachiolaria stage.

Fig. 12. The same as Fig. 10 seen in profile, with the mouth downwards.

\section{PLATE IV.}

Fig. 1. Seen from the mouth side. A larva with its arms fully developed and in full activity; no further changes take place in the general aspect of the larva, with the exception of those of the anal part where the Starfish is developing, and those of the brachiolar arms. All the arms are nearly equally advanced, with the exception of the median arms $(e l)$, which still retain their greater size. The odd terminal arm $\left(e^{6}\right)$ has also greatly increased in length, as well as the brachiolar arms $(f f)$, which are capable of motion, and into which the branches of the water-tubes can easily be traced. Brachiolaria stage.

Fig. 2. The same larva, seen from above, on a somewhat smaller scale, shows in what way the stomach and the intestine have been pushed to one side, by the great development of the actinal part of the Starfish, on the right of the figure (st). The shape of the mouth $(m)$ is particularly well seen in a dorsal view, at this stage of growth.

Fig. 3. The same larva on a different scale, seen endways, from the oral end, to show the connection between the pair of brachiolar arms $(f f)$ and the oral ventral pair $\left(e^{5}\right)$, as well as the position of the odd brachiolar arm $\left(f^{\prime \prime}\right)$ at the base of the odd terminal arm $\left(e^{6}\right)$.

Fig. 4. An adult larva seen from the right, actinal profile; the arms are in the position which they take when moving rapidly, arched towards the median arms, the brachiolar arms alone being curved in the opposite direction from the others. Here the erescentshaped ambulacral pentagon, as well as the lobed pentagonal outline of the abactinal area are plainly seen.

Fig. 5. A magnified profile view of the brachiolar arms.

Fig. 6. The brachiolar arms seen from the ventral side of the larva, to show the position of the single disk and of the double row of disks at the base and on each side of the odd brachiolar arm, somewhat less magnified than Fig. 5 .

Fig. 7. The anal part of the larva soon after the shrinking of the arms has begun. The whole of the terminal anal part of the larva has gradually been absorbed, so that the disk of the Starfish occupies the whole of the space between the median arms, seen from the ventral side; the oral extremity of the Brachiolaria is unchanged and not represented.

Fig. 8. The shrinking has gone so far that the whole of the anal part has been affected, and the oral extremity alone, with the brachiolar and the terminal arms, retain their original shape and proportions.

Fig. 9. A different view of the anal part of a larva from that of Fig. 7 ; in a slightly more advanced condition than that of the preceding figure, showing the great height of the abactinal region of the young Starfish; the oral extremity of the Brachiolaria is omitted, as it remains almost unchanged.

\section{PLATE $\mathrm{V}$.}

\section{Development of the Starfish proper.}

The Figures on this Plate show the gradual development of the actinal and abactinal regions of the Starfish, and the figures represent simply the anal part of the Brachiolaria, which is alone affected during this development.

Figs, 1-7 correspond to a Brachiolaria, having reached a state about as advanced as that of Pl. III. Fig. 10.

Fig. 8 is a Starfish developed on the Brachiolaria of Pl. IV. Fig. 11; while Figs. 9-14 are stages of development which are only found on Brachiolariæ having their full complement of arms, and in which, except these changes of the Starfish, but slight modifications take place.

Figs. 1, 2, 10, 12 represent that profile of the anal part of the Brachiolaria, in successively more advanced 


\section{EXPLANATION OF THE PLATES.}

stages, which shows the water-tube upon which is developed the actinal area-

Figs. 3, 5, 11 represent the opposite profiles of the anal extremity of the Brachiolaria, showing the water-tube, upon which is developed the abactinal area.

Figs. 4, 14 represent the ventral side of the anal extremity of the Brachiolaria, showing the extremities of the actinal and abactinal areas of the Starfish.

Figs. 6, 7, 8, 9, 13 represent the dorsal side of the anal extremity of the Brachiolaria, in the successive stages of growth of the young Starfish, showing the opposite extremities of the actinal and abactinal areas of the Starfish.

Owing to the partial transparency of the Brachiolaria, either the actinal or the abactinal area is always projected upon the other, when the larva is seen in profile. In the dorsal or ventral views, the angle made by the actinal and abactinal areas becomes visible.

Fig. 1. Actinal profile of the anal part of the watertube $\left(w^{\prime}\right)$ of the Brachiolaria, previous to the appearance of the pentagon of lobes. In stage of PI. III. Fig. 7.

Fig. 2. Somewhat more advanced actinal profile, showing the ambulacral pentagon, as well as the position of the five rods of limestone, opposite the angles of the actinal pentagon, seen through the thickness of the larva on the surface of the other water-tube $(w)$. In stage of PL. III. Fig. 8.

Fig. 3. The same larva seen from the opposite profile, to show the-abactinal area; small $\mathrm{Y}$-shaped rods have appeared at the extremities of the simple rods.

Fig. 4. The same larva seen from the ventral side of the Brachiolaria, to show the relative position of the pentagons of the two areas; only two of the rods of the abactinal side are seen, while the edges of three of the actinal folds $(t)$ can be perceived, one above the other, on the foot-like projection formed by the folding of the water-tube $w^{\prime}$.

Fig. 5. A more advanced Starfish, in stage of Pl. III. Fig. 10, from the abactinal profile; the $Y$-shaped appendages of the original rods have increased in number; smaller independent $\mathbf{Y}$-shaped rods have made their appearance in the intervals between the larger ones, in the spaces corresponding to the middle of the pentagon of the actinal side. The angles of the actinal pentagon are formed of a double fold, the sides of which are concave; the stomach is almost concealed by the great accumulation of limestone granules on the abactinal area.

vOL. $v$.
Fig. 6. The anal part of a larva from the dorsal side, to show the apparent dividing into elliptical compartments of the water-tubes $\left(w, w^{\prime}\right)$, made by folding and the bending of the extremities of these tubes (PI. III. Fig. 10).

Fig. 7. The same larva from the dorsal side, to show the manner in which the first fold $(t)$ is made on the exterior surface of the water-tube $\left(w^{\prime}\right)$, and the greater size of the right water-tube extending over the digestive cavity to the madreporic opening (b).

Fig. 8. A Starfish from the dorsal side of the Brachiolaria (Pl. III. Fig. 11); shows the lobes formed by the two arms which are in view, with the large cluster of rods in the centre of the lobe, and the small cluster in the space opposite the angle of two lobes.

Fig. 9. The same view of a more advanced embryo, somewhat older than Pl. IV. Figs. 1, 2; the lobes of the arms have become indented, the arms themselves are separated by a deep cut, the $\mathrm{Y}$-rods extend so as to form almost a continuous net-work over the whole abactinal area. The actinal pentagon has assumed the shape of prominent loops projecting beyond the foot-like, oblique fold of the water-tube.

Fig. 10. The same embryo, seen from the actinal profile; the tentacular loops stand out independently from the surface of the water-tube; the stomach and nearly the whole length of the intestine are enclosed by the abactinal area.

Fig. 11. Seen from the abactinal profile in stage of Pl. VII. Fig. 8 ; tubercles have formed upon the surface. the Y-shaped rods extend into them, the lobes of the edge of the disk are deeper, the second set of clusters of limestone cells have greatly increased.

Fig. 12. The same embryo from the opposite profile; the inner tentacular folds have become tipped with a triangular point. The thickness of the abactinal surface prevents the net-work of cells on the edge of the arms from being seen.

Fig. 13. A view of the embryo from the dorsal side of the Brachiolaria; the madreporic body $(b)$, the opening of the water-pore, is placed at the edge of the upper arm $\left(r_{1}^{\prime \prime \prime}\right)$, the tubercles on the edge of the arms are well shown by the great accumulation of small Y-shaped-rods.

Fig. 14. The same from the ventral side of the Brachiolaria (Pl. VII. Fig. 8). This figure shows, perhaps better than any other, the relative position of the extremity of the two pentagonal warped surfaces. The rough outline of the Starfish is due to the manner in which the tubercles of the abactinal surface 
project above. The Starfish in this condition is at the point of resorbing the larva, and of closing the actinal and abactinal areas.

\section{PLATE VI}

The young Stalfigir after the Brachiolaria has BHEN RESORBED.

Fig. 1. A young Starfish seen from the actinal side; the anal and oral clusters of arms of the Brachiolaria appear like small knobs, placed on opposite sides of the new mouth. The future rays are mere lobes, and are not symmetrieal.

Fig. 2. The same embryo seen from the abactinal side, to show the arrangement of the net-work of limestone meshes.

Fig. 3. A more advanced embryo, in which all traces of the appendages of the larva have entirely disappeared. Each side of the pentagon of suckers is a rosette made up of seven loops; the limestone particles are deposited so as to project at the angle of the arms between these loops. The mouth is movable, the pentagon is not closed, and the Starfish is not yet symmetrical; the shape of the different rays is not identical.

Fig. 4. The same embryo seen from the abactinal side, showing the arrangement of the successively formed rows of rounded spines and of the plates. The two ends of the open pentagon have approached nearer than in Figs. 1, 2; the outline is not yet regular.

Fig. 5. Magnified view of one of the ambulacral tubes, with its rudimentary tentacles.

Fig. 6. The young Starfish, in which the two pentagons have almost closed, and been brought into parallel planes. There has been a great increase in the size of the cut between adjoining rays; the spines also have grown longer and more pointed; the limestone points of the angle of the rays have advanced nearer the centre. The Starfish is not quite symmetrical, nor are the arms exactly alike.

Fig. 7. The same embryo, from the actinal side, shows the great inerease of the ambulacral system, the tentacles being distinct pouches on each side of the main tube. The basal tentacles of one system are much further apart than all the others, and this is the last indication that the ambulacral pentagon is not closed.

Fig. 8. A more magnified view of the actinal side, when the ambulacral pentagon is entirely closed, and the Starfish has become symmetrical, and all the basal suckers are equally distant.
Fig. 9. The ambulacral system of one arm, when confined by the circle of limestone which has been formed round each ambulacral system; the two first pairs of tentacles begin to develop disks; they become clubshaped; the three terminal tentacles are still closely connected, and show no sign of any disk.

Fig. 10. An abactinal view of one ray and the centre of a young Starfish, in which the spines project far beyond the edge of the disk. The arm-plates and the inter-radial plates have become connected by a narrow bridge. The limestone rods are so much thickened by additional deposits, that they form elliptical cells which have entirely lost the polygonal character of the younger stages.

Fig. 11. One arm and a portion of the centre, from the abactinal side, of the most advanced of the young Starfishes which have been raised by artificial fecusdation. The spines are very prominent, long, somewhat spreading, and becoming even fan-shaped. The limestone cells are gradually assuming the character of the limestone cells of the adult, small cells within larger ones; the cut between the rays is very deep.

Fig. 12. The same young Starfish as Fig. 11, seen from the actinal side; the three pairs of tentacles have suckers; the deposit of limestone of the actinal area having the same cellular structure as that of the abactinal area, though formed by the increase of small cells instead of rods. This Starfish also shows the position of the madreporic body, immediately on the edge of the disk of the lower side; the eye is very prominent at the base of the odd terminal tentacle. The young Starfish, Figs. 11, 12, is about four months old.

\section{PLATE VII}

Fig. 1. Two rays and the centre of the Starfish, PI. VI. Fig. 10, seen from the actinal side. All the tentacles are encased separately by the limestone deposit of the actinal region. The tentacles have grown so long that they extend beyond the edge of the arm. The pair of terminal tentacles has, as yet, increased but little in comparison to the other pairs. The odd terminal tentacle has, at its base, a bright carmine spot, the eye, which appears about this time. The mouth, limited by the limestone deposit, takes the shape of a pentagonal opening; the ambulacral tube is concealed.

Fig. 2. The same Starfish as Pl. VI. Fig. 11, seen in 
profile, to show the great development of the abactinal area, and the Echinus-like arrangement of the spines in the young Starfish. The odd tentacle is seen turned up, between two of the spines, with the eye at its base.

Figs. 3, 4, 5. Spines of the young Starfish in different stages of growth.

Fig. 6. An enlarged view of the terminal tentacle, to show the position of the eye at the base of the odd tentacle.

Fig. 7. An enlarged view of the mesh-work of limestone cells, to show the mode of formation of additional cells, by means of $Y$-shaped rods.

Fig. 8. A greatly magnified figure of a full-grown Brachiolaria in its natural attitude, at rest, with the Starfish almost ready to resorb the larva; the obliquity of the planes, in which the actinal and abactinal pentagons are situated, is especially well seen in the pointed anal extremity of this Brachiolaria. No letters have been added to this figure, as the different parts can readily be distinguished by comparing it with Pl. IV. Figs. 1, 2, 4.

\section{PLATE VIII.}

Fig. 1. Young Asteracanthion about one year old, seen from the abactinal side.

Figs. 2, 3, 4. Magnified views of spines $(p)$, and of rudimentary pedicellariæ $\left(p^{\prime}, p^{\prime \prime}\right)$.

Fig. 5. Odd terminal tentacle of a Starfish in the stage of Pl. VIII. Fig. 10, at the extremity of the arm, with the eye-speck (e)

Fig. 6. One of the abactinal water-tubes $\left(d^{\prime}\right)$ at the angle of the rays.

Fig. 7. One of the abactinal water-tubes $\left(d^{\prime \prime}\right)$ along the edge of the rays.

Fig. 8. Abactinal view of the arm of a young Starfish, probably two years old.

Fig. 9. Actinal view of an arm of a young Starfish in its third year.

Fig. 10. Abactinal view of a young Starfish, in which the rudimentary pedicellariæ have made their appear-" ance, also having median and lateral lines of abactinal water-tubes along the arm. Probably three years old. 


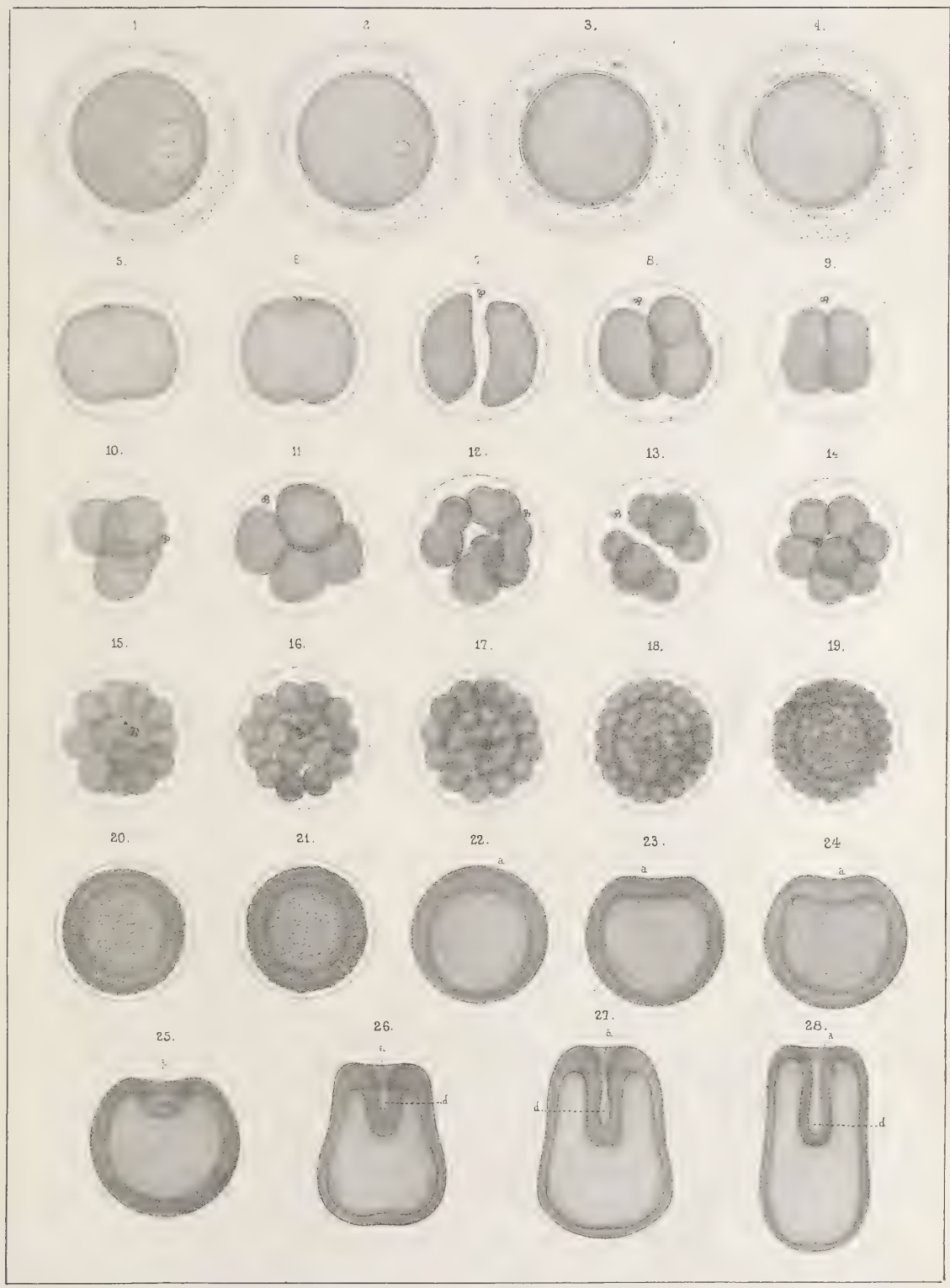

I Eumil, on etone.

A A $\{$ assizi, del

Finnted by JE Bufford. Bostor

ASTERACANYMTON BEFYLANUS A. 



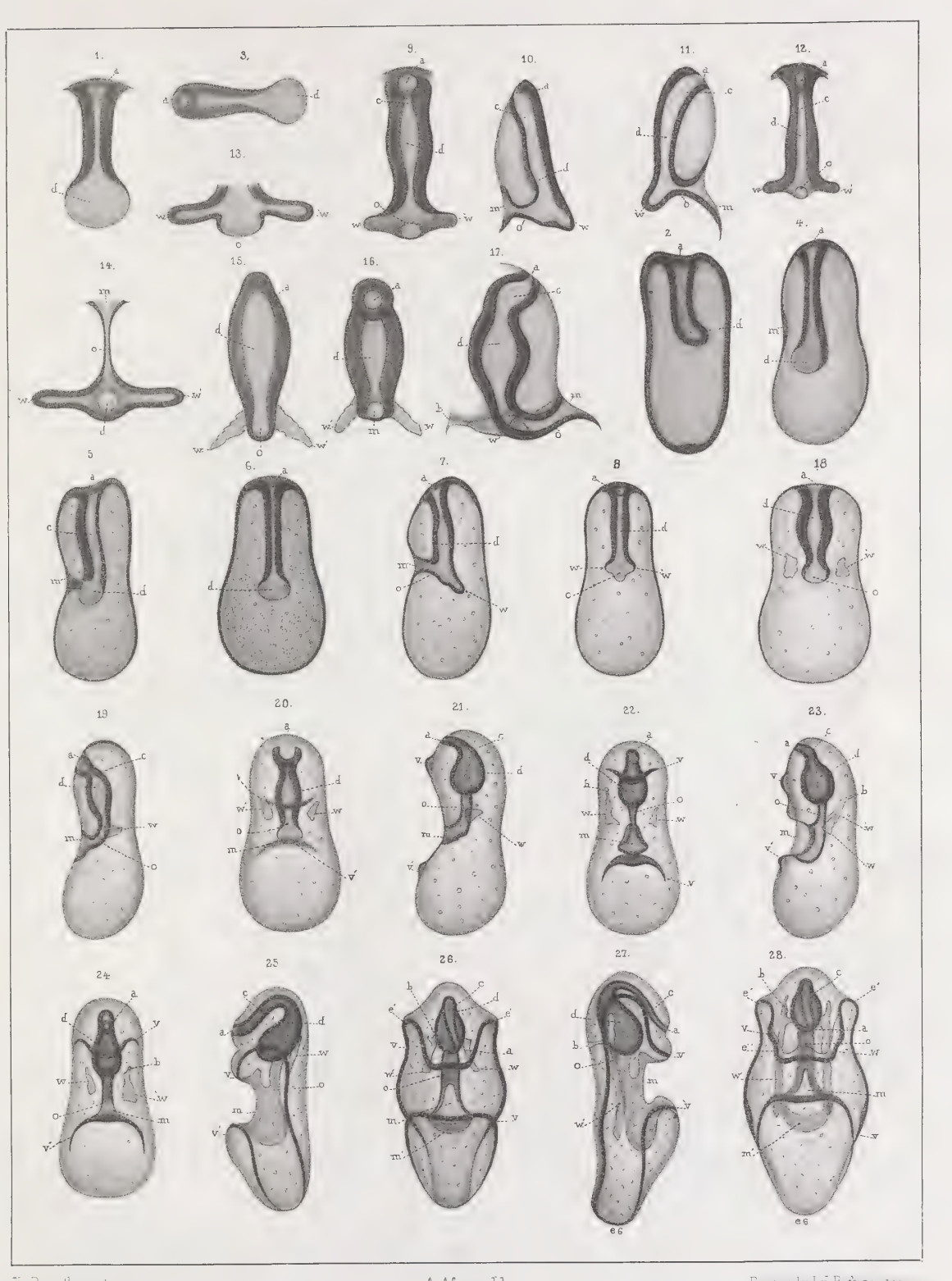





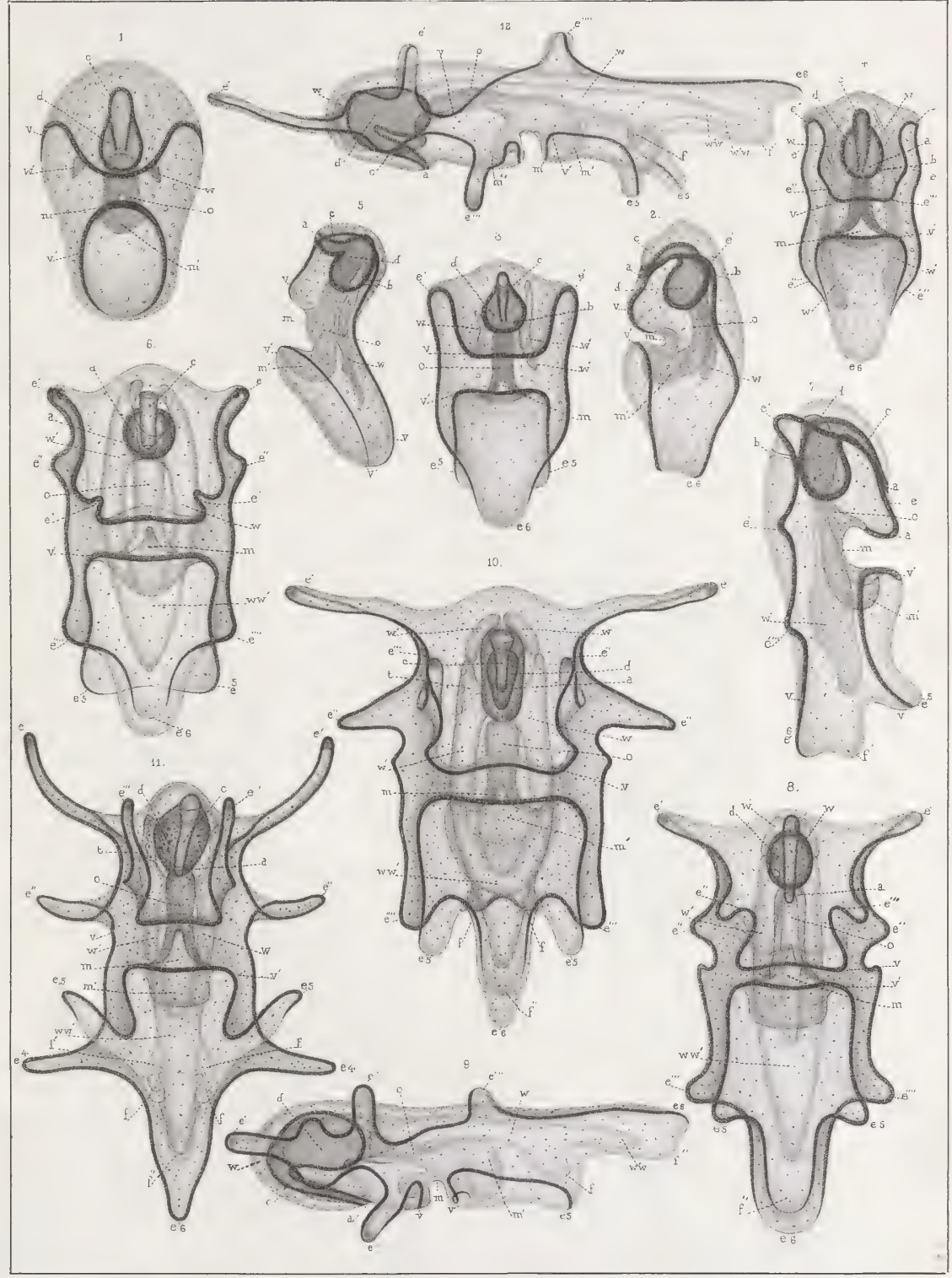





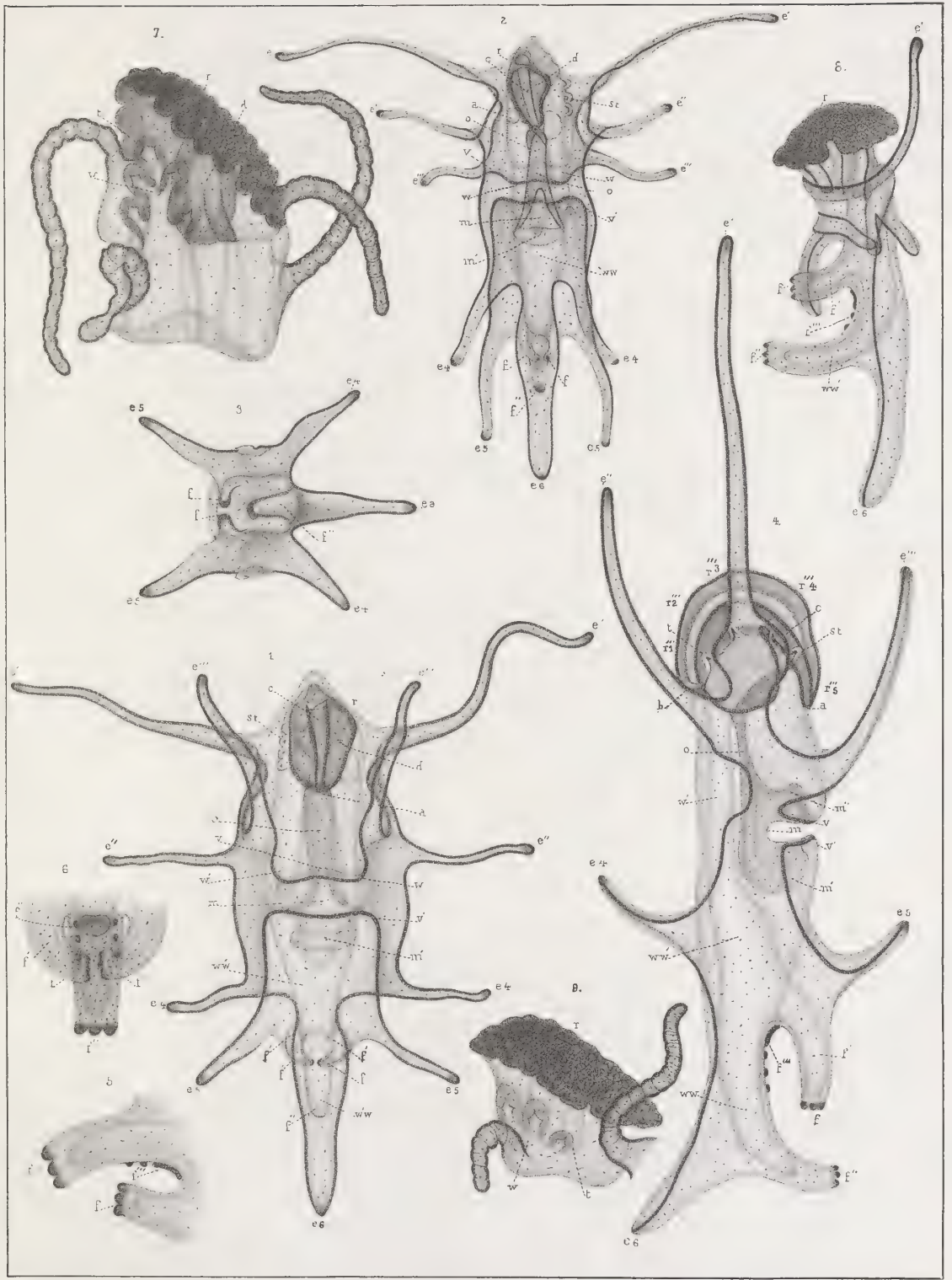




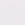




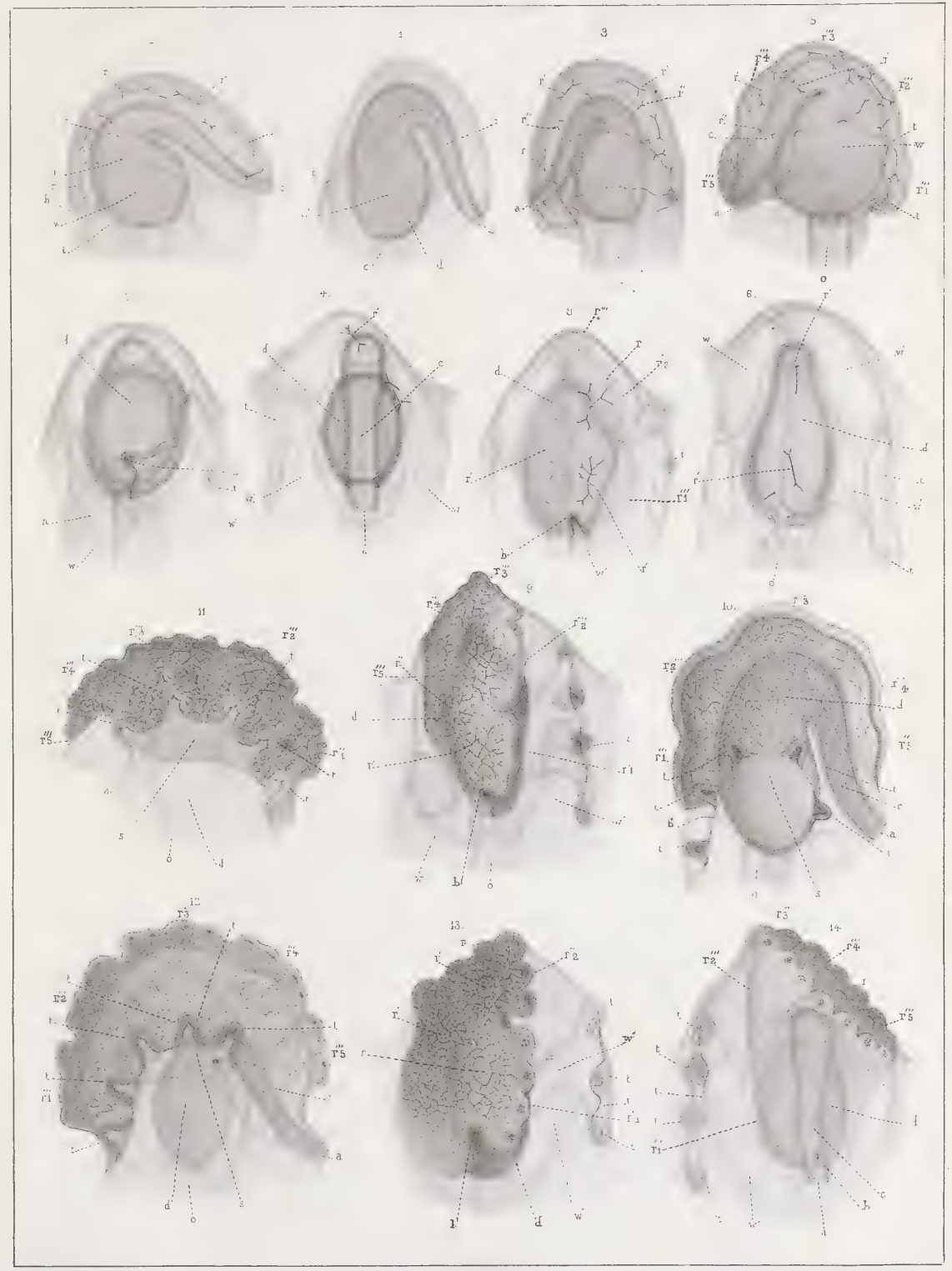





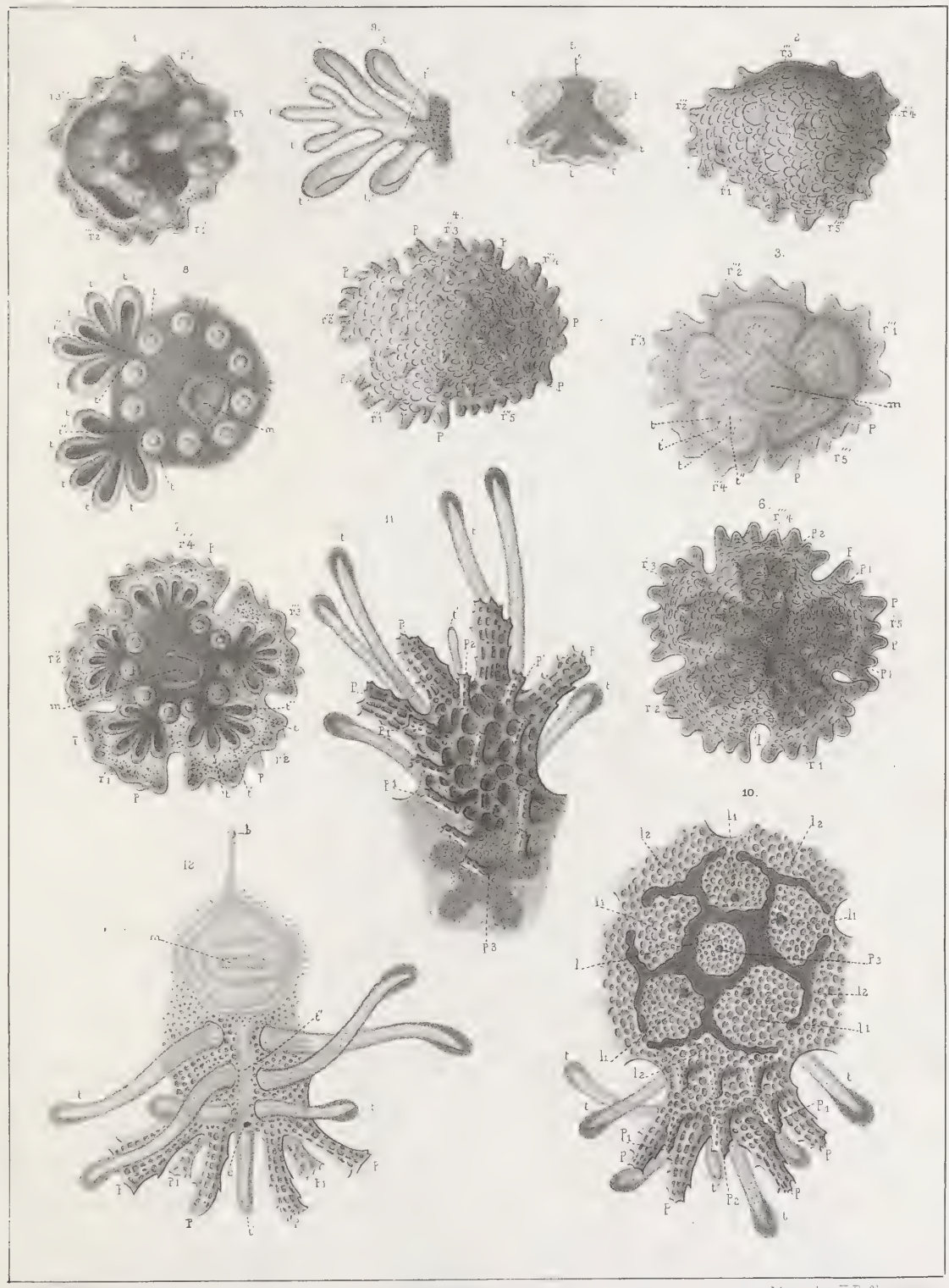





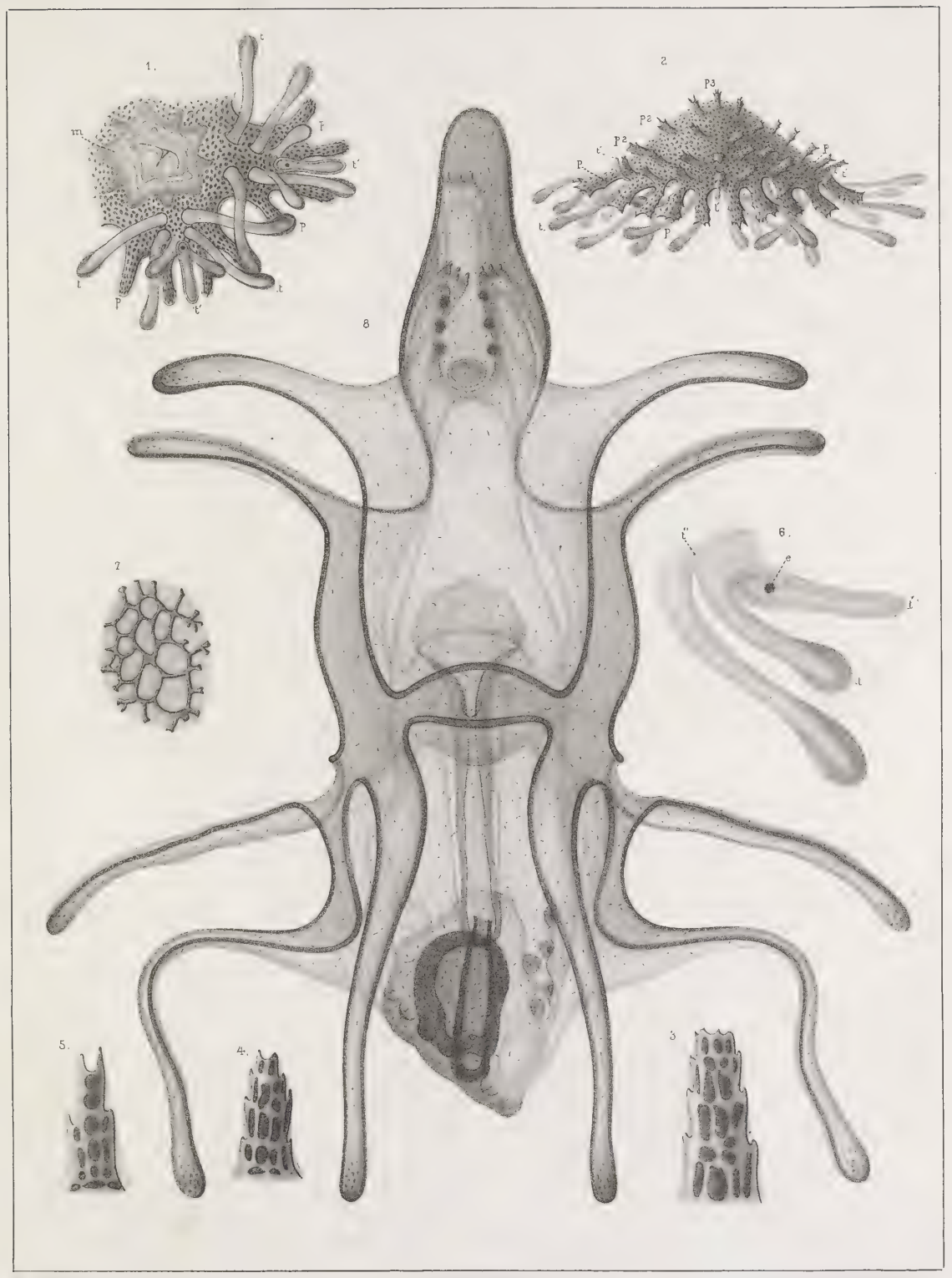

inrmll on etone 



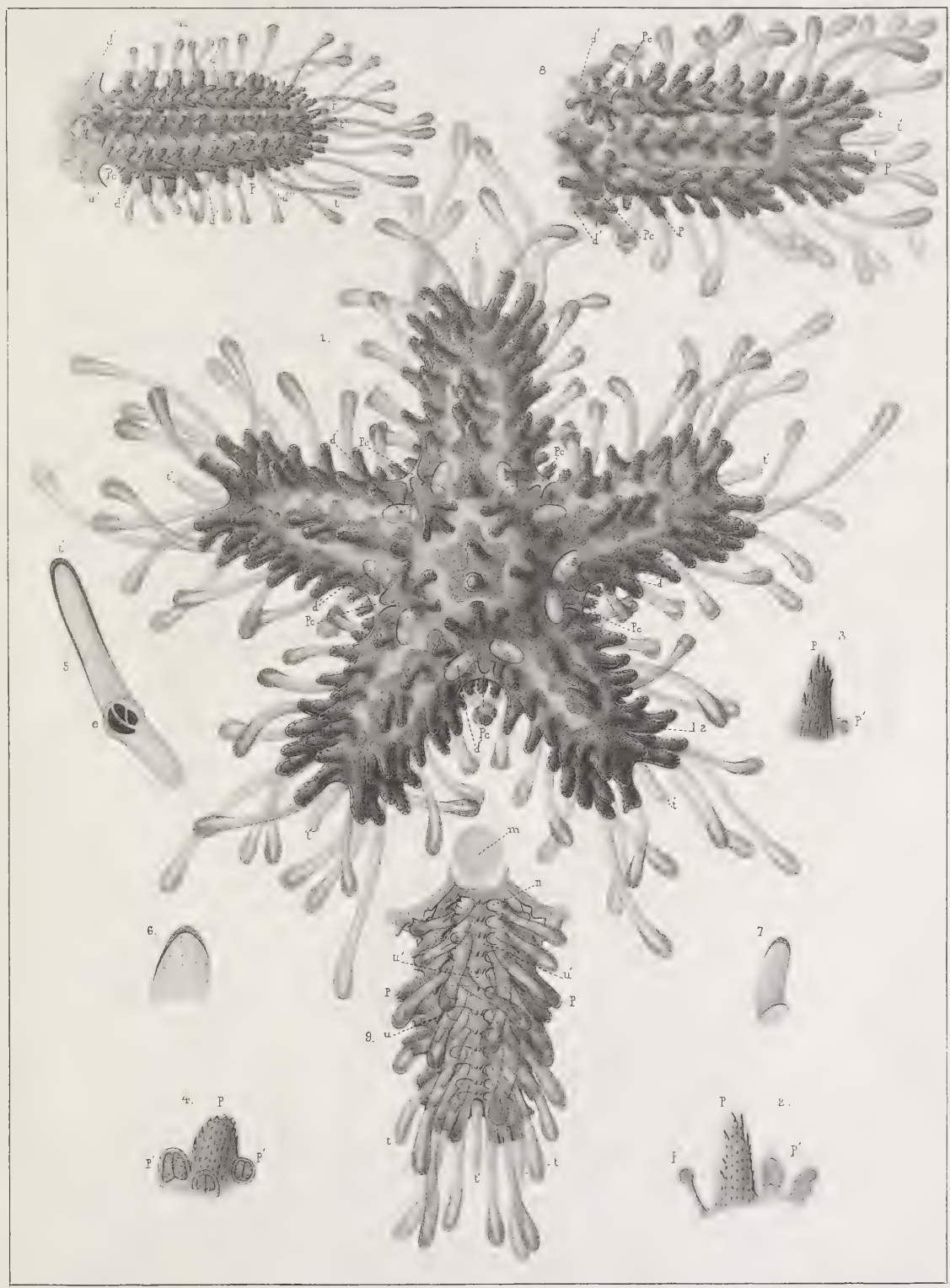

A A Anesin $\mathrm{A}=1$ 










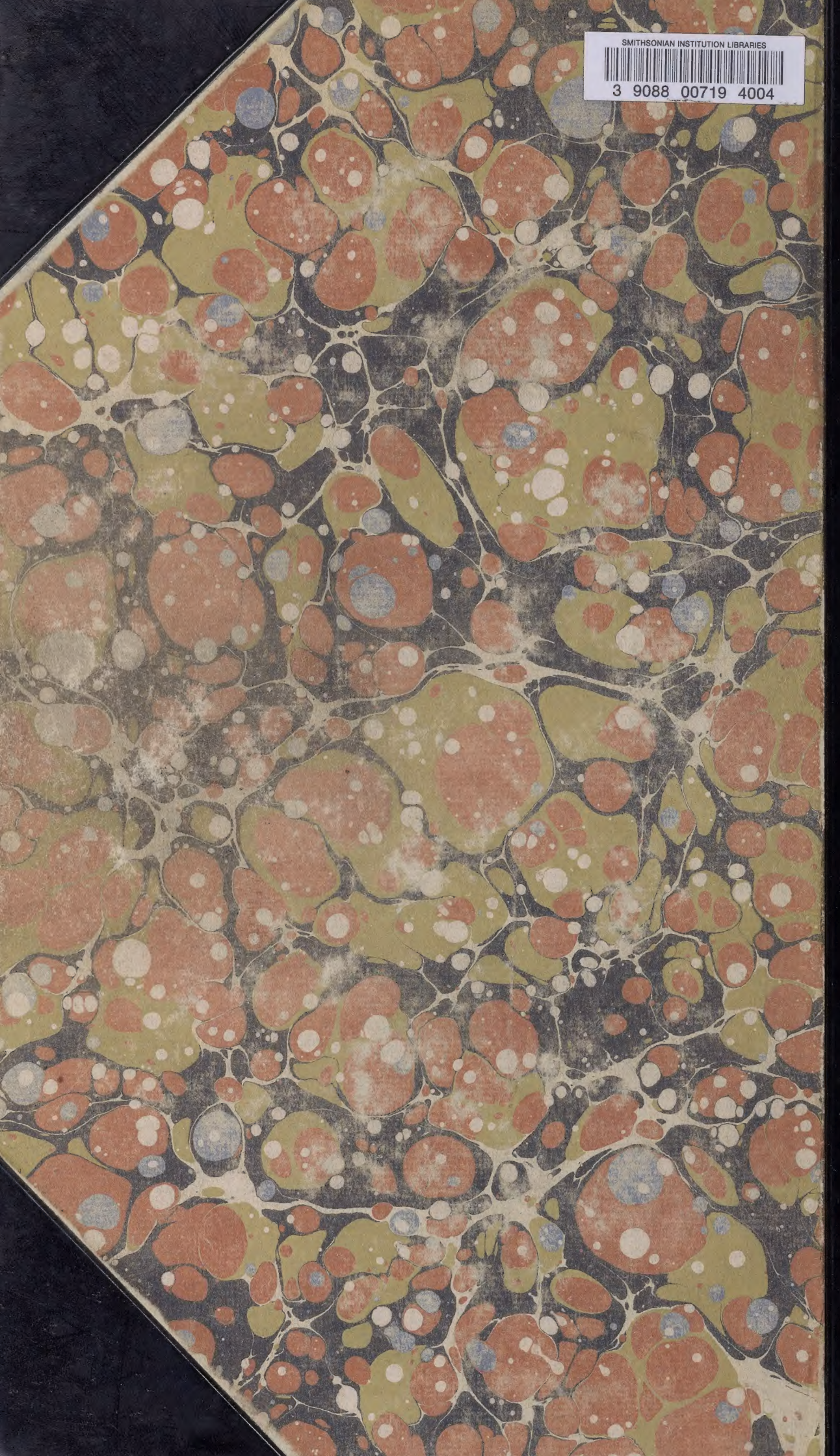

